University of Northern lowa

UNI ScholarWorks

$5-2020$

\title{
Challenging social systems under the threat of pollution: Replication and extension of Eadeh and Chang (2019)
}

\author{
Dylan J. Pieper \\ University of Northern lowa
}

Let us know how access to this document benefits you

Copyright @2020 Dylan J. Pieper

Follow this and additional works at: https://scholarworks.uni.edu/etd

Part of the Sociology Commons

\section{Recommended Citation}

Pieper, Dylan J., "Challenging social systems under the threat of pollution: Replication and extension of Eadeh and Chang (2019)" (2020). Dissertations and Theses@ UNI. 1028.

https://scholarworks.uni.edu/etd/1028

This Open Access Thesis is brought to you for free and open access by the Student Work at UNI ScholarWorks. It has been accepted for inclusion in Dissertations and Theses @ UNI by an authorized administrator of UNI ScholarWorks. For more information, please contact scholarworks@uni.edu. 
Copyright by

DYLAN J. PIEPER

2020

All Rights Reserved 
CHALLENGING SOCIAL SYSTEMS UNDER THE THREAT OF POLLUTION:

REPLICATION AND EXTENSION OF EADEH AND CHANG (2019)

\author{
An Abstract of a Thesis \\ Submitted \\ in Partial Fulfillment \\ of the Requirements for the Degree \\ Master of Arts
}

Dylan J. Pieper

University of Northern Iowa

May 2020 


\begin{abstract}
Purpose

I replicated and extended Eadeh and Chang (2019; Study 2) who found that reading a story about pollution harming a child increased self-reported liberalism and increased support for environmental regulation policies through greater negative affect (i.e., anger and disgust) (Hypothesis 1). Eadeh and Chang's (2019) threat-affordance model posits that perceived threat can increase greater support for liberalism or greater support for conservatism, depending on the type of threat. In contrast, Jost and colleagues' (2003) system justification theory posits that perceived threat asymmetrically predicts greater support for conservatism and greater systemsupporting collective action. This article advances a synthesis of these two theoretical perspectives such that the threat of environmental pollution (a) increases system-challenging collective action intentions and donation behavior through negative affect (Hypothesis 2) and (b) increases liberalism, support for environmental regulation, collection action intentions, and donation behavior through lower system justification (moderated by empathy), greater perceived injustice, and greater negative affect (in order; Hypothesis 3).
\end{abstract}

\title{
Methods
}

In a pre-registered experiment, Amazon Mechanical Turk workers $(n=429)$ were randomly assigned to read and write about one of two articles about environmental pollution harming a child (versus one of two control articles). Afterward, they completed self-report measures of their (a) emotional state and (b) perceptions of injustice, general system justification, political orientation, support for environmental regulation policies, collective action intentions, and willingness to donate a cash bonus to environmental conservation (versus keep the cash) (presented in a random order). 


\section{Results}

Hypotheses were tested using regression-based path analysis. As predicted, threat increased self-reported liberalism and increased support for environmental regulation through greater negative affect (Hypothesis 1). However, the direct effects of threat were inconsistent, resulting in increased conservatism and less support for environmental regulation policies. As predicted, threat also increased system-challenging collective action intentions and increased donations through greater negative affect (Hypothesis 2). However, the direct effects of threat were again inconsistent, resulting in less system-challenging collective action intentions and less donations. Contrary to what was predicted, threat had no direct effect on system justification; therefore, threat did not affect outcomes through low system justification (moderated by empathy), greater perceived injustice, and greater negative affect (in order; Hypothesis 3). Supplemental results did however reveal, however, that threat increased self-reported liberalism, support for environmental regulation, and system-challenging collection action intentions through greater negative affect (moderated by empathy), greater perceived injustice, and lower system justification and through liberal political orientation when measured as a mediator versus an outcome (in order). Supplemental analyses also revealed that fear and empathy mediated, and empathy and political orientation moderated, the effects of threat on some of the outcomes, which helped explain the inconsistencies between the direct and indirect effects.

\section{Discussion}

I interpret the current findings and their inconsistencies in the context of theoretical synthesis of the threat-affordance model and system justification theory. I conclude by discussing the consequences of perceived threats on political shifts and system change.

Keywords: threat, harm, environmental pollution, political ideology, injustice, system justification, collective action, cognition, affect, emotion 
CHALLENGING SOCIAL SYSTEMS UNDER THE THREAT OF POLLUTION:

REPLICATION AND EXTENSION OF EADEH AND CHANG (2019)

\author{
A Thesis \\ Submitted \\ in Partial Fulfillment \\ of the Requirements for the Degree \\ Master of Arts
}

Dylan J. Pieper

University of Northern Iowa

May 2020 
This Study by: Dylan J. Pieper

Entitled: Challenging Social Systems Under the Threat of Pollution: Replication and Extension of Eadeh and Chang (2019)

has been approved as meeting the thesis requirement for the

Degree of Master of Arts

Date

Date

Date

Date
Dr. Nicholas G. Schwab, Chair, Thesis Committee

Dr. Helen C. Harton, Thesis Committee Member

Dr. Jiuqing Cheng, Thesis Committee Member

Dr. Jennifer J. Waldron, Dean, Graduate College 
TABLE OF CONTENTS

PAGE

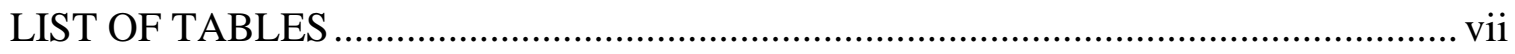

LIST OF FIGURES ................................................................................. viii

CHAPTER ONE: INTRODUCTION ................................................................. 1

Threat-Affordance Model ............................................................................... 4

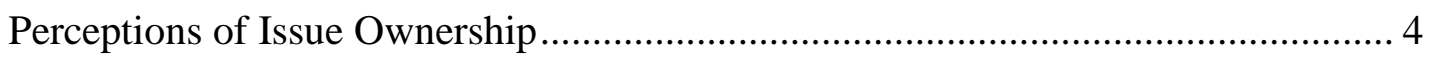

Direct Empirical Support .............................................................................. 5

Moral Emotions Motivate Threat-Mitigation ..................................................... 6

Differentiation in Harm Perception .............................................................. 9

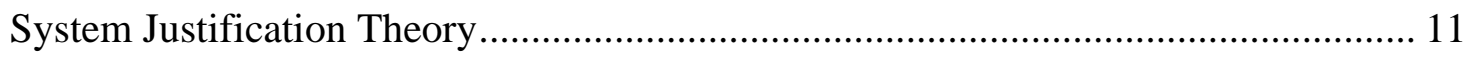

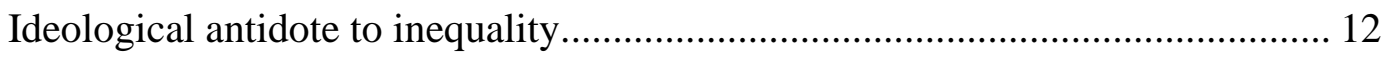

Relational, epistemic, and existential needs ............................................. 13

Meta-analyses on fundamental needs ..................................................... 15

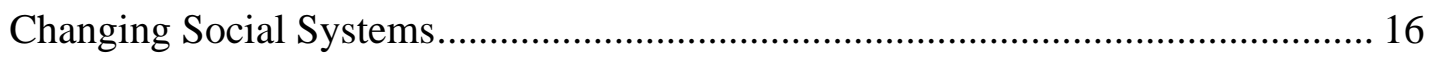

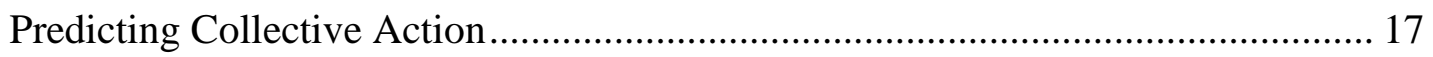

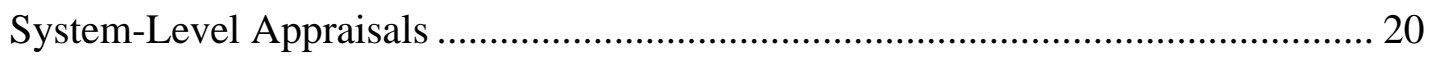

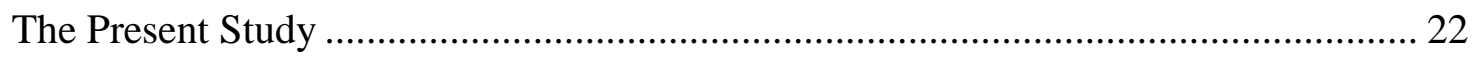

Hypothesis 1: Threat Increases Liberalism-Mediated by Greater Negative Affect 23

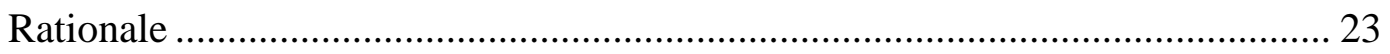

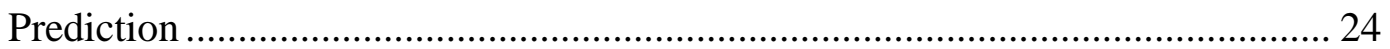

Hypothesis 2: Threat Increases System-Challenging Collective Action Intentions and Behavior-Mediated by Greater Negative Affect ....................................... 24

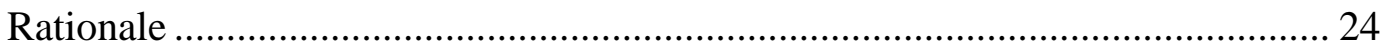

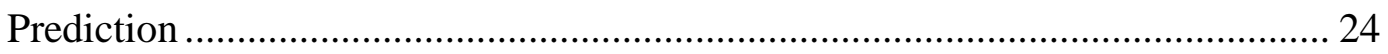


Hypothesis 3: Threat Increases Liberalism and System-Challenging Collective Action Intentions and Behavior-Mediated by Lower System Justification (Moderated by Greater Empathy), Greater Perceived Injustice, and Greater Negative

Affect 24

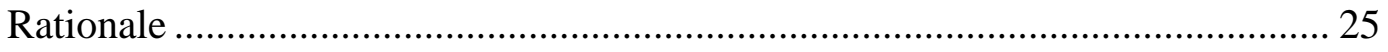

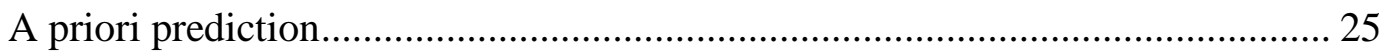

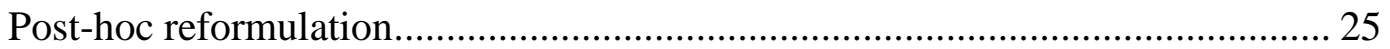

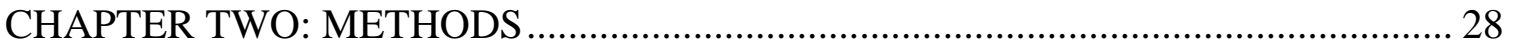

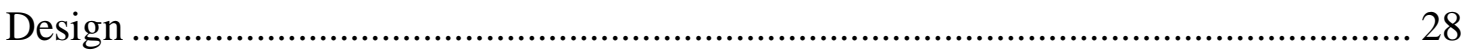

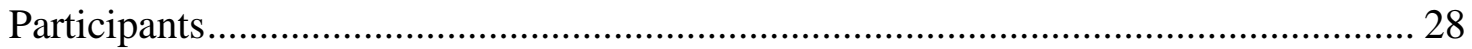

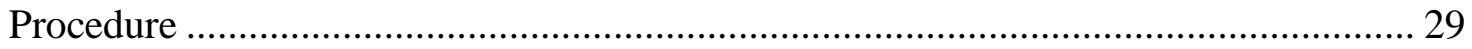

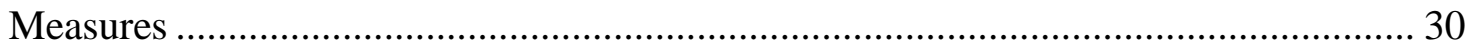

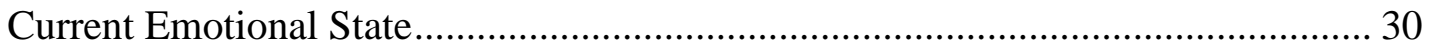

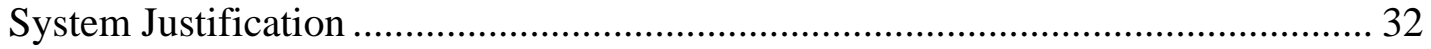

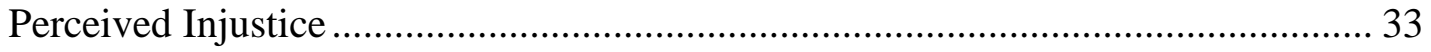

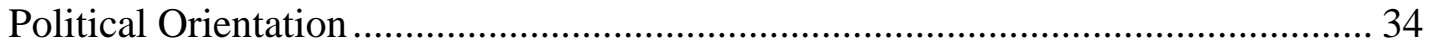

Support for Environmental Regulation ......................................................... 34

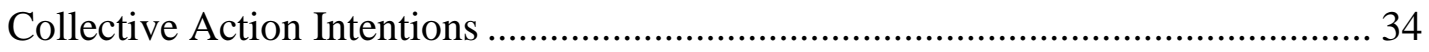

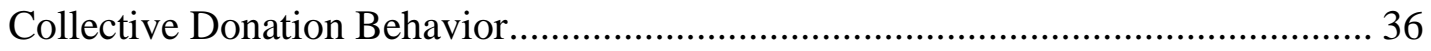

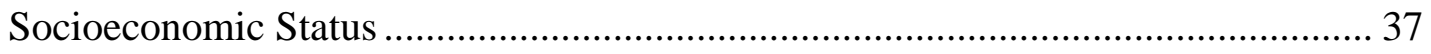

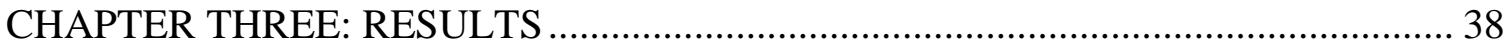

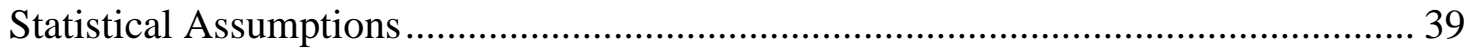

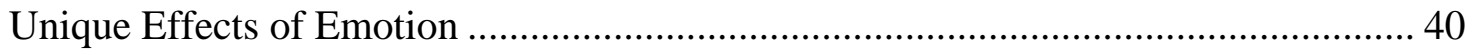

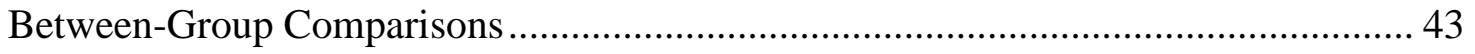

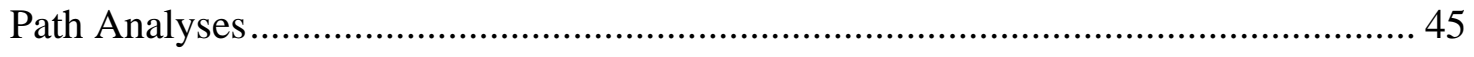

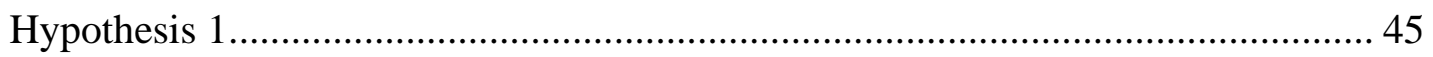




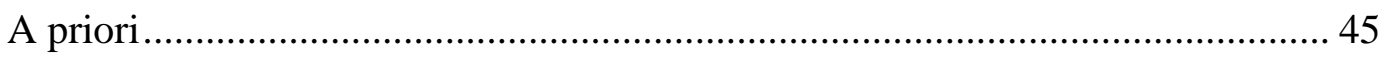

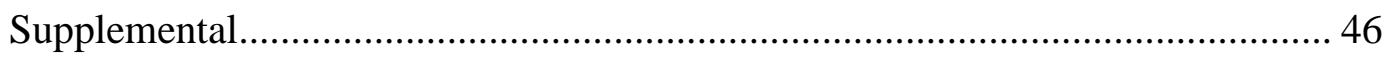

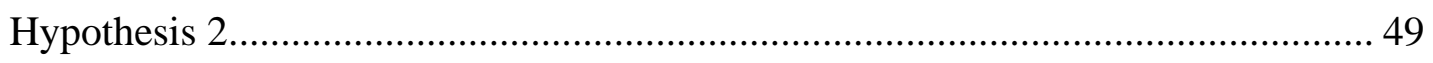

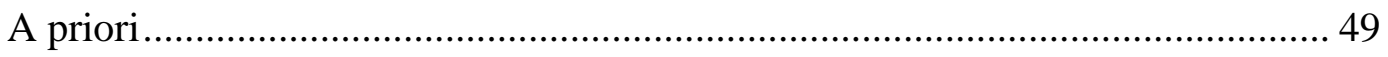

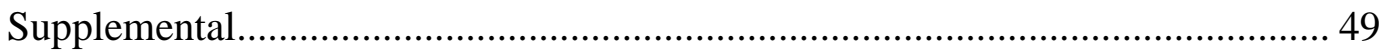

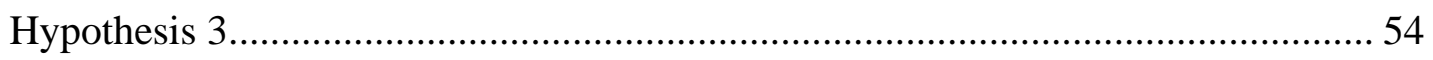

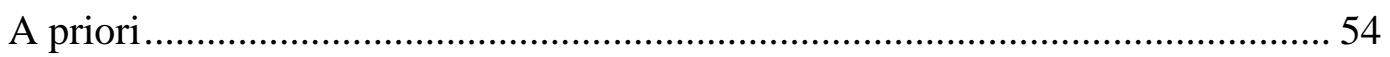

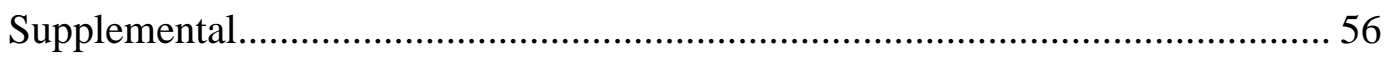

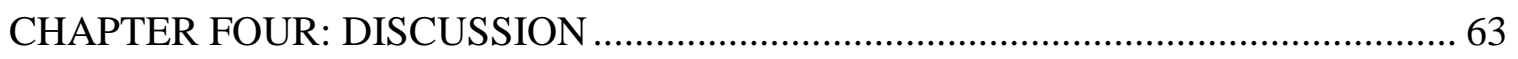

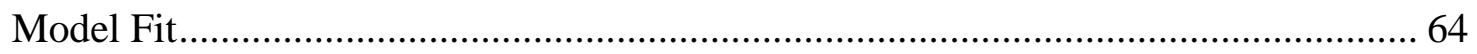

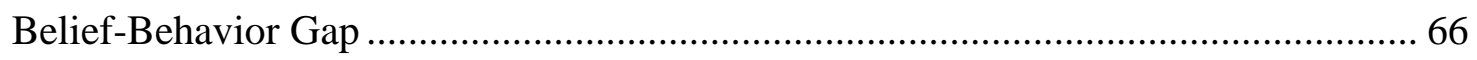

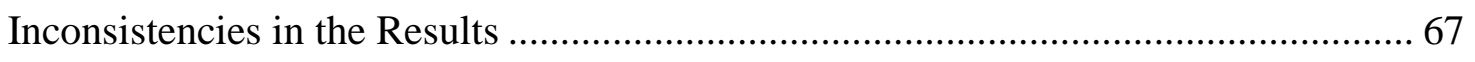

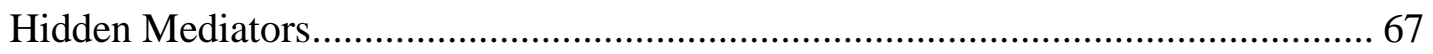

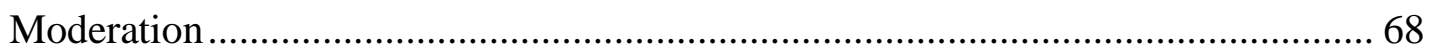

Limited Statistical Power .................................................................................. 70

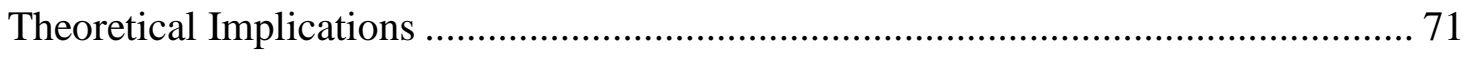

Limitations and Future Directions ...................................................................... 74

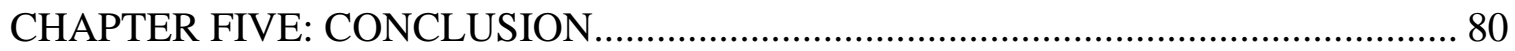

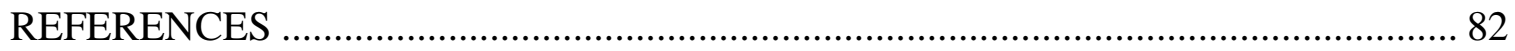

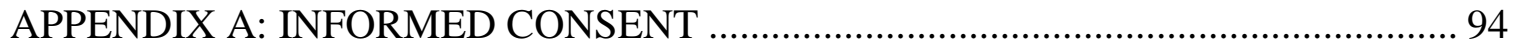

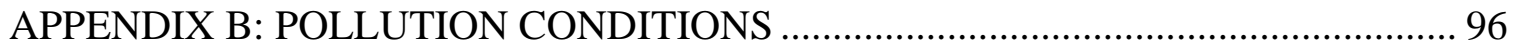

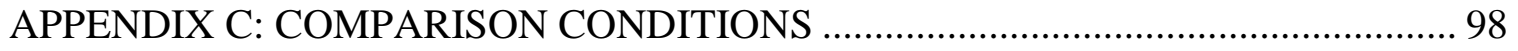

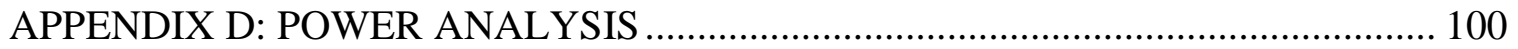

APPENDIX E: INCLUSION AND EXCLUSION CRITERIA ……………………....... 102

APPENDIX F: SYSTEM JUSTIFICATION SCALE .................................................... 103 
APPENDIX G: ENVIRONMENTAL POLICY PREFERENCES ............................. 104

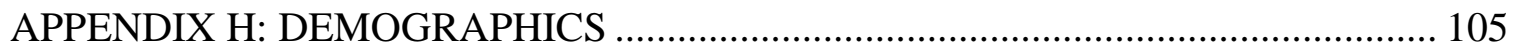

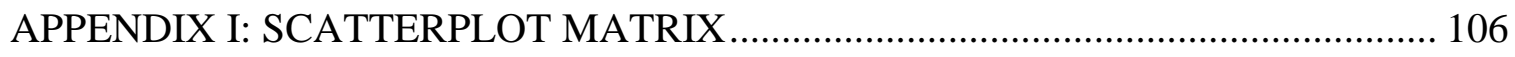
APPENDIX J: CORRELATION MATRICES ........................................................ 107 


\section{LIST OF TABLES}

PAGE

Table 1. Indirect Effect Sizes with Confidence Intervals for Mediation: The Effect of Environmental Threat on Sociopolitical Attitudes through Emotion ............................ 42

Table 2. Independent Samples T-Test (Mann-Whitney U).......................................... 44

Table 3. Means, Standard Deviations, and Correlations with Confidence Intervals for

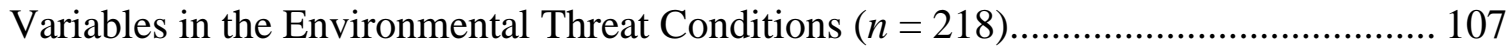

Table 4. Means, Standard Deviations, and Correlations with Confidence Intervals for

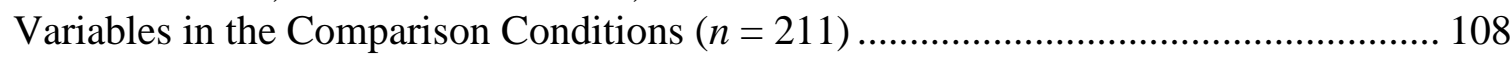




\section{LIST OF FIGURES}

PAGE

Figure 1. Path Diagrams for Hypothesis 3 (A Priori and Post-Hoc) .............................. 27

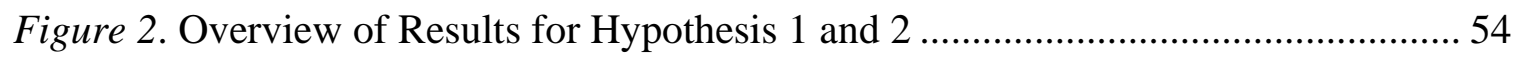

Figure 3. Regression Path Model Assessing Hypothesis 3 (A Priori)............................ 56

Figure 4. Regression Path Model Assessing Hypothesis 3 (Post-Hoc, Part 1) ............... 58

Figure 5. Regression Path Model Assessing Hypothesis 3 (Post-Hoc, Part 2) ............... 60 


\section{CHAPTER ONE:}

\section{INTRODUCTION}

In 2018, nine-year-old Ella Kissi-Debrah died because a thick mucus clogged her lungs (Marshall, 2018). This mucus was linked to illegally high levels of air pollution near the London roads where Ella walked to school. Spikes in air pollution, as measured by a nearby university, correlated with Ella's asthma symptoms and her hospital admissions. Since Ella's death, her mother has taken precautions to protect her other children by changing the path they walk to school and taking Ella's case to the High Court. Up to this writing, Ella's mother is still petitioning the High Court to rule air pollution as the cause of Ella's death, a ruling that would be the first of its kind for the court (Marshall, 2019). Ella's mother said that she wanted "to show to the British public what air pollution can actually do - they need to start getting angry [emphasis added] about this" (Oppenheim, 2019). Indeed, after Ella's death, concerned mothers and allies protested the government to address pollution and climate change (Christian, 2019).

Threats, such as environmental pollution in the example above, can motivate people to do something to ameliorate the threat. A threat may be anything that is likely to harm or endanger an organism (e.g., natural disasters and infectious disease). The threataffordance model (Eadeh \& Chang, 2019) predicts that people will endorse beliefs, behaviors, and collective actions that they believe will address a perceived threat, a process partially mediated by the degree to which perceived threats evoke anger and disgust (Lambert et al., 2019). Classically, affordances are perceptions that objects in the environment can help individuals meet their goals (Gibson, 1979). For example, a home 
affords dryness and warmth, and shoes afford walking on rough or sharp surfaces while avoiding pain and injury. Extending this concept to political attitudes, if a person is angered by distinct perceptual threats (e.g., terrorism and environmental pollution), they will likely endorse political policies and ideologies they expect to competently manage those threats (conservatism and liberalism, respectively; Eadeh, 2017; Eadeh \& Chang, 2019). Thus, people expect some shared issues (e.g., foreign enemies and climate change) to be addressed by the state or government and by certain political parties (Petrocik, 1996), perhaps because we expect that these issues could only be addressed by the state. In this way, particular political ideologies afford different perceived protections in response to specific perceived threats. ${ }^{1}$

The threat-affordance model contrasts with system justification theory (SJT; Jost \& Banaji, 1994) and the conservatism as motivated social cognition framework (Jost et al., 2003). Whereas the threat-affordance model suggests that people will shift toward specific policies and responses that address a particular threat based on the negative emotional state that the threat evokes, the latter theories suggest that people shift their global political ideology in response to threat. More precisely, research in this latter area claims that perceiving threats in general (e.g., terrorist attacks, home invasions, and system-threats) is associated with increased conservatism (Jost et al., 2003; Jost et al.,

\footnotetext{
${ }^{1}$ In this paragraph, I begin talking about perceptions of threat. Unlike the real threat Ella faced, researchers cannot create an environment where participants are likely to be harmed; however, people need only to perceive a threat to motivate a response. Thus, researchers often study how people's perceptions of threat change their beliefs and behavior. To do this, researchers either (a) conduct field studies after real disasters (e.g., the 9/11/01 attacks; Nail \& McGregor, 2009), (b) prime threat (e.g., by having participants read an article on recent terrorist attacks; Eadeh, 2017), or (c) ask participants to self-report how much they worry about a threat (e.g., "I worry that I might be killed or injured in a terrorist attack"; Crowson et al., 2006).
} 
2015; Jost, Stern et al., 2017). Jost, Stern et al. (2017) argue that there is a linkage "between existential needs to reduce threat and politically conservative rhetoric and ideology, insofar as the latter tends to offer relatively simple, decisive, rigid, orderly, familiar, conventional, efficient, black-and-white, hierarchical, and authoritative solutions to social problems, challenges, and opportunities" (p. 343). However, currently no research has attempted to integrate these two perspectives into one model, which I propose a resolution to below.

To accomplish this goal, I first review emerging work on the threat-affordance model and argue that (a) people hold stereotypical assumptions about the ability of political entities to address issues of threat, (b) moral emotions motivate political-shifts, and (c) political ideologies are perceptual systems for reducing harm. Then, I argue that perceptions of threat evoke appraisals of social systems (e.g., as unjust, unfair, or otherwise incompetent), which I follow with a literature review of SJT. Finally, I advance my rationale for synthesizing the threat-affordance model and SJT. Specifically, I propose that system justification is attenuated when people perceive threats that are associated with a liberal shift. I test this proposition by replicating a study that found that the threat of environmental pollution increased liberal attitudes through negative affect (i.e., anger and disgust; Eadeh \& Chang, 2019, Study 2) and extending this paradigm to examine whether perceptions of injustice and general system justification also mediate this relationship. In addition, I examine empathy as a mediator and moderator of these relationships, as it is expected to arise when perceiving pollution harming a person, in addition to political orientation, as it may function both as a predictor and an outcome. 


\section{$\underline{\text { Threat-Affordance Model }}$}

\section{Perceptions of Issue Ownership}

Different responses to threat may reflect differences in people's subjective judgement of political entities (e.g., liberals as effective at addressing and reducing corporate corruption; conservatives as effective at securing borders). The threataffordance model assumes that people's support for either a liberal or conservative response to a perceived threat is influenced by stereotypical assumptions about which political party will most competently address the threat. In line with this view, issueownership theory predicts that people support political parties and candidates based on their perceived competencies for addressing the issues that people are concerned about (Petrocik, 1996). Across 17 countries and three decades, voters considered liberals to more competently handle issues related to the environment, social security, and healthcare compared to conservatives, and voters considered conservatives to more competently handle issues related to asylum/immigration, law and order, the European Union, taxes, and the economy compared to liberals (Seeberg, 2017; see also Newport, 2014; Saad, 2007). Issues that are not clearly owned by a specific political party include education, elderly care, unemployment, and families (Seeberg, 2017). Shifts in issue ownership have only slightly shifted over the past three decades, with no major issue changes from the left to the right (Seeberg, 2017).

In contrast, other research suggests that the salience of some economic threats may favor liberalism over conservatism (Brandt et al., 2019), raising some doubt about 
the fidelity or stability of some issue-ownership stereotypes. However, one possible explanation is that some issues (e.g., the economy) may appeal to both conservative and liberal tendencies (e.g., the desire to reduce government spending compared to the desire to increase government-sponsored basic income). These limitations aside, people show differences in their stereotypes about which political parties will best handle certain threats, a finding that is largely consistent with the types of threats that tend to increase either conservative or liberal responses.

\section{Direct Empirical Support}

As of this writing, three experimental studies have been published on the threataffordance model (Eadeh \& Chang, 2019). These experiments primarily examined whether certain threats cause a liberal-shift, as many studies have already documented that many threats (mainly terrorist attacks, xenophobic threats, and home invasions) cause a conservative-shift (for a recent meta-analysis, see Jost, Stern et al., 2017). Across three studies, Amazon Mechanical Turk workers read short news-type articles as manipulations of threat, either depicting harm associated with denial of healthcare insurance (Study 1), environmental pollution (Study 2), or corporate greed (Study 3). In each respective study, people reported increased support for interventionist healthcare regulations (Study 1), increased support for environmental regulations (Study 2), and increased support for financial regulations (Study 3). These effects were explained primarily through feelings of self-reported anger and disgust but not through fear. As for other outcomes, there was evidence that the threat of environmental pollution (Study 2) directly increased liberal political orientation, increased support for regulation of 
healthcare systems, and decreased social conservatism. As for interactions between the threat manipulations and political orientation, there was some evidence that the denial of healthcare manipulation (Study 1) interacted with political orientation such that people who were more liberal reported increased anger in the threat (versus control) conditions and showed a greater association between anger and support for regulation of healthcare systems. This latter finding suggests that liberals may be more sensitive to some threats that cause liberal shifts than people of other political orientations.

In addition to Eadeh and Chang's (2019) recent experiments, other correlational studies lend support to the threat-affordance model (Brandt et al., 2019; Kahn \& Björklund, 2020). First, Brandt et al. (2019) conducted a cross-national, multi-level network analysis on the World Values Survey and found that some economic threats were associated with liberalism, whereas threats of violence were associated with conservatism. Second, Kahn and Björklund (2020) conducted a series of six studies across nations (mainly in North American, Europe, and Australia) and found that liberalism was associated with threats of omission (i.e., unintentional, indirect, nonmalicious, and passive threats) and conservatism was associated with threats of commission (i.e., intentional, direct, malicious, and active threats). Threats of omission were associated with environmental threats and threats against social justice, whereas threats of commission were associated with threats of violence.

Moral Emotions Motivate Threat-Mitigation

People are motivated to address threats particularly when they feel moral emotions, such as anger, disgust, and contempt — and perhaps empathy and sadness. 
According to appraisal theory (Frijda \& Mesquita, 1998), people's appraisals of situations (e.g., unfair or harmful) result in certain emotions (e.g., anger) and action tendencies (e.g., approaching the source of unfairness or harm; helping those affected by the source of unfairness or harm). From a dyadic morality perspective, harm is the dominant appraisal that results in emotions such as anger and disgust across the political spectrum (Gray \& Wegner, 2011). This perspective lends support for the threataffordance model finding that negative affect (i.e., anger and disgust) partially mediates the effect of perceived threat on political responses (Eadeh \& Chang, 2019).

Emotions such as anger, disgust, and contempt share action tendencies that compel people to act against moral transgressors who cause some type of harm (see Hutcherson \& Gross, 2011; for a full treatment on anger, see Lambert et al., 2019). For example, German participants who engaged in collective action against outgroup members who caused them harm reported feeling anger and contempt toward them and reported feeling positive emotions toward their ingroup (Becker et al., 2011). In addition, in online samples from the United States and Norway, participants responded to threats of corporate environmental irresponsibility and environmental pollution by reporting more moral emotions such as anger, disgust, and contempt (but not fear or sadness) after reading about the threat (Eadeh \& Chang, 2019, Study 2; Xie et al., 2015). In turn, anger, disgust, and contempt (but not fear or sadness) were also associated with more support for complaining about and boycotting the irresponsible corporation and more support for stricter environmental regulation policies. However, note that anger does not always lead to aggressive, punishing types of behavior. Anger has been associated with prosocial 
behaviors in response to unfairness or injustice (e.g., charitable giving), even when accounting for empathetic responses (for a review, see van Doorn et al., 2014).

It is reasonable to question whether these moral emotions, specifically anger, disgust, and contempt, are related to different types of appraisals and behaviors. Indeed, some research suggests that anger, disgust, and contempt are related to qualitatively different appraisals to sources of harm and varying extremities of retributive behavior (Hutcherson \& Gross, 2011; Tausch et al., 2011). For instance, Stanford students reported feeling more anger when a transgression was appraised as self-relevant, more disgust when a person was appraised as immoral, and more contempt when a person was appraised as incompetent (Hutcherson \& Gross, 2011). In addition, these moral emotions may result in various extremities of retributive behavior. Among German students, those who reported more perceived injustice and anger were more likely to support normative collective action (e.g., participating in meetings and demonstrations), but people who reported more contempt were more likely to support nonnormative behavior (e.g., violent retaliation; Tausch et al., 2011), suggesting that contempt is associated with more detachment and less peacekeeping. However, people also tend to report these emotions in concert, suggesting that these emotions make up an underlying moral-emotional factor and lead to similar action tendencies (e.g., Eadeh \& Chang, 2019; Hutcherson \& Gross, 2011; Xie et al., 2015).

Anger, disgust, and contempt may not be the only moral emotions. For example, empathy has been associated with perceptions of harm and heightened levels of moral outrage (i.e., anger), although it is debated whether this response stems from a motive to 
altruistically help people who are suffering or wanting to superficially help people in order to self-regulate (e.g., Batson et al., 2007; Neuberg et al., 1997). In addition, although fear is often associated with caution and avoidance and sadness is often associated with giving up and withdrawing, both emotions tend to correlate with anger and aggression such that, in some cases, fear indirectly predicts outgroup aggression through ingroup affiliation (Spanovic et al., 2010) and sadness predicts ingroup loyalty (Smith et al., 2008) as well as support for aggressive regulatory policies (Eadeh, 2017, Study 3 [Healthcare insurance denial threat]; Pieper et al., 2020). However, note that fear and sadness do not always align with the action tendencies of anger and do align with their expected emotional appraisals. In other words, as would be anticipated, fear (Miller et al., 2009) and sadness (Eadeh, 2017, Study 3 [ISIS threat]) have also been found to suppress the effect of anger on political attitudes and collective action.

Taken together, this research suggests that moral emotions - such as anger, disgust, and contempt — and perhaps other emotions such as empathy, sadness, and fearmotivate people to address threats by taking action against a moral transgressor or source of perceived threat (who is appraised as unjust, unfair, or otherwise incompetent) or by helping people who have been harmed.

\section{Differentiation in Harm Perception}

Other theories also support the threat-affordance model by explicating both the centrality of harm across political ideologies (the dyadic theory of morality; Schein \& Gray, 2015) and how differences between liberals and conservatives alter their harm 
perceptions (moral foundations theory and the differentiated threat model; Graham et al., 2011; Laham \& Corless, 2016).

According to the dyadic theory of morality, liberal and conservative ideologies share the same common module for perceiving harm between a moral agent and a moral patient, but people who endorse these ideologies vary in their exposure to harm and cultural scripts for perceiving and mitigating harm (Schein \& Gray, 2015). From this perspective, the differences between conservatives and liberals are variations in their harm perception. Liberals may be thought of as "out-group specialists" associated with greater out-group favoritism, universalism, creativity, openness, empathy, and compassion; whereas conservatives may be thought of as "in-group specialists" associated with greater in-group favoritism, politeness (an aspect of conscientiousness), dogmatism, and sensitivity to (as well as avoidance of) negative stimuli (Choma et al., 2012; Hasson et al., 2018; Hirsh et al., 2010; Mendez, 2017; Nail et al., 2009; Waytz et al., 2016).

This differentiation of qualities between liberals and conservatives can also be viewed through the lens of moral foundations theory (Graham et al., 2011), which suggests that liberals tend to endorse moral foundations associated with Individuating (i.e., they value care/harm and fairness) and conservatives tend to endorse moral foundations associated with Binding (i.e., they favor their ingroup, authority, and purity). Building from moral foundations theory, Laham and Corless's (2016) advanced a differentiated threat model, suggesting that liberals are more sensitive to social evaluation threats (associated with Individuating foundations) whereas conservatives are more 
sensitive to disgust-related threats (i.e., reminders of contagions and animals; associated with Binding foundations). However, this is not to say that liberals are not disgusted when perceiving certain types of threatening stimuli (e.g., environmental pollution or corporate greed; Eadeh \& Chang, 2019), which echoes the theme that conservatives and liberals share a common moral-emotional template for harm.

\section{System Justification Theory}

System justification (Jost \& Banaji, 1994) is broadly defined as the tendency to justify the status quo, especially established social systems. The primary goal of SJT is to explain the entrenchment of inequality and to account for its pervasiveness. SJT postulates that people justify social systems and rationalize inequality as a palliative remedy to satisfy relational, epistemic, and existential needs (e.g., Hennes et al., 2012; Jost \& Hunyady, 2003). These three fundamental motivations tend to increase system justification for both high- and low-status individuals. For instance, in community samples of Israelis, when participants were told that the Israeli system was weak and unstable (versus strong and stable), high-status Jews reported more ingroup favoritism, whereas low-status Jews reported more outgroup favoritism (e.g., by endorsing stereotypes of high status group as more "intelligent"; see Jost \& Hunyady, 2003).

Threats to social systems is a crucial motivation for people to rationalize inequality (e.g., the waning stability of Israel; Kay \& Friesen, 2011). System threats risk the legitimacy or stability of the status quo and societal systems that afford real or imagined protection from potential harm. In psychological experiments, system threats are often operationalized as essays criticizing the participants' country and its social, 
political, and economic systems. System criticism (ostensibly written by a local or foreign journalist, respectively) is especially likely to increase system justifying stereotypes (e.g., powerful people as more "intelligent"; e.g., Kay et al., 2005) and result in the derogation of people who challenge the system (e.g., a woman in a position of power when her high status is appraised as nonnormative; Kay et al., 2009).

People are especially likely to justify social systems if people think they depend on those systems to meet their goals, if they think of those systems as inescapable, or if they feel like they have little personal control over their lives (see Jost, 2019; Kay \& Friesen, 2011). People may rely on existing social systems or system authorities (e.g., university professors and police officers; van der Toorn et al., 2011) to feel safe from harm or to compensate for their feelings of powerlessness (e.g., Kay et al., 2008). Thus, under conditions of high system dependence, high system inescapability, and low personal control, people may think it is costly to criticize social systems and beneficial to justify social systems insofar as this behavior serves an antidote to inequality and satisfies relational, epistemic, and existential needs.

Ideological antidote to inequality. SJT postulates that people justify the status quo "to cope with circumstances they cannot change" (p. 148), and that privileged ideologies serve a palliative function against redressing inequalities (Jost \& Hunyady, 2003). System-justifying ideologies are manifold and include political conservatism, right-wing authoritarianism, a Protestant work ethic, and a meritocratic ideology (for more, see Jost \& Hunyady, 2005). For example, when American students read meritocratic "rags to riches" stories about becoming an advantaged person (e.g., a person who worked hard to 
become a newspaper editor), they reported less moral outrage than when they read low system-justification stories about helping a disadvantaged person (e.g., a person raising money for a friend with cancer; Wakslak et al., 2007). These reduced levels of moral outrage were associated with participants reporting less personal support for social programs for the disadvantaged (e.g., a crisis hotline) and less support for the government to fund them (Wakslak et al., 2007).

Not only does system-justification influence people to avoid redressing inequalities, but it is also associated with positive, system-affirming emotions. In a national survey across 10 countries, conservatives reported feeling happier than liberals even in countries with higher economic inequality, and this effect was not accounted for by their demographics or individual differences in cognition (Napier \& Jost, 2008; cf. McCall et al., 2017). Longitudinal evidence also suggests that system justification ameliorates anxiety and depression and promotes well-being regardless of variability in inequality across societies or the social status of individuals (Vargas-Salfate et al., 2018). Therefore, the overarching motive of system-justification is that it serves a palliative function against inequality by moving away from negative emotions (e.g., moral outrage) and moving toward positive emotions (e.g., happiness).

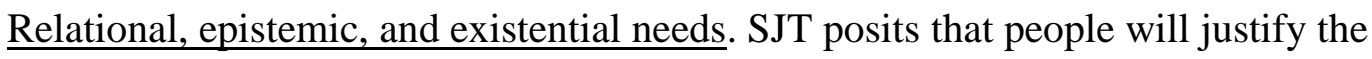
status quo to satisfy (1) relational needs (for shared reality with others), (2) epistemic needs (for knowledge and certainty), and (3) existential needs (for safety and security).

First, system justification satisfies relational needs to affiliate with close others; people bring their beliefs closer to close others' beliefs through social influence processes 
(Hardin \& Higgins, 1996). For instance, when students with one liberal and one conservative parent wrote about their conservative parent, they reported more general system-justification beliefs (e.g., that American society is fair)—regardless of whether the children wrote about positive or negative experiences with that parent (Jost et al., 2008). Therefore, to maintain relationships that help us meet affliction needs, people likely justify the privileged ideology in the relationship.

Second, system justification satisfies epistemic (i.e., knowledge-orientated) needs, specifically a dimension of closed-mindedness, commonly operationalized as a low need for closure and a low need for cognition. These epistemic needs are related to desiring certainty (or, in other words, avoiding uncertainty) and exerting less mental effort, respectively (Cacioppo et al., 1984; Kruglanski et al., 1993). For instance, when students or online participants report greater need for closure and a lower need for cognition, they also report greater system justification of American society, more support for systemjustifying political movements (i.e., the Tea Party or Occupy Wall Street), and greater political conservatism (Hennes et al., 2012; Thórisdóttir \& Jost, 2011).

Third, system justification satisfies people's existential needs for security or managing threat. When people perceive threat, they are more likely to endorse systemjustifying ideologies (i.e., conservatism and right-wing authoritarianism) and report greater levels of ingroup (ethnic and national) favoritism (Jost et al., 2003; Jost, 2017; Jost, Stern et al., 2017; Nail et al., 2009; Thórisdóttir \& Jost, 2011). However, Eadeh and Chang (2019) note that $82 \%$ of the threats in the recent meta-analysis conducted by Jost, Stern et al. (2017) consisted of terrorist attacks and the remaining threats were largely 
xenophobic threats or threats of physical violence or harm. Therefore, it is possible that only certain types of threats, such as threats of commission (Kahn \& Björklund, 2020), activate system-justifying existential needs.

These three needs may operate both dependently and independently to increase system-justification. In terms of dependent relationships, existential needs have been found to predict epistemic needs. In one study, students' answered items about how much they worry about terrorism with response options ranging from somewhat to a great extent (or not at all to somewhat) to prime perceptions of threat (Thórisdóttir \& Jost, 2011). Priming these students to think that they worry about terrorism resulted in them reporting a more conservative political orientation. The effect of the threat prime on increased conservative orientation was mediated by closed-mindedness, suggesting that one need can explain the effects of another. However, these three needs may also operate independently. In another study, when people in an online sample self-reported greater relational, epistemic, and existential needs, each need independently predicted greater general system-justification and support for political movements (Hennes et al., 2012).

In summary, there is a wealth of evidence suggesting that people endorse systemjustifying ideologies and resist social change (e.g., movements toward equality) to satisfy relational, epistemic, and existential needs. This evidence implies that system-justifying ideologies are favored when people need to fulfill these fundamental needs.

Meta-analyses on fundamental needs. Meta-analyses show small to medium effects for relational, epistemic, and existential needs increasing conservatism (Jost, 2017; Jost, Stern et al., 2017). The authors of the meta-analysis claim that there is 
ideological asymmetry across existential needs (e.g., perceived threat favors conservatism), however, the design of the meta-analyses is not a symmetrical design on which to test assumptions of existential asymmetries. Specifically, the authors do not catalog types of threats that could symmetrically span across conservative and liberal ideologies. As discussed previously, a majority of these threats were threats of terrorism, and other types of threats seem to in fact increase liberalism (e.g., Eadeh \& Chang, 2019).

Although Jost et al. (2003) pioneered research and theory associating threat with conservatism, his and his colleagues' meta-analysis (Jost, Stern et al., 2017) also found that some threats increase liberalism. In their meta-analysis, the authors reviewed a survey conducted at Chapman University with 1,287 participants (from unpublished data provided by Christopher Brader). Twelve of the 73 specific fearful stimuli showed a relationship to political attitudes (see Figure 5 in Jost, Stern et al., 2017). Fear of "climate change, pollution, overpopulation, growing old, and police brutality" were associated with increased liberal attitudes. Fear of "government surveillance, government drones in the U.S., terrorist attacks, whites losing majority status, government corruption, illegal immigration, and gun control" was associated with increased conservative attitudes. This pattern is consistent with predictions made by the threat-affordance model. However, Jost, Stern et al. (2017) did not address these data in their conclusion.

\section{Changing Social Systems}

People may not always think it is beneficial to justify social systems under threat. System change is especially likely when (a) there is an opportunity to change the system (e.g., to vote), (b) the social change aligns with system-level values or is supported by 
system authorities, or (c) when the current system becomes too corrupt or illegitimate to fulfill people's fundamental needs for affiliation, certainty, and safety (Friesen et al., 2019). For instance, people are less likely to justify social systems when they perceive low social mobility or high economic inequality (Day \& Fiske, 2017; McCall et al., 2017). Similarly, according to an analysis of the World Values Survey, respondents' perceptions of system instability (e.g., government corruption) were associated with increased support for more government responsibility despite system-justifying motives due to low perceived self-control (Kay et al., 2008, Study 3). Therefore, one approach suggests that people have dual motives: A system-justification motive and a systemchange motive (Johnson \& Fujita, 2012). Johnson and Fujita (2012) found that people are more likely to desire system change when people think a system is changeable and selfrelevant and that the problem was formally diagnosed by high-level system authorities. People may therefore experience motives to both justify and change social systems, depending on the context. More work on the dual-motive approach may reveal that fundamental needs are also linked to a system-change motive (see also Jost, 2019).

\section{Predicting Collective Action}

Although system-change may be possible, according to SJT, most people are not easily motivated to protest injustices or inequality given the advantage of systemjustifying ideologies to satisfy people's fundamental needs. Unlike the assertion made by the affordance model that people are motivated to fix perceived threats (i.e., an existential need; Eadeh \& Chang, 2019), SJT predicts that people's existential needs tend to motivate them to downplay or support false information about perceived threats 
altogether (e.g., climate change and environmental problems; Jost, 2015; Vainio et al., 2014). In addition, changing the status quo can be difficult because of negative judgments system-justifiers have of system-challengers. For example, in one study, traditionalists judged reformers as extreme and ignored their shared qualities (Keltner \& Robinson, 1997). Thus, to change the status quo, a person must actively imagine and work against the system (the needs the current system satisfies) toward an alternative system, a pursuit that may "feel colder and less appealing than the status quo" (Eidelman \& Crandall, $2009 ;$ p. 100). Therefore, the route to system-challenging action tendencies requires focused effort.

SJT predicts that there two types of collective action that a person could be motivated to move toward (Jost, Becker et al., 2017). First, people could be motivated to move toward a system-supporting collective action (or inaction). System-supporting collective action may take the form of counter-protest (e.g., climate activists in Canada encountered gas and oil workers who gathered in a counter-protest; Zabjek, 2019). SJT suggests that higher levels of system-justification proceed system-supporting collective actions. Second, people could be motivated to move toward system-challenging collective action (or inaction). For example, hostile sexism (versus benevolent sexism) tends to motivate women to take collective action against gender inequality (e.g., participate in a rally; Becker \& Wright, 2011). System-challenging collective action was also demonstrated in the opening story when people protested the British government to prevent environmental pollution and climate change (Christian, 2019). SJT suggests that 
lower levels of system-justification proceeds system-challenging collective action. Although driven by different motivations, both actions are examples of collective action. In addition to system justification, people's motivation to engage in systemsupporting versus system-challenging collective action is also partially mediated by their perceptions of injustice and levels of anger (Jost, Becker et al., 2017). As people justify social systems, they perceive less inequality toward disadvantaged groups, which decreases their anger and increases their system-supporting protest intentions-however, as people begin to condemn social systems, they perceive more inequality toward disadvantaged groups, which increases their anger and increases their system-challenging protest intentions (Osborne et al., 2019). Research that I discussed previously also shows that perceptions of injustice increases feelings of outrage (Jost et al., 2012; Wakslak et al., 2007). Thus, in line with the dual-motives approach (Johnson \& Fujita, 2012), people may be motivated to downplay injustice, but when injustice is sufficiently salient, people feel angry and move toward social change instead.

It is also important to note that there are multiple appraisals for anger when comparing ingroup and outgroup members. Specifically, group-based anger is associated with system-challenging collective action for low-status groups, but with systemsupporting action for high-status groups (Osborne et al., 2019). To engage the systemchange motive for a high-status outgroup member, other-oriented emotions, such as empathy, may motivate perceptions of injustice for the other group and systemchallenging collective action. For instance, in one study, empathy, but not anger, motivated men to take collective action on behalf of women (Iyer \& Ryan, 2009). 
Therefore, low- and high- status individuals differ in their system needs and routes to system-challenging collective action.

In summary, system justification makes predictions for when people will engage in collective action that challenges or supports existing social systems. High systemjustification, low perceived injustice, and low system-based anger tend to predict systemsupporting collective action, especially among high-status individuals. In contrast, low system-justification, high perceived injustice, and high system- or group-based anger tend to predict system-challenging collective action, especially among high-status individuals. In contrast to the threat-affordance model, SJT suggests that under threat, people tend to report more system justifying attitudes, perceive less injustice, feel less system-based anger, and endorse system-supporting collective actions (e.g. counter-protests to proenvironment protests; Jost, Becker et al., 2017; Osborne et al., 2019). However, given the knowledge that certain threats also activate possible system-challenging ideologies (i.e., liberalism; Eadeh \& Chang, 2019), the effect of perceived threat on increase liberal responses may be explained by the opposite processes: low system-justification, high perceived injustice, and high anger (or moral affect). In addition, people's need to manage the types of threat that tend to increase liberalism may decrease, rather than increase, system-justification attitudes and increase system-challenging collective action.

\section{$\underline{\text { System-Level Appraisals }}$}

Upon perceiving threat, people may appraise both a specific transgressor and a social system as incompetent or immoral (e.g., unjust or unfair) and become motivated to act against both agents. Research in the moral emotion literature typically examines the 
appraisal of a specific transgressor (e.g., Hutcherson \& Gross, 2011). Two of three experimental manipulations of threat in studies of the threat-affordance model, however, depicted more than one transgressor (Eadeh \& Chang, 2019). In the denial of healthcare insurance threat condition (Study 1), the story suggested that the insurer refused to pay for a drug and that FDA was too slow to act to approve the use of drug. In the environmental pollution threat condition (Study 2), the story suggested that local industries were the cause of the pollution and that the lenient regulation of toxic pollution across the U.S. also contributed to the harm. In the corporate greed condition (Study 3), both loan-servicing banks and the government were appraised as responsible for the financial crisis of 2008. The participants may have reported more support for stricter government regulation policies across all three threat conditions, because the government was appraised as culpable for the harm. Thus, participants may have considered social systems to have a central influence over the perceived threat, which may lead them to act against those systems when they were appraised as incompetent, unfair, or immoral or otherwise responsible for the harm.

Action in response to these types of threat likely go beyond support for government regulation to individual and collective actions. Recall the story in the introduction about Ella's death likely due to London pollution, and the government permitting the pollution to occur at illegal and deadly levels (Marshall, 2018). Ella's mother took direct action by changing the route her children walked - in attempt to avoid further harm from the source of the threat (possibly motivated by fear) —and taking Ella's case to the High Court—in attempt to fix the lack of regulation of deadly pollution 
(possibly motivated by anger). These two actions represent distinct threat-affordance strategies at individual- and collective- levels of action. Either people may be motivated to take individual action to protect themselves (or a few people) or to take collective action to improve the welfare and status of a group (Iyer \& Leach, 2009). Motivation to act for the collective good is particularly relevant to the threat-affordance model, because collective action often manifests as political action (e.g., protests, petitions, boycotts, and formal complaints), which may align with shifts in political attitudes in response to a perceived threat.

\section{The Present Study}

The threat-affordance model and SJT may be complementary such that the types of perceived threats that increase liberalism (versus conservatism) may be associated with low (versus high) system justification. SJT differs fundamentally from the affordance model in that it was created to explain pervasive inequality in society rather than political shifts due to perceived threat. However, both perspectives make predictions related to political attitudes and ideology. SJT suggests that perceived threat is linked to systemjustifying ideologies such as conservatism (Jost, Stern et al., 2017). The threat-affordance model, on the other hand, suggests that some threats may increase conservatism and other threats may increase liberalism, depending on the type of threat (Eadeh \& Chang, 2019). The present study replicated and extended Eadeh and Chang (2019, Study 2) to integrate these two perspectives.

The present study examined people's self-reported emotions and political attitudes in response to reading about environmental pollution harming a child by (a) 
replicating the effect that the perceived threat increased liberal political orientation and increases support for liberal environmental regulatory policies through negative affect (i.e., anger and disgust; Hypothesis 1; Eadeh \& Chang, 2019, Study 2); (b) evaluating the effect of the perceived threat on self-reported system-challenging collective action intentions and collective donation behavior through negative affect (Hypothesis 2); and (c) further explaining the liberal-shift through self-reported system appraisals (i.e., system justification [moderated by empathy] and perceived injustice) and negative affect (in order; Hypothesis 3; see Figure 1). For Hypothesis 1 through 2, empathy and fear were tested along with negative affect as mediators of threat and political responses. Empathy — and political orientation — were tested as moderators of perceived threat and negative affect in supplemental analyses of Hypotheses 1 through 3. This analytic strategy follows Xie et al. (2015) who found that empathy moderated the effect of environmental irresponsibility on feelings of anger, which, in turn, was associated with increased collective action intentions.

The following hypotheses were preregistered on OSF (https://osf.io/2md4e/) (including the hypotheses labeled "a priori") except for the post-hoc reformulation of Hypothesis 3 (see next section).

Hypothesis 1: Threat Increases Liberalism-Mediated by Greater Negative Affect

Rationale. The first hypothesis functions as a replication of the findings of Eadeh and Chang (2019, Study 2). They primarily found that stories of environmental pollution harming a child increased support for government regulation of the environment (as a direct effect) through negative affect (i.e., anger and disgust; as an indirect effect) but not 
through fear. In their supplementary analyses, they showed that perceived threat directly increased liberal political orientation, a finding that was absent for other threats (i.e., denial of healthcare and corporate greed).

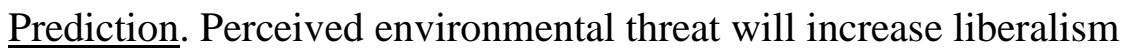
(operationalized as increased liberal political orientation and support for environmental regulatory policies). This effect will be mediated by participants' negative affect in response to the threat primes.

Hypothesis 2: Threat Increases System-Challenging Collective Action Intentions and $\underline{\text { Behavior-Mediated by Greater Negative Affect }}$

$\underline{\text { Rationale. }}$ The second hypothesis functions as an extension of Eadeh and Chang's (2019) original findings to capture a wider range of political action affected by the threat of environmental pollution, specifically collective action intentions (e.g., support for boycotting corporate polluters and support for protesting the government) and collective donation behavior (i.e., choosing to donate [versus keep] an extra 25 cents to support environmental conservation).

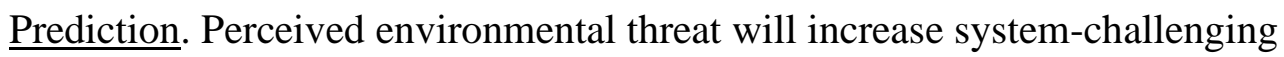
collective action intentions and collective donation behavior. The effect between environmental threat and collective action intentions and behavior will be mediated by how much participants report feeling negative affect after reading about the threat. Hypothesis 3: Threat Increases Liberalism and System-Challenging Collective Action Intentions and Behavior-Mediated by Lower System Justification (Moderated by Greater Empathy), Greater Perceived Injustice, and Greater Negative Affect 
Rationale. The third hypothesis functions as an extension of Eadeh and Chang's (2019) original findings to include general system justification and perceptions of injustice (i.e., that corporations and governments are corrupt do not care about people's health) as mediators of perceived environmental threat and political attitudes. Unlike Eadeh and Chang, in Hypothesis 3 (a priori), I predicted that the perceived threat would directly manipulate system justification. The rationale for this prediction was based on the system justification theory of collection action (Osborne et al., 2019), which suggests that perceived threat influences collection action through system justification, perceived injustice, and anger (in order). Therefore, this system justification perspective assumes cognitive (versus affective) primacy. However, recent research suggests that affect and cognition are interdependent (Storbeck \& Clore, 2007) and primacy is context dependent (Tzuyin Lai et al., 2012); thus, both possibilities were tested.

A priori prediction. The effect of the environmental-threat prime stories on increased liberal political orientation, support for stricter environmental regulation policies, system-challenging collective action intentions, and collective donation behavior will be mediated by less general system justification, more perceived injustice, and more negative affect. The effect of the threat primes on system justification will also be moderated by empathy such that as empathy increases, system justification will be further weakened when reading a story about environmental pollution harming a child. Figure 1 illustrates these predictions in a path diagram.

Post-hoc reformulation. In a post-hoc reordering of the variables, I followed Eadeh and Chang's (2019) finding that perceived threat directly increases negative affect. 
I predicted that, in addition to negative affect, progressively increasing the broadness of the constructs in order from high perceived injustice (context-specific) to low system justification (diffuse), would, in turn, predict more liberal political orientation, more support for environmental regulation policies, more system-challenging collective action intentions, and more collective donation behavior (post-hoc, part 1). I also examined political orientation as additional mediator, rather than an outcome, following general system justification (post-hoc, part 2). This latter decision was made, because political orientation and system justification are conceptualized as intimately related, such that people justify systems "by latching onto pre-existing ideologies such as conservatism" (Jost et al., 2009, p. 326). Therefore, this perspective assumes affective (versus cognitive) primacy. This order is also conceptually consistent with the order of the survey, in which participants responded to the emotional state inventory before the cognitive measures. 
Figure 1. Path Diagrams for Hypothesis 3 (A Priori and Post-Hoc)
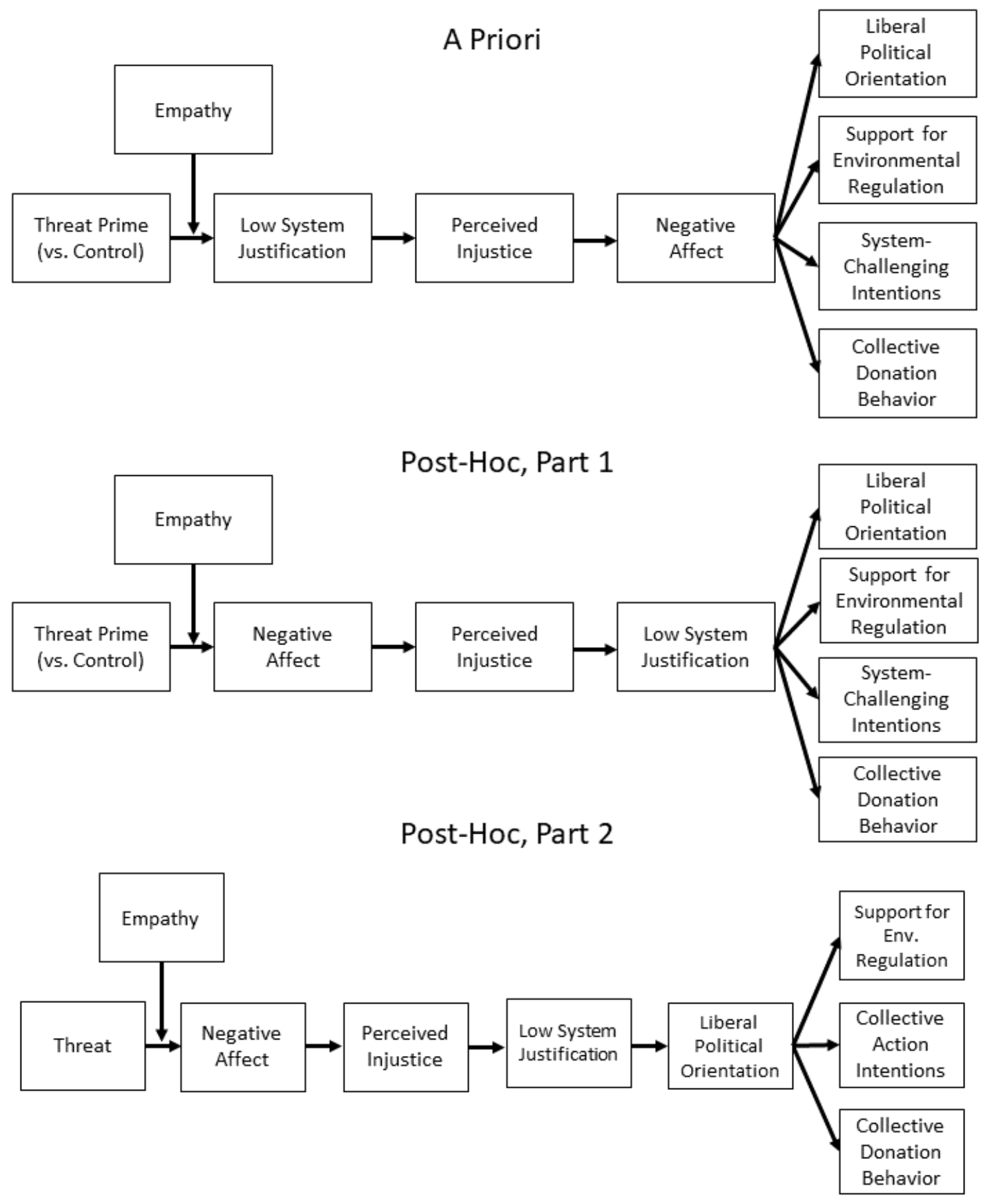

Note. Support for Env. Regulation = Support for Environmental Regulation . 


\section{CHAPTER TWO:}

\section{METHODS}

\section{$\underline{\text { Design }}$}

This study was a preregistered experiment administered online with approval of an institutional review board (see Appendix A for informed consent). Participants were randomly assigned to either read one of two threat-priming articles (about air or water pollution harming a child; Appendix B), a threat-priming comparison article about food allergies (following Eadeh \& Chang, 2019; Appendix C), or another comparison article about how water systems keep U.S. citizens safe (Appendix C).

\section{$\underline{\text { Participants }}$}

Data from 498 participant responses were initially collected from Amazon's Mechanical Turk, a service that offers high quality data (Buhrmester et al., 2011; see Appendix D for a power analysis). Participants were recruited using the research recruitment tool CloudResearch (formerly known as TurkPrime; Litman et al., 2017) and included only United States (U.S.) citizens who met screening criteria for having high task completion rate and a unique and unsuspicious location (see Appendix B). Exclusion procedures were used to flag and filter out participants who had a non-U.S. IP address or who had duplicate IP addresses and participants who displayed automated, inattentive, careless, or dishonest response patterns (Appendix B). These exclusion criteria resulted in a final sample of 429 participants whose responses were analyzed.

Participants' average age was 44.8 years old $(S D=13.37)$. There were slightly more women $(n=226)$ than men $(n=201)$ in addition to two non-binary individuals. 
Most participants were White $(n=350)$, with a smaller proportion of participants reporting non-White ( $n=79$; i.e., American Indian or Alaskan Native; Asian; Black or African American; Native Hawaiian or another Pacific islander; and Hispanic or Latinx). Subjective socioeconomic status (measured on a 1 to 10 MacArthur scale) was slightly below the mean and did not significantly differ between the perceived threat conditions $(M=4.73 S D=1.92)$ and the comparison conditions $(M=4.90, S D=1.97)$.

Participants completed this study in exchange for 75 cents with the opportunity to earn or to donate an additional 25 cents to the Sierra Club Foundation (i.e., an organization engaged in conservation efforts). A total of 134 participants indicated they wanted to donate their 25 cents, which meant they collectively donated $\$ 33.50$ toward environmental conservation.

\section{Procedure}

Participants on Amazon Mechanical Turk read the following task description: "People's attitudes on world events, natural systems, and society." Participants who selected the task were asked if they consented to the study (Appendix C). Upon giving their consent, participants were randomly assigned to one of two threat-priming conditions (Appendix D) or one of two comparison conditions (Appendix E). All participants were asked to write five to six sentences (at least 100 characters) about the article. Then, participants responded to items capturing their current emotional state. Next, participants completed measures of system justification, perceived injustice, political orientation, support for environmental regulatory policies, collective action intentions, and collective donation behavior (all counter-balanced randomly across 
separate pages). Third, participants answered demographic questions about their age, ethnicity, gender, educational achievement, and subjective socioeconomic status (SES); answered a question regarding how honest their answers were; and typed a response in an open-ended textbox if they had any questions or comments for the researcher (Appendix F).

This procedure deviates from the procedure used by Eadeh and Chang (2019), such that people did not always receive the environmental regulation policy attitudes scale after completing the emotion items, because the order in which the cognitive measures were presented were randomized. In addition, Eadeh and Chang presented the political orientation item as part of the demographic's measures, whereas, in the present study, political orientation was presented in a randomized order with other attitude variables. These changes were made to minimize possible order effects of threat on the dependent variables (e.g., fatigue or context).

\section{$\underline{\text { Measures }}$}

Items for each scale were presented in a random order. Alpha reliability coefficients were computed in R using the psych package (Revelle, 2019), and SpearmanBrown reliability coefficients were also computed in $\mathrm{R}$ using the following formula: $(2 *$ variable $) /(1+$ variable $)$. All factor analyses were conducted using JASP, which is a point-and-click application that uses R as its computational engine (JASP Team, 2019).

\section{Current Emotional State}

Participants rated how they were feeling in the moment while completing the questionnaire on a five-point Likert-type scale $(1=$ Not at all; $2=$ A little $; 3=$ Somewhat ; 
$4=A$ good deal; $5=$ Very much ) across 12 emotion adjective items organized in 6 item pairs. Feeling adjective pairs tapped into anger (angry and furious), disgust (disgusted and sickened), fear (fearful and afraid), anxiety (anxious and worried), sadness (sad and sorrowful), and empathy (sympathetic and compassionate). The empathy items were obtained from Niezink et al. (2012), and the remaining emotion items were obtained from Eadeh and Chang (2019) except for the author-generated adjective sorrowful, which replaced the adjective dejected due to concerns about reader comprehension). A mean score was calculated for each emotion for each participant by collapsing their answers to these pairs of items. These emotion item pairs demonstrated high reliability (SpearmanBrown $[\mathrm{S}-\mathrm{B}]$ coefficients $>.88$ ).

A principal component analysis with a promax rotation revealed a negative affect component comprised of 10-items (i.e., anger, disgust, fear, anxiety, and sadness), which explained $69 \%$ of variance (eigenvalue $=8.26$ ), and an empathy component, which explained $11 \%$ of variance (eigenvalue $=1.31$ ). The following eigenvalue was 0.75 , and a parallel analysis suggested a two-factor solution. The component loadings were between .66 and .92 for negative affect $(\alpha=.96)$ and between .95 (sympathetic) and .98 (compassionate) for empathy ( $\mathrm{S}-\mathrm{B}=.90)$. There were no significant cross-loadings between these two components (none > .32). See Supplemental Analysis, Part A, https://osf.io/2md4e/ for more details on this factor analysis.

As pre-registered, given the results of the PCA, a mean score should have been calculated for negative affect and the empathy adjective pair for each participant by collapsing their answers to the 10-items for negative affect. However, as discussed in the 
supplemental results, the fear adjectives were removed from the negative affect scale score due to fear suppressing the effect of perceived threat on political attitudes across conditions (see "Unique Effects of Emotion" in "Results" section). This pattern of results is consistent with Eadeh and Chang's (2019) distinction between negative affect (i.e., disgust and anger) and fear. Hence, although the current data did not show two components for fear and negative affect (as found by Eadeh \& Chang, 2019), these emotions were still analyzed separately.

\section{System Justification}

Participants rated their support for eight items on the System Justification scale (Kay \& Jost, 2003), such as "In general, you find society to be fair" and "American society needs to be radically restructured" (reverse-scored) on a five-point Likert scale (from $1=$ Strongly disagree to $7=$ Strongly agree). A mean score was calculated for each participant by collapsing their answers to these eight items (see Appendix D for all the items for this measure.) The reliability of this scale was high $(\alpha=.90)$, which was similar to the alpha coefficient found by the authors of the scale ( $\alpha=.87$; Kay $\&$ Jost, 2003). Kay and Jost (2003) conducted an independent validation of the system justification scale (SJS) and found convergence, but not redundancy, with other related concepts and scales, specifically a need for a Just World Scale (JWS; e.g., "I feel that people get what they deserve"; Lipkus, 1991) and a need for a Balanced Social World Scale (BSWS; e.g., "All in all, the world is a 'balanced' place"; Kay \& Jost, 2003). More precisely, Kay and Jost found that SJS scores strongly predicted JWS scores $(r=.67$; adjusting for BSWS $r=$ $.62)$ and modestly predicted BSWS scores ( $r=.37$; after adjusting for JWS $r=.21$ ). 


\section{$\underline{\text { Perceived Injustice }}$}

Perceived injustice has been measured by (a) using items that tap into people's experience with group discrimination or disadvantage (Osborne et al., 2019) and (b) using questions about feeling that a certain situation is unfair, unjust, and illegitimate (Tausch et al., 2011). However, because no measures of perceived injustice were found that were suitable for the topic of pollution, participants rated their support for six authorgenerated items on a Likert scale (from $1=$ Strongly disagree to $7=$ Strongly agree): "Many corporations don't care enough about people's health in the United States"; "Most companies don't do enough to protect the public from harm"; "Big industries do not care much about people's well-being, only the bottom-line"; "I am afraid that the government doesn't care enough about people's health in the United States"; "As long as the government is 'in bed' with corporations, the government does not work for the people"; and "The government does not prioritize people's well-being" on a five-point scale. The former three items were written to emphasize corporate injustice, and the latter three items were written to emphasize governmental injustice.

Perceived injustice against the government was positively correlated with perceived injustice against the corporate polluters (Pearson's $r=.82$ ), suggesting that they were highly related constructs. A principal components analysis revealed that all six items loaded onto one component for perceived injustice, explaining $77 \%$ of the variance (eigenvalue $=4.60 ;$ following eigenvalue $=0.46$, which fell below the parallel analysis 
simulated eigenvalue of > 1; see Supplemental Materials, Part B; https://osf.io/2md4e/). Component loadings were between .85 and .90 . Therefore, a mean score was calculated for each participant by collapsing their answers to these six items. The reliability of this scale was high $(\alpha=.94)$

\section{$\underline{\text { Political Orientation }}$}

Participants rated one item tapping political orientation: "What is your political orientation?" on a seven-point scale $(1=$ Very Conservative $; 2=$ Conservative $; 3=$ Lean Conservative $; 4=$ Moderate $; 5=$ Lean Liberal; $6=$ Liberal $; 7=$ Very Liberal .

\section{$\underline{\text { Support for Environmental Regulation }}$}

Participants rated 16 items related to their support for governmental regulation of environmental pollution on a seven-point Likert scale (from $1=$ Strongly disagree to $7=$ Strongly agree; constructed by Eadeh \& Chang, 2019). Sample items include "The federal government should aggressively carry out environmental protection regulations" and "The federal government should have a minimal role in regulating the coal industry" (reverse-scored; see Appendix E for all the items included in this measure). A mean score was calculated for support for environmental regulatory policies for each participant by collapsing their answers to these 16 items. The reliability of this scale was high $(\alpha=.94)$ and approximated the reliability found by the original authors of the scale $(\alpha=.92$; Eadeh \& Chang, 2019, Study 2).

\section{Collective Action Intentions}

Participants rated four items related to their support for environmental activism and governmental protest on a seven-point Likert scale (from $1=$ Strongly disagree to $7=$ 
Strongly agree). Two of these four items were revised from the Environmental Attitude Inventory (EAI) and the Environment Movement Activism sub-scale to emphasize political activism: "I would like to join and participate in an environmentalist group involved in local politics" and "I don't think I would help to raise funds for a politician who cared about environmental protection" (reverse-scored; Milfont \& Duckitt, 2010). Two additional author generated items were added to tap into people's readiness to protest the government: "I am willing to protest the government to take action against environmental pollution" and "If asked to go to a pro-environmental protest outside my local courthouse, I would."

Participants rated four items related to their support for complaining about and boycotting corporate polluters on a seven-point Likert scale (from 1 = Strongly disagree to $7=$ Strongly agree). Three items were revised from Xie et al. (2015) to make corporate polluters the target of the collective action intentions, specifically "I would complain directly to a corporate polluter, such as those who have dumped toxic waste into public waterways", "I would put pressure on corporate polluters to be socially responsible and correct their bad practices", and "I would encourage local suppliers or other companies not to do business with known corporate polluters" ( $\alpha=.97$ for complaining; originally a 5-item scale with boycotting as a separate variable; Xie et al., 2015). One additional author generated item was added to tap into people's readiness to protest corporate polluters: "I would support protesting a corporate polluter, such as coal plants, to be more socially responsible about their emissions." 
Collective action intentions against the government were positively associated with collective action intentions against corporate polluters (Pearson's $r=.83$ ), suggesting that they were highly related constructs. A principal components analysis revealed that all eight items loaded onto one component for collective action intentions, explaining $68 \%$ of the variance (eigenvalue $=5.40$; following eigenvalue $=0.83$, which fell below the parallel analysis simulated eigenvalue of > 1; see Supplemental Materials, Part C; https://osf.io/2md4e/). Component loadings were between .53 and .89. The lowest loading of .53 was for the reverse coded item "I don't think I would help to raise funds for a politician who cared about environmental protection". The remaining loadings were similar (between .83 and .89). Therefore, a mean score was calculated for each participant by collapsing their answers to these eight items. The reliability of this scale was high $(\alpha=.93)$.

\section{Collective Donation Behavior}

Collective action behavior was operationalized in the present study using an online donation paradigm (O'Grady \& Vandegrift, 2019). Following this paradigm, participants were presented with the following donation task as a proxy of collective action behavior: "You have the opportunity to earn an additional 25 cents for this survey, or you can rally with other MTurk workers to help maintain a clean and unpolluted environment by donating 25 cents to environmental conservation efforts. Please indicate what you want to do with this additional 25 cents." The possible response options were binary: "I want to keep the 25 cents" or "I want to donate the extra 25 cents to 
environmental conservation efforts (the Sierra Club Foundation)”. Responses were dummy coded for categorical contrast ( $0=$ kept bonus; $1=$ donated bonus).

\section{$\underline{\text { Socioeconomic Status }}$}

Socioeconomic status was measured using the MacArthur scale (Adler et al., 2000). This measure originally used a conceptual "ladder"; however, for the purposes of the present study, this "ladder" was converted to a numbered slider for ease of measurement. Participants read: "On the left side are the people who are the worst off, those who have the least money, least education, worst jobs, or no job. On the right side are the people who are the best off, those who have the most money, most education, and best jobs. Use the slider to indicate where you think you stand in society." The slider included tick marks ranging from 1 to 10 . 


\section{CHAPTER THREE:}

\section{RESULTS}

The critical alpha value ( $p$-value) for inferring the significance of the hypotheses was pre-registered $(p<.05)$ and used the power analysis (see Appendix D). In addition, for all path analyses, effect sizes with $95 \%$ confidence intervals including zero were not considered significant, because with high statistical power, there is a high probability of accurately failing to reject the null hypothesis.

Mean missing data across variable columns was less than 3\%, which was calculated using the MICE package (van Buuren \& Groothuis-Oudshoorn, 2011) for R. Missing data was addressed by averaging across all available data (as proportion of available item-level data was high and resulted in high reliability coefficients; following Graham, 2009) and deleting cases listwise if they had mostly missing data across all the observed variables (1 case; see Appendix E).

The two threat-priming conditions did not differ in their effects on political orientation, environmental attitudes, collective action intentions, perceived injustice, or system justification $(p s>.11)$, nor did they show independence in regards to collective donation behavior, $\chi 2(3)=0.35, p=0.95$; hence, these conditions were combined into a single threat-priming group. Following the pre-registration, the comparison articles were to be treated separately, because I predicted that the article on safe water systems would increase system justification compared to the food allergies article. However, there was no difference found between the control articles on general system justification $(p=.95)$; therefore, these conditions were combined for all further analyses. 


\section{$\underline{\text { Statistical Assumptions }}$}

Univariate normality was assessed using Shapiro-Wilks tests (Bonferronicorrected), and multivariate normality was assessed using the gvlma package for R (Pena \& Slate, 2019). In both tests, the null hypothesis of a normal distribution of data was rejected for all the variables in the current hypotheses and their corresponding linear equations. However, no transformations were made to these variables as the primary regression analyses used for this study are typically robust to normality violations (see Hayes, 2017, p. 70).

Univariate homogeneity of variance was assessed using Levine's test with Bonferroni corrections, and multivariate homogeneity was assessed using the gvlma package for R (Pena \& Slate, 2019). In the univariate analyses, the null hypothesis of homogeneity was rejected for negative affect and empathy. However, in the multivariate analyses, the null hypothesis of homogeneity was not rejected for any of the hypothesized linear equations. To be safe, heteroscedasticity-consistent standard errors (HC4) were used for path modeling in the PROCESS macro (Hayes, 2017), which has been recommend as a default standard error construction procedure (Hayes \& Cai, 2007).

Linearity was assessed using a scatterplot matrix (Appendix I) and correlation matrices (Appendix J) sorted by experimental condition. The scatterplot matrix visually illustrates the bivariate distribution of data plotted as points and the linear associations between the variables through a line of best fit. The assumption of linearity is strongest when the data concentrates around the line of best fit (e.g., negative affect and fear) (Appendix I). A flat line suggests no linear relationship, whereas a diagonal line indicates 
a positive or negative linear relationship. As a supplement to this visual approach, correlation matrices provide numerical coefficients of association (Pearson's $r$ ) for the bivariate associations between the variables across groups (ranging from 0 to 1 ) (see Appendix J). Correlations that differ across conditions, such as in the case of negative affect and environmental policy preferences, indicate group differences in the relationships between the variables. In the threat-priming conditions, 30 of $36(83 \%)$ of bivariate correlations were significantly positive (or negative in the case of system justification). This meant that 6 of $36(17 \%)$ of intercorrelations were not correlated in either condition (i.e., political orientation and fear; political orientation and empathy; fear and environmental attitudes; system justification and empathy; donation behavior and system justification; and donation behavior and perceived injustice). In the control conditions, only 14 of 36 (39\%) of the intercorrelations were significantly positive (or negative in the case of system justification) - specifically, the emotion variables were no longer correlated with political attitudes (see Appendix J). These results suggest that the assumption of linear relationships was satisfied for most variables in the threat conditions; however, many of these relationships disappeared in the control conditions.

\section{Unique Effects of Emotion}

I pre-registered that I would examine the emotional components that emerged from the principal components analysis, which resulted in components for negative affect and empathy (see "Measures" section). However, in a supplemental analysis using the PROCESS macro (Hayes, 2017) for SPSS, I examined the unique contribution of the adjective item pairs on the dependent variables across experimental conditions (following 
Eadeh \& Chang, 2019; see Table 2). When splitting up these adjective pairs as parallel mediators, I found that anger, anxiety, and empathy positively predicted political attitudes (except for system justification, which was only negatively related to anxiety). The adjective item pair for fear, on the other hand, demonstrated a suppression effect on all the political outcomes (except for general system justification). Therefore, to improve the interpretably of the negative affect component and avoid statistical suppression, fear was examined separately from negative affect in the following analyses. Although this was a deviation from the pre-registered analysis plan, the total effect of all the emotions predicted all outcomes except for levels of general system justification. This latter finding suggests that regardless of whether fear was retained or removed from the negative affect scale, levels of statistical significance would have remained the same. 
Table 1. Indirect Effect Sizes with Confidence Intervals for Mediation: The Effect of Environmental Threat on Sociopolitical Attitudes through Emotion

\begin{tabular}{|c|c|c|c|c|c|c|c|}
\hline Variable & Total & Anger & Disgust & Fear & Anxiety & Sadness & Empathy \\
\hline P.O. & $\begin{array}{c}.67 \\
{[.24,1.08]}\end{array}$ & $\begin{array}{c}.70 \\
{[.16,1.29]}\end{array}$ & $\begin{array}{c}.19 \\
{[-.48, .78]}\end{array}$ & $\begin{array}{c}-.31 \\
{[-.65, .01]}\end{array}$ & $\begin{array}{c}.29 \\
{[-.09, .70]}\end{array}$ & $\begin{array}{c}-.15 \\
{[-.69, .39]}\end{array}$ & $\begin{array}{c}-.06 \\
{[-.27, .15]}\end{array}$ \\
\hline $\begin{array}{l}\text { Env. } \\
\text { Atts. }\end{array}$ & $\begin{array}{c}.43 \\
{[.14, .72]}\end{array}$ & $\begin{array}{c}.37 \\
{[.06, .71]}\end{array}$ & {$\left[\begin{array}{c}.10 \\
{[-.27, .44]}\end{array}\right.$} & $\begin{array}{c}-.28 \\
{[-.48,-.08]}\end{array}$ & $\begin{array}{c}.26 \\
{[.04, .46]}\end{array}$ & $\begin{array}{c}-.14 \\
{[-.46, .18]}\end{array}$ & $\begin{array}{c}.13 \\
{[.001, .25]}\end{array}$ \\
\hline $\begin{array}{l}\text { Coll. } \\
\text { Act. }\end{array}$ & $\begin{array}{c}1.08 \\
{[.75,1.42]}\end{array}$ & $\begin{array}{c}.43 \\
{[.07, .87]}\end{array}$ & $\begin{array}{c}.38 \\
{[-.07, .81]}\end{array}$ & $\begin{array}{c}-.30 \\
{[-.57,-.04]}\end{array}$ & $\begin{array}{c}.41 \\
{[.11, .71]}\end{array}$ & $\begin{array}{c}-.08 \\
{[-.50, .34]}\end{array}$ & $\begin{array}{c}.24 \\
{[.08, .39]}\end{array}$ \\
\hline Donate & $\begin{array}{c}.89 \\
{[.34,1.54]}\end{array}$ & $\begin{array}{c}-.02 \\
{[-.67, .68]}\end{array}$ & $\begin{array}{c}.16 \\
{[-.60, .86]}\end{array}$ & $\begin{array}{c}-.34 \\
{[-.83, .04]}\end{array}$ & {$\left[\begin{array}{c}.69 \\
{[.23,1.23]}\end{array}\right.$} & $\begin{array}{c}.23 \\
{[-.40, .95]}\end{array}$ & $\begin{array}{c}.17 \\
{[-.06, .44]}\end{array}$ \\
\hline Sys. Just. & $\begin{array}{c}-.25 \\
{[.57, .05]}\end{array}$ & $\begin{array}{c}-.20 \\
{[-.58, .21]}\end{array}$ & $\begin{array}{c}-.34 \\
{[-.79, .06]}\end{array}$ & $\begin{array}{c}.14 \\
{[-.10, .38]}\end{array}$ & $\begin{array}{c}-. .34 \\
{[-.65,-.05]}\end{array}$ & $\begin{array}{c}.50 \\
{[.12, .88]}\end{array}$ & $\begin{array}{c}-.002 \\
{[-.15, .14]}\end{array}$ \\
\hline P. Injust. & $\begin{array}{c}.46 \\
{[.18, .77]}\end{array}$ & $\begin{array}{c}.15 \\
{[-.25, .58]}\end{array}$ & $\begin{array}{c}.27 \\
{[-.13, .68]}\end{array}$ & $\begin{array}{c}-.09 \\
{[-.29, .11]}\end{array}$ & $\begin{array}{c}.32 \\
{[.06, .56]}\end{array}$ & $\begin{array}{c}-.22 \\
{[-.62, .14]}\end{array}$ & $\begin{array}{c}.05 \\
{[-.10, .20]}\end{array}$ \\
\hline
\end{tabular}

Note. Variables were measured using 5- or 7-point Likert-type scales, except for "donate", which was a binary outcome and appears in log-odds. For each variable, the emotions were tested as parallel mediators, testing each mediator while accounting for their shared variance. Values in square brackets indicate the $95 \%$ confidence interval (CI) for each indirect effect. Effects that appear in bold do not include zero in the $95 \%$ CI. Total $=$ Total Indirect Effect. P.O. = Political Orientation (Conservative to Liberal). Env. Atts. = Environmental Regulation Attitudes. Coll. Act. = Collective Action Intentions. Sys. Just. $=$ System Justification. P. Injust. $=$ Perceived Injustice. 


\section{Between-Group Comparisons}

Preliminary between-group analyses of variance were conducted to illustrate the effects of the threat-priming conditions across all the observed variables before computing the hypothesized models (See Table 3). Mann-Whitney U analyses were conducted using the statistical computing software JASP (JASP Team, 2019), because it does not assume homogeneity of variance, which was violated according to Levene's test.

Hypothesis 1 and 2 suggested that threat would increase liberal responses through negative affect. As predicted in Hypothesis 1 and 2, there was a significant mean difference for negative affect (i.e., generalized anger) between the threat conditions and the comparison conditions such that there was more negative affect in the threat conditions $(M=3.03 ; S D=1.07)$ than the comparison conditions $(M=1.28 ; S D=0.57)$. There was also a significant mean difference for empathy between the threat conditions and the comparison conditions such that there was more empathy in the threat conditions $(M=3.75 ; S D=1.13)$ than the comparison conditions $(M=2.59 ; S D=1.26)$. However, the mean difference between threat conditions and the comparison conditions on political orientation was opposite of what was predicted, such that people were more conservative in the threat conditions $(M=4.32 ; S D=1.81)$ than in the comparison conditions $(M=$ 4.70; $S D=1.77$ ). Also, counter to predictions, there were no significant mean differences between conditions on support for environmental regulation policies $(p=.38)$, collective action intentions $(p=.98)$, or collective donation behavior $(p=.97)$.

Hypothesis 3 suggested that threat would increase liberal responses by first decreasing system justification. However, contrary to Hypothesis 3, there was no 
significant mean difference between conditions on system justification $(p=.45)$. This comparison suggests that Hypothesis 3 may have been incorrectly formulated or reflect the fact the sample consisted of people who were more liberal and had lower systemjustification overall (See Appendix J). Taken together, these findings suggest that instead of environmental threat directly increasing system justification, negative affect could mediate a reduction in levels of system justification. This possibility was tested in the following section (see "Hypothesis 3" in "Path Analyses").

Table 2. Independent Samples T-Test (Mann-Whitney U)

95\% CI for Rank-

Biserial

Correlation

\begin{tabular}{|c|c|c|c|c|c|}
\hline & \multirow[b]{2}{*}{$W$} & & & \multirow[b]{2}{*}{ Upper } \\
\hline & & $p$ & $\begin{array}{c}\text { Rank-Biserial } \\
\text { Correlation }\end{array}$ & Lower & \\
\hline Political Orientation & 20183.50 & .03 & -.12 & -.23 & -.01 \\
\hline Negative Affect & 42859.00 & $<.001$ & .86 & .83 & .89 \\
\hline Fear & 35157.50 & $<.001$ & .53 & .45 & .60 \\
\hline Empathy & 34542.50 & $<.001$ & .50 & .42 & .58 \\
\hline System Justification & 22029.00 & .45 & -.04 & -.15 & .07 \\
\hline Perceived Injustice & 24088.50 & .40 & .05 & -.06 & .16 \\
\hline Environmental Policy Preferences & 21868.50 & .38 & -.05 & -.16 & .06 \\
\hline Collective Action Intentions & 22968.50 & .98 & -.001 & -.11 & .11 \\
\hline Collective Donation Behavior & 22942.00 & .97 & -.002 & -.11 & .11 \\
\hline
\end{tabular}

Note. For the Mann-Whitney test, effect size is given by the rank biserial correlation.

Bold indicates $p<.05$. 


\section{$\underline{\text { Path Analyses }}$}

For each hypothesis, I first present results for the pre-registered (a priori) hypotheses. Then, I present supplemental results aimed at explaining some of the inconsistent effects in the data.

To test Hypothesis 1 and 2, the PROCESS (Hayes, 2017) macro for SPSS was used for mediation (Model 4) and moderated mediation (Model 59) with 5,000 bootstrap samples for 95\% CI construction, heteroscedasticity-consistent standard errors (HC4), and mean-centered moderators (i.e., variables that define products). To test Hypothesis 3 , I wrote custom syntax for the PROCESS (Hayes, 2017) macro for SPSS using the same parameters listed above.

Hypothesis 1

See Figure 2 for an overview of the results for Hypothesis 1 and 2.

A priori. Hypothesis 1 suggested that environmental threat primes would increase support for environmental regulation policies and liberalism, specifically through negative affect. As predicted, negative affect mediated the relationship between the threat (versus comparison) conditions on increased support for environmental regulation policies $(b=.38,95 \% \mathrm{CI}[0.15,0.62])$ and increased liberal political orientation $(b=.65$, 95\% CI $[0.30,1.00])$. Consistent with the between-group comparisons, there was greater negative affect in the threat (versus comparison) conditions ( $b=1.7595 \%$ CI [1.59, 1.91]). Subsequently, there was a positive association between negative affect on increased liberal political orientation $(b=0.37,95 \% \mathrm{CI}[0.17,0.57])$ and increased support for environmental regulation policies $(b=0.21,95 \% \mathrm{CI}[0.08, .35])$. Opposite of 
what was predicted, the direct effect of the threat (versus comparison) conditions resulted in greater conservativism $(b=-1.03,95 \% \mathrm{CI}[-1.54,-0.53])$ and less support for environmental regulation policies ( $b=-0.44,95 \%$ CI $[-0.79,-0.10])$. The total effect (i.e., direct effect plus indirect effect) of threat on political orientation was negative $(b=-0.38$, $95 \%$ CI $[-0.73,-0.04])$ whereas the total effect of threat on support for environmental regulation policies was nearly zero $(b=-0.07,95 \% \mathrm{CI}[-0.28,-0.14])$.

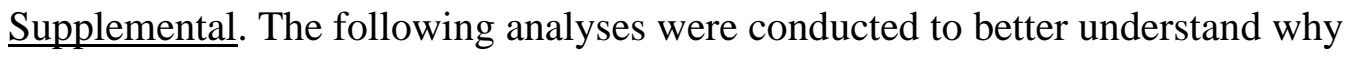
the indirect effects were inconsistent with the direct effects, which led to testing whether the inconsistency was still present when (a) fear and empathy were added as mediators of threat and political attitudes (in addition to negative affect), (b) political orientation was examined as a covariate, and (c) political orientation or empathy were added as moderators of the direct or indirect effects.

First, negative affect, fear, and empathy were examined as parallel mediators of perceived threat and policy preferences. Negative affect mediated perceived threat and greater support for environmental regulation policies $(b=0.67,95 \%$ CI $[0.26,1.12])$, whereas fear mediated perceived threat and less support for these policies $(b=-0.23$, $95 \%$ CI $[-0.42,-0.05])$ and empathy had no effect on policy preferences $(b=0.08,95 \%$ CI $[-0.03,0.20])$. The direct effect of threat was negative and resulted in less policy support $(b=-0.59,95 \% \mathrm{CI}[-0.98,-0.21])$, whereas the total effect was nearly zero and statistically nonsignificant $(b=-0.07,95 \% \mathrm{CI}[-0.28,0.14])$. However, when controlling for political orientation, only empathy mediated perceived threat and greater support for environmental regulation policies $(b=0.13,95 \% \mathrm{CI}[0.03,0.23])$ compared to negative 
affect $(b=0.28,95 \% \mathrm{CI}[-0.07,0.65])$ and fear $(b=-0.13,95 \% \mathrm{CI}[-0.30,0.01])$. Controlling for political orientation also resulted in a nonsignificant direct effect $(b=$ $0.20,95 \%$ CI $[-0.53,0.13])$ and did not change the total effect (nonsignificant), suggesting that political orientation may explain why perceived threat was associated with less support environmental regulation policies.

Second, negative affect, fear, and empathy were examined as parallel mediators of perceived threat and political orientation. Negative affect mediated perceived threat and greater self-reported liberalism ( $b=1.18,95 \% \mathrm{CI}[0.37,1.21])$, whereas fear mediated perceived threat and less self-reported conservatism $(b=-0.57,95 \%$ CI $[-0.42,-0.007])$ and empathy had no effect on political orientation $(b=-0.13,95 \%$ CI $[-0.33,0.06])$. The direct effect $(b=-1.16,95 \% \mathrm{CI}[-1.73,-0.60])$ and total effect $(b=-0.38,95 \%$ CI [-0.04, $-0.21])$ of threat was negative and resulted in greater self-reported conservatism.

Third, political orientation was examined as a moderator of threat and policy preferences. Political orientation moderated the mediation paths for the effect of threat on increased support for environmental regulation policies via negative affect, such that the indirect effect was only significant for participants who were more conservative $\left(16^{\text {th }}\right.$ percentile) $(b=0.53,95 \%$ CI $[0.04,1.23])$ compared to those who were more moderate $\left(50^{\text {th }}\right.$ percentile $)(b=0.27,95 \% \mathrm{CI}[-0.10,0.65])$ and more liberal $\left(84^{\text {th }}\right.$ percentile $)(b=$ $0.14,95 \%$ CI $[-0.35,0.64])$. Political orientation also moderated the mediation paths for the effect of threat on decreased support for environmental regulation policies via fear, such that the indirect effect was only significant for participants who were more moderate $(b=-0.16,95 \% \mathrm{CI}[-0.32,-0.01])$ compared to those were more conservative $(b=-0.16$, 
95\% CI $[-0.49,0.11])$ and more liberal $(b=-0.16,95 \%$ CI $[-0.35,0.02])$. Moreover, political orientation moderated the mediation paths for the effect of threat on increased support for environmental regulation policies via empathy, such that the indirect effect was only significant for participants who were more moderate $(b=0.13,95 \%$ CI $[0.04$, $0.23])$ and more liberal $(b=0.12,95 \% \mathrm{CI}[0.01,0.25])$ compared to those who were more conservative $(b=0.13,95 \%$ CI $[-0.003,0.28])$. Political orientation did not, however, moderate the direct effect of perceived threat on changes in policy preferences (i.e., all CIs included zero).

Fourth, empathy was examined as a moderator of threat and political outcomes. When examining empathy as moderator and controlling for political orientation, empathy did not moderate the indirect effect of threat on support for environmental regulation policies via negative affect or fear (i.e., all CIs included zero). However, empathy did moderate the indirect effect of threat on greater liberal political orientation via negative affect, such that the indirect effect was only significant for participants who were more empathetic $\left(84^{\text {th }}\right.$ percentile) $(b=2.33,95 \%$ CI $[1.47,3.14])$ and moderately empathetic $\left(50^{\text {th }}\right.$ percentile $)(b=1.10,95 \%$ CI $[0.51,1.67]$ compared to those who were less empathetic $\left(16^{\text {th }}\right.$ percentile $)(b=-0.12,95 \%$ CI $[-0.67,0.36])$. Empathy also moderated the indirect effect of threat on lower liberal political orientation via fear, such that the indirect effect was only significant for participants who were more empathetic $(b=-0.70$, $95 \%$ CI $[-1.12,-0.33]$ compared to those who were moderately empathetic $(b=-0.33$, $95 \%$ CI $[-0.52,0.03])$ and less empathetic $(b=0.02,95 \%$ CI $[-0.15,0.18])$. 


\section{Hypothesis 2}

See Figure 2 for an overview of the results for Hypothesis 1 and 2.

A priori. Hypothesis 2 suggested that environmental threat primes would increase collective action intentions and collective donation behavior through negative affect. As predicted, negative affect mediated the relationship between the threat (versus comparison) conditions on increased collective action intentions ( $b=1.03,95 \% \mathrm{CI}[0.77$, 1.31]) and increased collective donation behavior (indirect effect in log-odds $=0.93,95 \%$ CI $[0.50,1.43] ;+72 \%$ probability). Again, there was greater negative affect in the threat conditions $(B=1.7595 \%$ CI $[1.59,1.91])$. There was a positive association between negative affect and greater collective action intentions $(B=0.59,95 \%$ CI $[0.44,0.74])$ and greater collective donation behavior $(B=0.53,95 \% \mathrm{CI}[0.28,0.78])$. The direct effect of the threat (versus comparison) conditions resulted in less collective action intentions $(B=-1.05,95 \%$ CI $[-1.44,-0.66])$ and less collective donation behavior $(B=-$ $0.98,95 \% \mathrm{CI}[-1.61,-0.34])$. The total effect (i.e., direct effect plus indirect effect) of threat on collective action intentions was nearly zero $(b=-0.02,95 \%$ CI $[-0.30,0.26])$ and no total effect was available for donation behavior.

Supplemental. As with Hypothesis 1, the following analyses were conducted to better understand why the indirect effects were inconsistent with the direct effects.

First, negative affect, fear, and empathy were examined as parallel mediators of perceived threat and system-challenging collective action intentions. Negative affect ( $b=$ $1.26,95 \% \mathrm{CI}[0.75,1.76])$ and empathy $(b=0.18,95 \% \mathrm{CI}[0.03,0.34])$ mediated perceived threat and greater collective action intentions, whereas fear mediated perceived 
threat and less collective action intentions $(b=-0.23,95 \%$ CI $[-0.46,-0.01])$. The direct effect was negative and resulted in less collective action intentions $(b=-1.22,95 \%$ CI [$1.66,-0.78])$ whereas the total effect was nearly zero and not statistically significant $(b=$ $-0.02,95 \%$ CI $[-0.29,0.26])$. However, when controlling for political orientation, only negative affect $(b=0.83,95 \%$ CI $[0.41,1.28])$ and empathy $(b=0.23,95 \%$ CI $[0.10$, 0.37]) mediated perceived threat and greater collective action intentions, whereas fear no longer mediated this effect $(b=-0.13,95 \%$ CI $[-0.33,0.06])$. Also, when controlling for political orientation, the direct effect of perceived threat on collective action intentions remained negative $(b=-0.79,95 \% \mathrm{CI}[-1.18,-0.40])$ but the direction of the total effect was unaffected and remained nonsignificant $(b=0.14,95 \%$ CI $[-0.10,0.38])$.

Second, negative affect, fear, and empathy were examined as parallel mediators of perceived threat and collective donation behavior. Only negative affect mediated perceived threat and greater collective donation behavior $(b=1.05,95 \% \mathrm{CI}[0.75,1.76])$, whereas fear $(b=-0.15,95 \%$ CI $[-0.51,0.18])$ and empathy $(b=0.17,95 \%$ CI $[-0.04$, 0.41]) resulted in nonsignificant mediation. The direct effect of threat was negative and resulted in less collective donation behavior $(b=-1.13,95 \%$ CI $[-1.82,-0.44])$. These patterns of findings remained consistent and statistically significant, even when controlling for political orientation. Again, negative affect mediated perceived threat and greater collective donation behavior $(b=0.90,95 \%$ CI $[0.19,1.76])$ whereas fear $(b=-$ $0.11,95 \%$ CI $[-0.48,0.23])$ and empathy $(b=0.20,95 \%$ CI $[-0.03,0.43])$ resulted in nonsignificant mediation. In addition, the direct effect was negative and resulted in less collective donation behavior $(b=-0.98,95 \%$ CI $[-1.68,-0.27])$. 
Third, political orientation was examined as moderator of threat and political outcomes. Political orientation did not moderate the mediation paths for the effect of threat on greater collective action intentions via negative affect. More precisely, this indirect effect was positive and significant for participants who were more conservative $\left(16^{\text {th }}\right.$ percentile $)(b=0.86,95 \% \mathrm{CI}[0.16,1.76])$, more moderate $\left(50^{\text {th }}\right.$ percentile $)(b=$ $0.88,95 \%$ CI $[0.47,1.32])$, and more liberal $\left(84^{\text {th }}\right.$ percentile $)(b=0.87,95 \%$ CI $[0.31$, 1.40]). Political orientation did however moderate the mediation paths for the effect of threat on less collective action intentions via fear, such that the indirect effect was only significant for participants who were more liberal $(b=-0.31,95 \%$ CI $[-0.56,-0.09])$ and more moderate $(b=-0.21,95 \% \mathrm{CI}[-0.41,-0.03])$ compared to those who were more conservative $(b=0.08,95 \% \mathrm{CI}[-0.39,0.50])$. Political orientation also moderated the mediation paths for the effect of threat on greater collective action intentions via empathy, such that the indirect effect was only significant for participants who were more liberal $(b=0.34,95 \%$ CI $[0.17,0.54])$ and more moderate $(b=0.28,95 \%$ CI $[0.15$, 0.42]) compared to those who were more conservative ( $b=0.13,95 \%$ CI $[-0.02,0.31])$. Political orientation did not however moderate the direct effect of perceived threat on collective action intentions. More precisely, the direct effect was negative and significant for participants who were more conservative $\left(16^{\text {th }}\right.$ percentile $)(b=-0.80,95 \%$ CI $[-1.50,-$ $0.10])$, more moderate $\left(50^{\text {th }}\right.$ percentile $)(b=-0.83,95 \% \mathrm{CI}[-1.22,-0.43])$, and more liberal $\left(84^{\text {th }}\right.$ percentile $)(b=-0.84,95 \%$ CI $[-1.33,-0.35])$.

Political orientation did, however, moderate the mediation paths for the effect of threat on greater collective donation behavior via negative affect, such that the indirect 
effect was significant for participants who were more conservative $\left(16^{\text {th }}\right.$ percentile $)(b=$ $1.80,95 \%$ CI $[0.77,3.70])$ compared to those who were more moderate $\left(50^{\text {th }}\right.$ percentile $)$ $(b=0.77,95 \%$ CI $[-0.04,1.78])$ and more liberal $\left(84^{\text {th }}\right.$ percentile $)(b=0.27,95 \%$ CI $[-$ $0.87,1.50])$. Political orientation did not however moderate the mediation paths for the effect of threat on collective donation behavior via fear, where the indirect effect was not statistically significant for participants who were more conservative $(b=-0.49,95 \%$ CI [$1.45,0.15])$, more moderate $(b=-0.09,95 \%$ CI $[-0.50,0.28])$, and more liberal $(b=0.05$, $95 \%$ CI $[-0.43,0.53])$. Political orientation did, however, moderate the indirect effect of threat on greater collective donation behavior via empathy, such that the indirect effect was only significant for participants who were more liberal $(b=0.39,95 \%$ CI $[0.06$, $0.80])$ and more moderate $(b=0.28,95 \% \mathrm{CI}[0.04,0.57])$ compared to those who were more conservative $(b=0.03,95 \%$ CI $[-0.28,0.33])$. Moreover, political orientation moderated the direct effect of threat on less collective donation behavior, such that the direct effect was only significant for participants who were more conservative $(b=-1.37$, $95 \%$ CI $[-2.58,-0.16])$ and more moderate $(b=-0.87,95 \%$ CI $[-1.62,-0.12])$ compared to those who were more liberal $(b=-0.70,95 \%$ CI $[-1.63,0.23])$.

Third, empathy was examined as a moderator of threat and political outcomes. When controlling for political orientation, empathy did moderate the indirect effect of threat on greater collective action intentions via negative affect, such that the indirect effect was only significant for participants who were more empathetic $\left(84^{\text {th }}\right.$ percentile $)(b$ $=1.00,95 \% \mathrm{CI}[0.46,1.59])$ and moderately empathetic $\left(50^{\text {th }}\right.$ percentile $)(b=0.79,95 \%$ CI $[0.41,1.23]$ compared to those who were less empathetic $\left(16^{\text {th }}\right.$ percentile $)(b=0.35$, 
95\% CI [-0.01, 0.84]). Empathy did not, however, moderate the indirect effect of threat on collective action intentions via fear (i.e., all CIs included zero).

Similarly, when controlling for political orientation, empathy moderated the indirect effect of threat on greater collective donation behavior via negative affect, such that the indirect effect was only significant for participants who were more empathetic ( $84^{\text {th }}$ percentile) $(b=1.77,95 \%$ CI $[0.56,3.28])$ and moderately empathetic $\left(50^{\text {th }}\right.$ percentile) $(b=0.80,95 \% \mathrm{CI}[0.11,1.62]$ compared to those who were less empathetic $\left(16^{\text {th }}\right.$ percentile $)(b=-0.16,95 \%$ CI $[-0.18,0.31])$. Empathy did not moderate the indirect effect of threat on collective donation behavior via fear (i.e., all CIs included zero). 
Figure 2. Overview of Results for Hypothesis 1 and 2

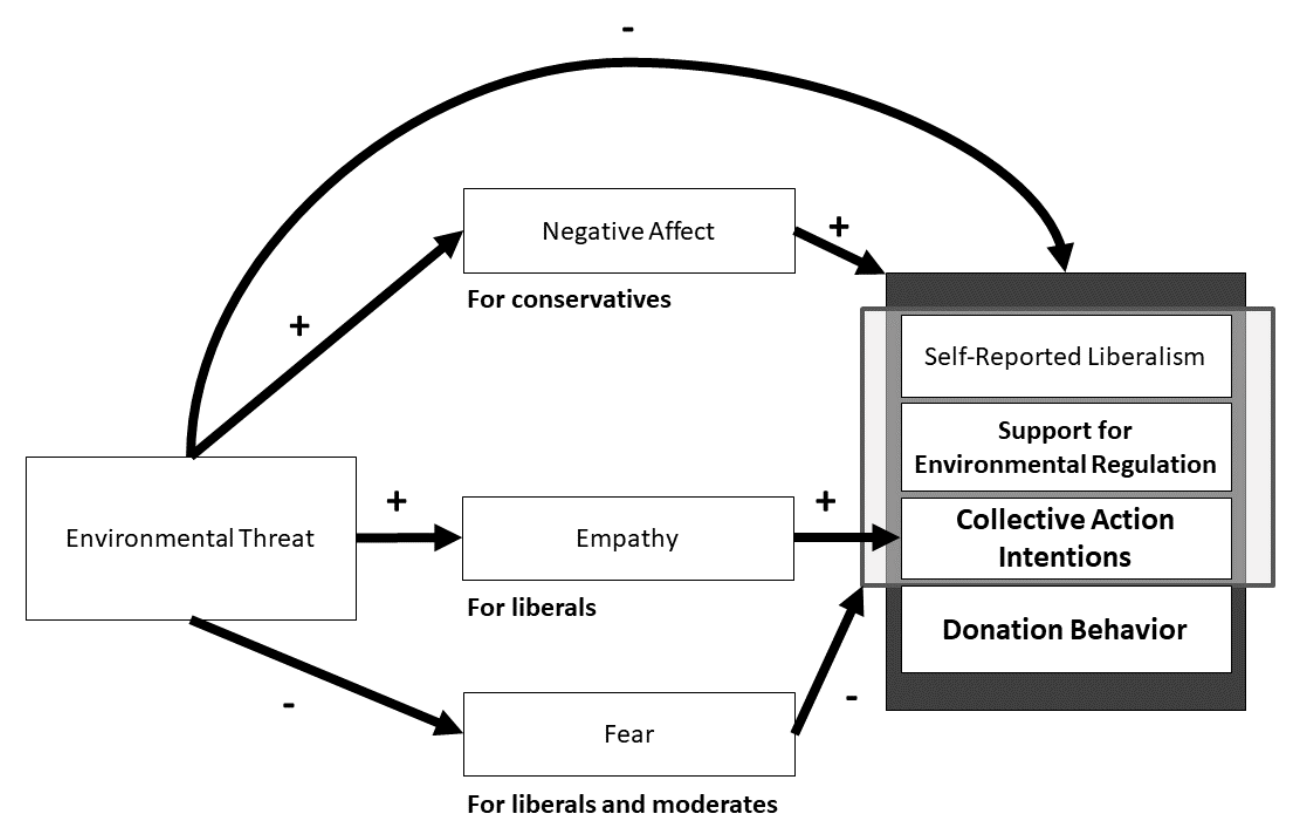

Note. The (+) sign indicates a positive relationship, whereas the (-) sign indicates a negative relationship. Gray boxes indicate groups of variables affected by the mediators. Moderation of the bold variables by political orientation is shown below the mediators.

\section{Hypothesis 3}

See Figure 3 for an overview of the results for Hypothesis 3.

A priori. Hypothesis 3 suggested that environmental threat primes would increase self-reported liberalism, support for environmental regulation, collective action intentions, and collective donation behavior - and this effect would be mediated by less system justification (moderated by empathy), greater perceived injustice, and greater negative affect (see Figure 1). Author-generated syntax for the PROCESS (Hayes, 2017) macro for SPSS was used to specify the mediators, moderators, and outcomes in Hypothesis 3, for example, "process $\mathrm{y}=\mathrm{PO} / \mathrm{m}=$ SysJust PInjust 
NegAffect_NF/x=threat/w=Empathy/bmatrix $=1,1,1,1,1,1,1,1,1,1 /$ wmatrix $=1,0,0$, $0,0,0,0,0,0,0 / \mathrm{hc}=4 / \mathrm{center}=2 / \mathrm{boot}=5000 . ”$.

As was evident from the absence of a between-groups effect of perceived threat on system justification, there were no significant indirect effects of threat on any of the political attitude or action outcomes through the hypothesized order of mediators (i.e., system justification [moderated by empathy], perceived injustice, and negative affect) (see Figure 4). Again, inconsistent with these indirect effects, the direct effects of threat on political orientation, collective action intentions, and collective donation behavior were negative, indicating more conservative system-justifying beliefs. In addition, the direct effect of threat on support for environmental regulation policies was insignificant, also indicating inconsistent mediation effects. 
Figure 3. Regression Path Model Assessing Hypothesis 3 (A Priori)

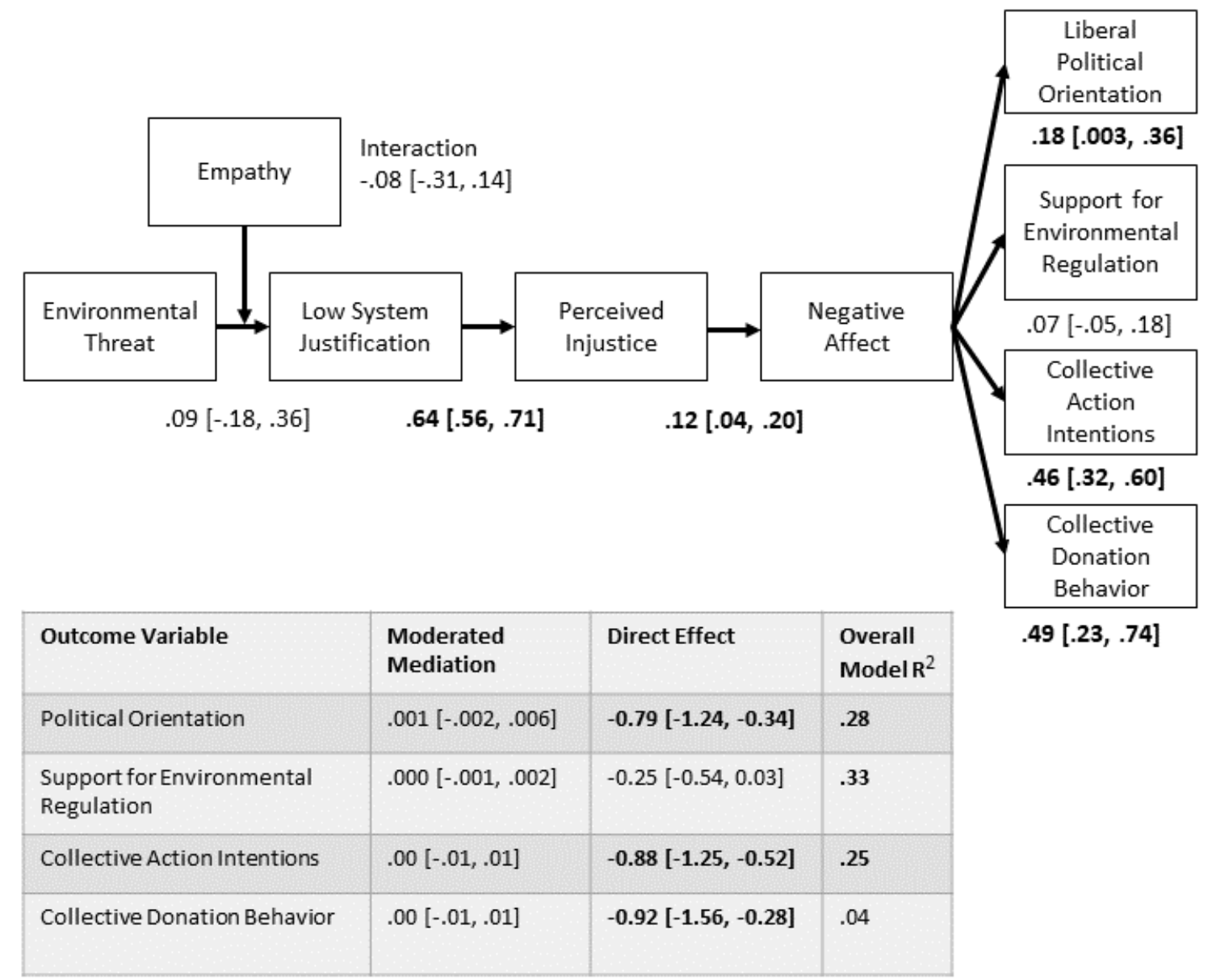

Note. Effect sizes appear as unstandardized regression coefficients. Empathy was mean centered. Values in square brackets indicate the $95 \%$ confidence interval (CI) for each effect. Significant effects appear in bold-effects were flagged as significant if they did not contain zero within a $95 \% \mathrm{CI}$ or if $p<.05$ (for the $f$-test for the model $\mathrm{R}^{2}$ ).

Supplemental. The indirect effects may not have been significant for Hypothesis 3 due to the order of the mediating variables. The first part of the post-hoc reformulation of Hypothesis 3 suggested that the threat of environmental pollution would increase selfreported liberalism, support for environmental regulation, collective action intentions, and collective donation behavior (mediated by greater negative affect [moderated by empathy], greater perceived injustice, and less system justification). Author-generated 
syntax for the PROCESS macro (Hayes, 2017) for SPSS was also used to specify the mediators, moderators, and outcomes relevant to the Hypothesis 3 (post-hoc, part 1), for example, "process y=PO/m = NegAffect_NF PInjust SysJust / $\mathrm{x}=$ threat $/ \mathrm{w}=$ Empathy_Scale/bmatrix $=1,1,1,1,1,1,1,1,1,1 /$ wmatrix $=1,0,0,0,0,0$, $0,0,0,0 / \mathrm{hc}=4 /$ center $=2 /$ boot $=5000 .$.

As expected, there were significant indirect effects for Hypothesis 3 (post-hoc, part 1), such that the threat of environmental pollution increased self-reported liberalism, support for environmental regulation policies, and collective action intentions through more negative affect (moderated by empathy), more perceived injustice, and less system justification (see Figure 4). These findings provided some post-hoc support for Hypothesis 3, although the direct effects were still inconsistent with the indirect effects (i.e., negative or nonsignificant) (Figure 4). 
Figure 4. Regression Path Model Assessing Hypothesis 3 (Post-Hoc, Part 1)

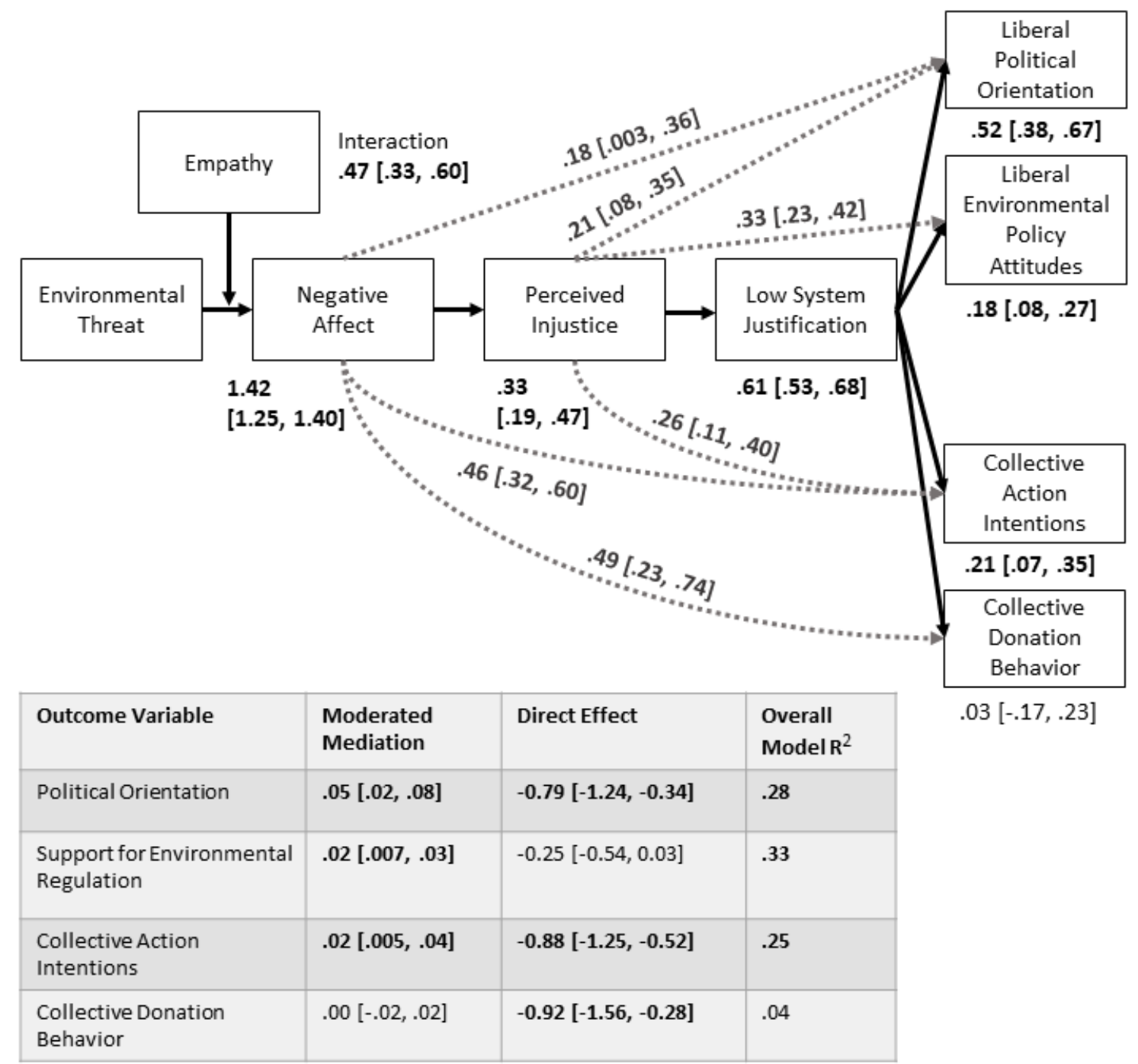

Note. Effect sizes appear as unstandardized regression coefficients. Empathy was mean centered. Values in square brackets indicate the $95 \%$ confidence interval (CI) for each effect. Dashed lines show all significant mediation effects in the model-nonsignificant effects were suppressed for graphical clarity. Significant effects appear in bold - effects were flagged as significant if they did not contain zero within a 95\% CI or if $p<.05$ (for the $f$-test for the model $\mathrm{R}^{2}$ ).

Because the direct effects for Hypothesis 3 (post-hoc, part 1) were inconsistent with the indirect effects, the second part of the post-hoc reformulation of Hypothesis 3 attempted to address these inconsistencies by adding political orientation as a predictor 
variable rather than as an outcome variable in the model. More precisely, the second part of the post-hoc reformulation of Hypothesis 3 suggested that the threat of environmental pollution would increase support for environmental regulation, collective action intentions, and collective donation behavior (mediated by more negative affect [moderated by empathy], more perceived injustice, less system justification, and more self-reported liberalism). Author-generated syntax for the PROCESS (Hayes, 2017) macro for SPSS was used to specify the mediators, moderators, and outcomes relevant to Hypothesis 3 (post-hoc, part 2), for example, “process y=EnvAtts/m = NegAffect_NF PInjust SysJust PO/ x=threat/ w=Empathy_Scale / bmatrix $=1,1,1,1,1,1,1,1,1,1,1$, $1,1,1,1 /$ wmatrix $=1,0,0,0,0,0,0,0,0,0,0,0,0,0,0 /$ hc $=4 /$ center $=2 /$ boot $=5000 . "$. As expected, the threat of environmental pollution increased support for environmental regulation and collective action intentions (mediated by more negative affect [moderated by empathy], more perceived injustice, less system justification, and more self-reported liberalism) (see Figure 5). Consistent with the previous results, the threat of environmental pollution did not increase collective donation behavior through these mediators; however, greater negative affect did mediate this relationship. In addition, the directs effects remained inconsistent with the indirect effects in this reformulated model (Figure 5). 
Figure 5. Regression Path Model Assessing Hypothesis 3 (Post-Hoc, Part 2)

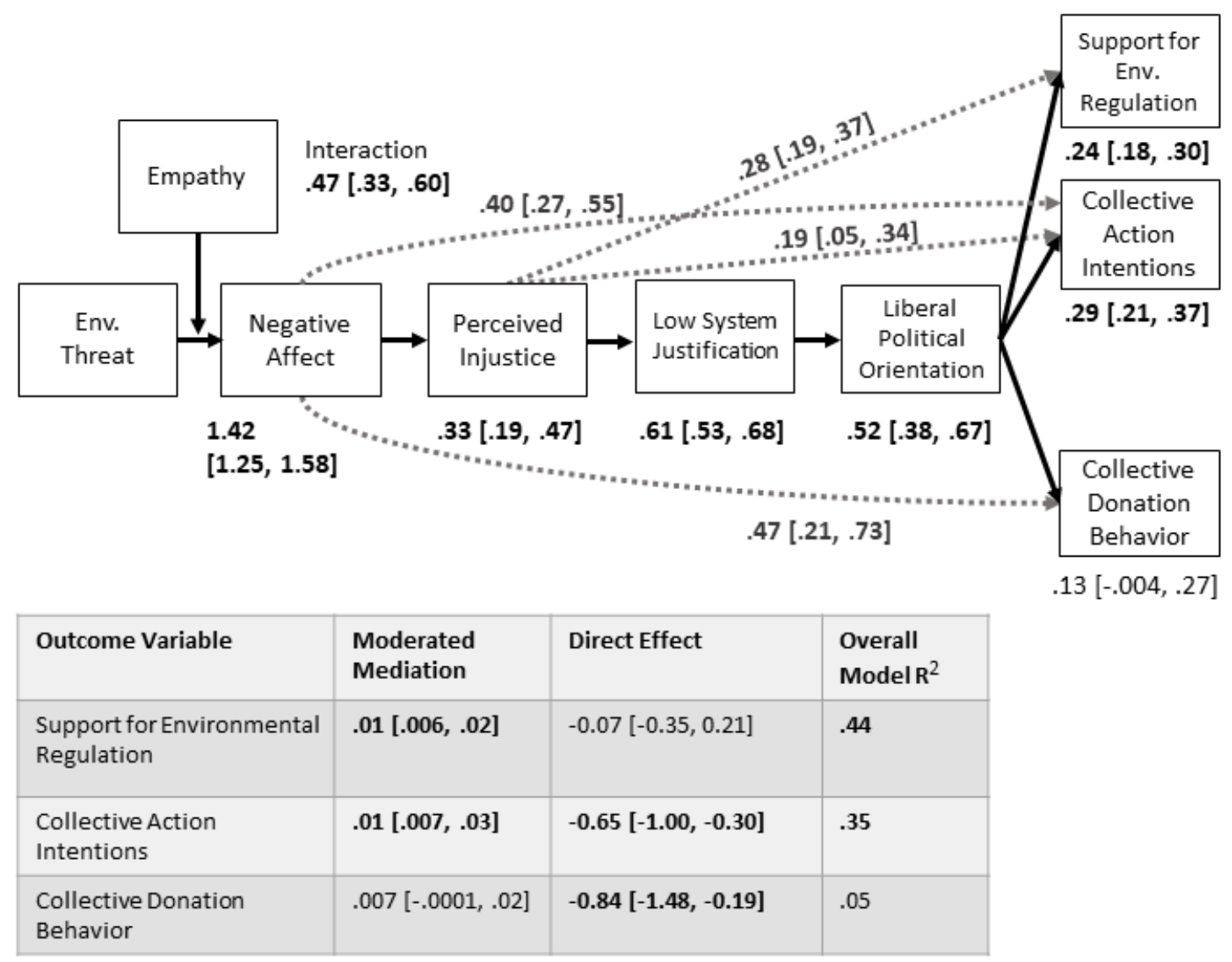

Note. Effect sizes appear as unstandardized regression coefficients. Empathy was mean centered. Values in square brackets indicate the $95 \%$ confidence interval (CI) for each effect. Dashed lines show all significant mediation effects in the model-nonsignificant effects were suppressed for graphical clarity. Significant effects appear in bold-effects were flagged as significant if they did not contain zero within a 95\% CI or if $p<.05$ (for the $f$-test for the model $\mathrm{R}^{2}$ ). Env. Threat = Environmental Threat. Support for Env. Regulation $=$ Support for Environmental Regulation.

Because the direct and indirect effects for Hypothesis 3 (post-hoc, part 2) remained inconsistent, political orientation was examined as a moderator of the direct effects of threat on political outcomes and the indirect mediation paths. 
Political orientation did not moderate the direct effect of perceived threat on policy preferences, although this effect trended toward less support for environmental regulation for conservatives. More precisely, the direct effect was not significant for participants who were more conservative $(b=-0.20,95 \%$ CI $[-0.70,0.30])$, more moderate $(b=-0.04,95 \%$ CI $[-0.36,0.28])$, and more liberal $(b=0.01,95 \%$ CI [-0.41, 0.44]). Political orientation only moderated the partial indirect effect of perceived threat on greater support for environmental regulation through negative affect and perceived injustice, such that the effect was only significant for participants who were more conservative $(b=0.15,95 \% \mathrm{CI}[0.05,0.27])$ and more moderate $(b=0.10,95 \% \mathrm{CI}$ $[0.02,0.19])$ compared to those who were more liberal $(b=0.04,95 \% \mathrm{CI}[-0.08,0.16])$.

Political orientation did not moderate the direct effect of perceived threat on collective action intentions, although this effect trended toward less intentions for conservatives. More precisely, this direct effect was negative and significant for participants who were more conservative $(b=-0.84,95 \%$ CI [-1.45, - 0.24$])$, more moderate $(b=-0.63,95 \%$ CI $[-0.95,-0.31])$, and more liberal $(b=-0.56,95 \%$ CI $[-0.92,-$ 0.19]). Political orientation only moderated the partial indirect effect of perceived threat on greater support for environmental regulation through negative affect and perceived injustice, such that the indirect effect was only significant for participants who were more moderate $(b=0.08,95 \% \mathrm{CI}[0.01,0.18])$ compared to those who were more liberal $(b=$ $0.04,95 \% \mathrm{CI}[-0.08,0.16])$ and more conservative $(b=0.02,95 \% \mathrm{CI}[-0.14,0.18])$.

Political orientation did moderate the direct effect of perceived threat on less collective donation behavior, and this effect resulted in no negative direct effect for 
liberals. More precisely, this direct effect was negative and significant for participants who were more conservative $(b=-1.23,95 \%$ CI $[-2.37,-0.09])$ and more moderate $(b=-$ $0.77,95 \% \mathrm{CI}[-1.44,-0.10])$ but not for those who were more liberal $(b=-0.62,95 \% \mathrm{CI}$ $[-1.43,0.20])$. Political orientation did not moderate the indirect effects of threat on collective donation behavior (i.e, all CIs included zero) beyond the finding that the indirect of threat on greater donation behavior (through negative affect) only held for individuals who were more conservative (see "Hypothesis 2" in this section). 


\section{CHAPTER FOUR:}

\section{DISCUSSION}

The primary purpose of the present study was to examine whether system-level appraisals would mediate a liberal-shift in response to environmental threat. First, the study aimed to replicate the threat-affordance model, which showed a liberal-shift in responses (i.e., self-reported liberalism; support for environmental regulation policies) to environmental threat through negative affect (Eadeh \& Chang, 2019, Study 2), and to extend this paradigm to include outcomes related to system-challenging collective action. More importantly, the goal was to integrate the threat-affordance model with system justification theory, such that a liberal-shift in responses would be mediated by less system justification (moderated by empathy), more perceived injustice, and more negative affect. This hypothesis suggests that certain threats do not necessarily predict increased system justification or conservatism, which runs counter to predictions made by system justification theory (see Jost, Stern et al., 2017).

The present study was partially successful at replicating Eadeh and Chang (2019, Study 2) and integrating the threat-affordance model with SJT. The threat of environmental pollution increased liberal responses and system change intentions through negative affect, and this effect was further explained by empathy (as a moderator of negative affect) and through system-level appraisals (i.e., more perceived injustice and less system justification; in order). However, the order of significant mediators described above was exploratory and not the order that was predicted. In addition, only negative affect mediated the effect of threat on increased donations. Therefore, I attempt to explain 
(a) why the hypothesized synthesis model did not fit the data and (b) why system-level appraisals did not predict collection donation behavior. Further, despite these significant indirect effects, there were no direct effects of perceived threat on increased liberalism, support for environmental regulation policies, system-challenging collective action intentions, or collective donation behavior. In fact, perceived threat increased selfreported conservatism as opposed to self-reported liberalism. Therefore, I offer several explanations to better understand these inconsistencies between the indirect and direct effects, specifically (a) inconsistent mediation due to opposing mediators, (b) moderation due to political orientation and empathy, and (c) limited statistical power to detect the effect of threat on political orientation. Last, I discuss the theoretical and practical implications of these findings.

\section{$\underline{\text { Model Fit }}$}

Hypothesis 3 suggested that the threat of pollution would increase liberal responses through lower system justification (moderated by empathy), greater perceived injustice, and greater negative affect. However, the current data did not fit the original formulation of Hypothesis 3 (Figure 3) and only when the variables were reordered (Figure 4 and 5) were three out of the four outcomes significant. Instead, there was evidence of affective versus cognitive primacy in response to the threat of environmental pollution. However, this primacy may simply be statistical artifact. In a cross-sectional design, such as in this study, these indirect effects are correlational and derive from a priori hypotheses about the direction of the relationships. 
The theory for the original formulation of Hypothesis 3 was derived from Osborne et al. (2019) who suggested that, under threat, system justification and perceived injustice proceed emotional responses and collective action tendencies. However, their validation of this model was entirely correlational model in the sense that there were no experimental conditions (only known-group comparisons). In the present research, there was an experimental stimulus (i.e., environmental threat). Eadeh and Chang (2019) found this experimental paradigm to impact current emotional states. In addition, emotion was measured before any of the cognitive attitude variables. Therefore, phenomenologically, these effects may be a function of the design or it may be that emotions are proximate and conceptually related to the threat prime, which may modulate more distal and abstract political constructs (e.g., political orientation). In addition, perceived injustice (e.g., how much corporate polluters and the government care about pollution harming people) may proceed system justification and political orientation because it is more conceptually related to the threat prime (i.e., is about pollution).

Given these considerations, it is not entirely surprising that the hypothesized model did not fit the data. The order of the variables should be interpreted with caution, as they represent correlations, and future research should validate them. Further research should also try to examine the phenomenological unfolding of these processes by examining the (a) fine-grained change in emotion and cognition in response to threat over time using methods such as beta-blockers, fMRI, or a talk-aloud protocol; and (b) coursegrained change of emotion and cognition in response to threat over time using a longitudinal design. For example, in one longitudinal study, natural disaster increased 
recalled threat intensity over time and hindered improvement of PTSD symptoms (Heir et al., 2009). In addition, during the 9/11 terrorist attacks, conservatives, but not liberals, who were closely affected by the attacks showed increased chronic health issues (Bonanno \& Jost, 2007).

\section{$\underline{\text { Belief-Behavior Gap }}$}

System justification failed to predict collective donation behavior. In other words, no matter how much participants began to challenge the system under threat, they did not significantly change the way they donated. Only through negative affect were the odds of donation greater in the threat (versus control) conditions. However, it was assumed that donating was symbolic of challenging the system and that not donating was symbolic of justifying the system. This assumption, however, did not hold up in the bivariate correlations (i.e., there was no correlation between system justification and donation behavior; Appendix J). One possible systems-level explanation for this lack of correlation is that participants may have not seen charitable organizations as mitigating the harm of corporate polluters or the government, because the charitable organization does not directly address the proximate cause of the threat. Future studies may find it useful to include measures that check researchers' assumptions about how participants view social systems, especially if they are ancillary to the primary systems of interest.

A more practical explanation for the lack of association between system justification and donation behavior is that MTurk workers were motivated to earn an extra 25 cents, and this motivation was stronger than their willingness to donate due to 
diminished system justification. In other words, participants' may have had personal or economic justifications that influenced their behavior more than their system needs.

Another possible reason why negative affect, but not system justification, was associated with greater donation behavior is that participants experienced self-other overlap, felt negative affect, and were motivated to reduce this negative affect by donating (Neuberg et al., 1997). In other words, participants may have donated in order to upregulate their emotions after perceiving threat, which led to feeling a "warm glow". If this assumption were true, negative affect should be reduced and positive affect should increase after donation task.

These latter two possibilities suggest that researchers should evaluate multiple motives in system justification models relevant to prosocial behavior (e.g., egotism, altruism, collectivism, and principalism; Batson et al., 2011).

\section{$\underline{\text { Inconsistencies in the Results }}$}

\section{$\underline{\text { Hidden Mediators }}$}

Following Eadeh and Chang (2019), I predicted that negative affect (mainly anger and disgust) would be mediate environmental threat and liberal responses. Eadeh and Chang did not find fear to mediate threat and political attitudes. In addition, although they measured positive emotions, they did not measure empathy. In the current study, both negative affect and empathy tended to mediate opposite responses to threat (increasing liberal responses) compared to fear (increasing conservative responses). Hence, these emotions were inconsistent mediators. Inconsistent mediation occurs when "at least one mediated effect has a different sign than other mediated or direct effects in a model" 
(MacKinnon et al., 2007, p. 8). But despite the inconsistent mediation, the overall indirect effects were positive (i.e., increasing liberalism), and overall, the direct effects were negative (i.e., increasing conservatism), suggesting that fear alone could not account for the inconsistencies between the indirect and direct effects.

Other unobserved variables may help account for these inconsistencies. Specifically, reactions such as feeling "skeptical”, "manipulated”, “tricked”, or "suckered" may help account for the conservative-shift. For example, one participant wrote, "It's sad when someone dies young, but you don't get assume that this appeal to emotion is actually true and then try to make policy based on that [sic]." This participant also indicated being "very conservative". This type of reaction may also be due to solution aversion among conservatives. For example, Campbell and Kay (2014) found that conservatives (versus liberals) tend to be solution averse, such that when presented with a government regulation solution (versus free market friendly solution) to climate change, they showed less agreement with climate change science. Similarly, conservatives in the current study may have been solution averse, as they read an article in favor of environmental regulation. Overall, this possibility implies that that the variability in response patterns and their additive effects may have contributed to the overall direct effect. Future studies may benefit from measuring more responses to threatening stimuli.

$\underline{\text { Moderation }}$

Hypothesis 1 and 2 predicted that environmental threat would increase liberal responses through negative affect. These effects may differ across participants' levels of 
political orientation or their feelings of empathy. In its most basic form, moderation occurs when the effect of $\mathrm{X}$ variable on $\mathrm{Y}$ variable (e.g., the effect of perceived threat on political attitudes) differs across the levels of $\mathrm{Z}$ variable (e.g., political orientation or empathy). However, moderation can also occur across indirect effect pathways, such as the effect of perceived threat on negative affect and the effect of negative affect on political attitudes. Both types of moderation were examined in the current study.

The supplemental moderation analyses for Hypothesis 1 and 2 revealed patterns about the data suggesting that liberals, moderates, and conservatives experienced different emotional reactions to the perceived threat, which, in turn, led them to orient toward liberal responses or orient toward conservative responses. Under threat, conservatives tended to experience a liberal shift through negative affect (except for showing less collective action intentions), whereas liberals tended to experience a liberal shift through feelings of empathy. In contrast, liberals and moderates tended to experience conservative shifts through feelings of fear. As for political orientation moderating the direct effects of threat on attitudes, conservatives donated less bonus money, but the remaining direct effects were unaffected by political orientation.

The supplemental moderation analyses for Hypothesis 1 and 2 also revealed patterns about the data suggesting that people who were less empathetic, moderately empathetic, or more empathetic experienced different emotional reactions to the perceived threat, which, in turn, led them to orient toward liberal responses or orient toward conservative responses. Except for policy preferences, empathy moderated the effects of threat on political orientation, collective action intentions, and donation 
behavior through negative affect and fear. More precisely, people who experienced moderate to high levels of empathy were more likely to report liberal responses through negative affect and to report more conservative responses through fear.

These moderation results suggest that both conservatives and liberals experienced a liberal shift through negative affect and empathy, respectively. However, there was limited moderation of a conservative-shift across political ideologies, both indirectly and directly. The results accounted for a conservative shift among liberals through fear (similar to Nail et al., 2009), and only conservatives became more conservative in the donation behavior task. Therefore, it remains an empirical possibility that conservatives became more conservative through a hidden mediator as discussed in the previous section (e.g., through disbelief, skepticism, or feelings of being manipulated). If evidence for this possibility is found, the indirect effects may result in a smaller conservative-shift or a zero-sum direct effect of threat on political attitudes.

\section{Limited Statistical Power}

Eadeh and Chang (2019) measured multiple outcomes of threat, including increased support for support for environmental regulation, increase support for other liberal policies, increased support for broader political attitudes, and increased liberal ideological endorsement. This current study was powered to detect the focal outcome: the direct effect of environmental threat on support for environmental regulation policies with an effect size of $r=.24$ (from Eadeh \& Chang, 2019, Study 2; see Appendix D). However, Lakens (2017) argues that researchers should power for the smallest effect of interest. The present study failed to achieve power for the smallest effect of threat: the 
effect of environmental threat on liberal political orientation $(r=-.12$, the present study; $r$ $=.20$, Eadeh \& Chang, 2019, Study 2).

For a two-tailed $t$-test with $95 \%$ power and an effect size of $r=-.12$, the chance of detecting this effect in the data is about $39 \%$. For a two-tailed $t$-test with $95 \%$ power and a mean effect size of $r=.16([.12 \times .20] / 2)$, the chance of detecting this effect in the data is about $9 \%$. These power analyses suggest that the effect of threat on political orientation in the current study, as well as the study by Eadeh and Chang (2019, Study 2) who had fewer participants, may have been a result of a Type I error, and future replications would require a larger sample size to detect such an effect. For a two-tailed $t$-test with $95 \%$ power and an alpha equal to .05 , a sample almost twice the size of the current sample ( $n=$ 892) would be necessary to detect an effect size of $r=-.12$.

\section{Theoretical Implications}

This article advanced a replication of Eadeh and Chang (2019, Study 2) and a synthesis of the threat-affordance model with SJT. However, given the inconsistencies in the results, the model misspecification, and a belief-behavior gap, it is reasonable to question whether these efforts were successful. To conduct a fair analysis of this question, I first discuss the empirical findings that were theoretically strong in the current study. Second, I discuss the findings that were limiting or theoretically inconsistent. Last, I compare the strong and weak elements of this study and their implications for the goal of theoretical synthesis.

Hypothesis 1 and 2 suggested that environmental threat would increase liberal responses through negative affect. The strongest finding that best aligned with 
Hypothesis 1 and 2 was that the threat of environmental pollution resulted in a robust increase in negative affect $(r=.86)$, and, in turn, negative affect led to increases in selfreported liberalism, support for environmental regulation policies, system-challenging collective action intentions, and donation behavior. This was a successful replication of Eadeh \& Chang (2019, Study 2) and extension to include a wider variety of outcomes beyond policy preferences. Hypothesis 3 suggested that, in addition to negative affect, system-level appraisals would mediate the effect of threat on liberal responses. Indeed, in addition to negative affect (moderated by empathy), perceived injustice and system justification mediated the effects of threat on the outcome variables except for donation behavior (see Figure 4). Moreover, in addition to the aforementioned mediators, selfreported liberalism mediated the effect of threat on support for environmental regulation policies and collective action intentions (see Figure 5). Although these models were specified post-hoc, and additional analyses tend to inflate the Type 1 error rate, these results demonstrate that system-level processes, including lower system justification, may have mediated the threat of environmental pollution on political attitudes.

In Hypothesis 1, I predicted that environmental threat would increase liberal ideological endorsement and support for environmental regulation policies (following Eadeh \& Chang, 2019, Study 2). Therefore, the most theoretically inconsistent aspect of my data was that environmental threat increased self-reported conservatism $(r=-.12)$ and showed no effect on support for environmental regulation policies $(r=-.05)$. In addition, when negative affect mediated the effect of threat on the outcome variables, all of the direct effects were inconsistent (i.e., indicating greater conservatism). In the models with 
system-level variables, this inconsistent direct effect disappeared for support of environmental regulation policies; however, the effect remained near-zero, rather than resulting in greater policy support (as found by Eadeh \& Chang, 2019, Study 2). Furthermore, as discussed previously, the original hypothesized model did not fit the data, and perceived threat only increased donation behavior through negative affect. These results suggest that there may have been inconsistent mediation, hidden moderators, or limited statistical power to detect some of the direct effects. System justification may also be correct in claiming that perceived threat favors increased political conservatism (Jost, Stern et al., 2017). However, perceived threat did not directly affect system justification as predicted by Osborne et al. (2019), which suggests that threat may not directly change levels of system justification as SJT suggests.

With these strengths and limitations taken together, I offer two possible implications of these findings for theory.

First, the hypothesized theoretical synthesis between the threat-affordance model and system justification theory may hold true with a larger sample size and a confirmatory analysis of the post-hoc models. Given the robustness of the effect size of perceived threat on negative affect compared to political orientation, it may be possible that the that inconsistent effects were due to concluding there was an effect in the data when there was no effect in the population. If this explanation is true, then a replication of this study with a larger sample size $(n>890)$ should not find effects with inconsistent directions; in other words, the threat of environmental pollution would increase selfreported liberalism, support for environmental regulation policies, and system- 
challenging collective action. In addition, I would expect that system-level processes, specifically greater perceived injustice and lower system justification, would mediate these effects following negative effect. However, this possibility is worth criticizing given that the study was powered to detect the effect of threat on policy preferences but failed to find this effect.

Second, it may be possible that neither the threat-affordance model nor SJT can account for variation in response patterns. This possibility suggests that these theories should be modified such that they allow for ambiguity and inconsistency between the direct and indirect effects. In other words, not only will the type of threat increase liberalism or increases conservativism, but the distribution of observed and unobserved response patterns in the sample will influence the direction of a political shifts. For instance, in the current study, negative affect and empathy increased levels of selfreported liberalism, whereas fear increased levels of self-reported conservatism across the threat conditions. However, there may have been hidden mediators, such as levels of demoralization, feelings of being manipulated, or motivated disbelief (e.g., Campbell \& Kay, 2014). These hidden mediators may help account for an increased probability of a conservative shift when people perceive a particular threat.

\section{$\underline{\text { Limitations and Future Directions }}$}

Some limitations have already been discussed, specifically (a) the lack of a casual design to test the model specification (see "Model Fit"), (b) equating donations to environmental conservation with system-challenging collective action (see "BeliefBehavior Gap"), (c) the lack of measurement of other potential mediators (e.g., motivated 
disbelief; skepticism; see "Hidden Mediators" in "Inconsistencies in the Results"), and (d) the limited statistical power to detect an effect of threat on political orientation (see "Limited Statistical Power" in "Inconsistencies in the Results"). However, there were several additional limitations in this study that bear on the interpretability of the findings and conclusions. First, I discuss the limited measurement of (a) positive current emotional state items, (b) comparative threats, and (c) possible outcomes of interest that are most sensitive to perceived environmental threat. Then, I discuss the non-random order in which the affective versus cognitive measures were presented. Last, I discuss how to improve the methodology of this research paradigm and what novel hypotheses can be drawn from this research and tested in future studies.

The measurement of negative affect and empathy was necessary, because they were included in the hypotheses, and they closely replicate the emotion adjectives used by Eadeh and Chang (2019). However, the measures of emotion in the current study had fewer items (i.e., adjectives such as fear and anxiety) per emotion (2 vs. 6) and more negative items than positive items compared to Eadeh and Chang (2019). This decision was made for the sake of brevity and lessening participant demand, but it also risks potential demand characteristics for participants to display negative affect and empathy rather than other positive emotion items (e.g., "happy"). The lack of positive items may have also clued participants into what emotions the researcher was trying to evoke, potentially leading those who were more skeptical and conservative to reject the experimental manipulation. That said, the reliability was quite high for the two item scales for each emotion, suggesting that that number of items was not a huge issue. 
Eadeh and Chang (2019) originally examined three different types of threats that increased liberal policy attitudes, and Eadeh (2017) also examined the threat of terrorism, which increased conservative policy attitudes. In the current study, only one type of threat was examined: the threat on environmental pollution. However, without examining different types of the threat that increase both liberal responses and conservative responses, it is not possible to test the hypothesis that some threats (e.g., corporate greed) lead to decreased system justification whereas other threats (e.g., terrorism) lead to increased system justification, especially in a comparable design. Hence, there is limited ability to draw conclusions from the current study about how system justification is affected across different types of threats.

Eadeh and Chang (2019) originally examined many different outcomes related to threat, including support for environmental regulation policies, support for healthcare regulation policies, support for hawkish military policies, social conservatism, social liberalism, and ideological self-placement (from liberal to conservative). The current study only examined two significant outcomes from Eadeh and Chang (2019): support for environmental regulation and ideological self-placement. However, changing one's ideology may represent more stable attitudes that are difficult to change compared to briefly shifting policy preferences — or motivation to protest or donate - in response to a perceived threat. In support of this hypothesis, Eadeh and Chang (2019) found that certain perceived threats reliably increased liberal policy shifts rather than ideological endorsement (Eadeh \& Chang, 2019). Only one of the three types of threats Eadeh and Chang measured (i.e., environmental pollution) led to an increase in liberal political 
orientation, a result that was found in an exploratory analysis. Other researchers have also focused on shifts in attitudes toward policy and voting preferences across political ideologies, such as in the case of the conservative policy shift after the $9 / 11$ terrorist attacks (e.g., Nail \& McGregor, 2009). However, I took the approach of conceptualizing policy shifts and ideological endorsement as a set of liberal responses rather than more or less stable attitudes. This approach is not uncommon. For example, Jost, Stern, and colleagues (2017) include both ideological and policy-based responses in their metaanalysis of threat on political asymmetries. The current findings showed a main effect of threat on political ideology rather than policy_or rather, environmental threat led to greater conservatism and had no direct effect of threat on policy attitudes across political ideologies. However, given the lack of power to detect the effect of threat on political orientation, it would be premature to make conclusions about how environmental threat affects ideological endorsement. Therefore, it remains uncertain the degree to which perceived threat affects political orientation and whether perceived threat better predicts policy shift and under what circumstances.

The order in which the measures were completed could have affected participants' responses and the order of significant variables in the model. As discussed previously in the section on model (mis)fit, after the threat-priming article was presented to the participants, they completed measures of their current emotional state, then measures of political attitudes. This order was originally used by Eadeh and Chang (2019) and was also used in the current study. However, it is possible that the experimental manipulation had the greatest effect on the variables measured closest to the 
manipulation, and that the effect weakened or decayed as the study progressed.

Therefore, one possible reason that the threat-prime had the largest effect on participants' current emotional state (versus political attitudes) could be due to its primacy to the threat-prime. This primacy may also weaken the effect of the threat prime on the political attitude variables. Hence, the order of response measures and potential decay effects may have influenced which outcomes were most affected by perceived threat.

As discussed in previous sections, future research may benefit from (a) using methods that can elucidate causality, (b) testing assumptions about the donation paradigm reflecting collective action motives, (c) measuring possible hidden mediators (e.g., solution aversion), and (d) increasing statistical power to detect the small effect of interest (in this case, perceived threat on political orientation). Based on the additional limitations discussed in this section, future research may also benefit from (a) balancing negative emotion items with an equal amount of positive emotion items, (b) adding more comparative threat conditions, and (c) considering the conditions that lead to ideological shifts versus policy-oriented shifts to perceived threat. In addition, given that political orientation can be both modeled as a predictor (moderator or mediator) and outcome it should be treat as both; however, the effect of perceived threat might be weak and mostly stable, which means that shifts may only be detected with large sample sizes. In addition, it may prove to be beneficial to counterbalance the affective and cognitive responses to reduce order effects, or, in other words, to reduce the chance that the effects are dependent on the order that the measures were presented in the survey design. 
Given the current findings and limitations, there are several novel hypotheses researchers could test in future studies. The first hypothesis is based on the exploratory finding that current emotional state proceeded perceived injustice and system justification in mediating the effects of perceived threat: Under perceived threat, changes in emotion statistically (or phenomenologically) may proceed changes in cognition (e.g., perceived injustice and system justification), and those changes predict political attitudes. The second hypothesis is based on the inconsistencies between the direct versus indirect effects of threat on greater conservatism versus greater liberalism, which could include comparing a couple different possibilities: (1) The threat of pollution indirectly leads to more liberal responses through emotion (i.e., negative affect and empathy) but directly leads to more conservative ideological endorsement, or (2) These inconsistencies were due to (a) insufficient statistical power, (b) hidden moderators (e.g., motivated disbelief or solution aversion), or (c) moderation of hidden moderators (mainly political orientation). Future research should also consider how their hypotheses for the political consequences of perceived threat might differ from hypotheses about the political consequences of real threats. For example, in one paper, with almost four million participants, real-life ecological threats (e.g., natural disaster, resource scarcity, pathogens, warfare, and conflict) predicted increases in cultural tightness, prejudice, and nationalism (Jackson et al., 2019). This study raises questions as to whether divergent effects of perceived threat on increased liberal or conservative responses have any meaningful effect in a world composed of many different threats. 


\section{CHAPTER FIVE:}

\section{CONCLUSION}

Whether or not people challenge the government or other social-political institutions may have consequential effects on their health and future. For example, the coronavirus (COVID-19) global viral pandemic was, and as of writing this article, still remains, a real threat. A lack of concern about the virus could, for example, lead people to dismiss social distancing policies and further spread the virus. In the United States, after the stock market crash and a national emergency was declared, concern about coronavirus has risen to extreme and moderate levels (Civiqs, 2020). However, data also shows that liberals are far more concerned about the coronavirus than are conservatives (Civiqs, 2020; Cova \& Díaz, 2020). In addition, United States is still lagging behind countries such as South Korea in "flattening the curve" of confirmed cases and deaths (Roser et al., 2020). Considering the results of the present study, one path to increase people's concern about the virus and bolster prevention measures may occur through increasing negative affect among conservatives (e.g., anger and disgust about people contracting the virus and dying unfairly due to incompetent systems and policies), increasing empathy among liberals, and decreasing fear among liberals and moderates.

This article began with the story about the death of Ella Kissi-Debrah and the role air pollution played in the decline of her health. Ella's mother insisted that Britain's High Court take action against the pollution and that people feel angry. These types of feelings and action may in fact spur action toward system-level changes, because people can and do leverage political institutions for purposes of threat-mitigation. The participants in the 
present study also felt negative affect—including anger-when they read stories similar to the story about Ella Kissi-Debrah's death. When participants felt upset or empathetic about air or water pollution harming a child, they reported more liberalism and were more likely to challenge sociopolitical systems and donate more cash to environmental conservation. In addition to the activation of these moral emotions, a heightened perception of injustice and a reduction in system justification predicted more liberal, system-challenging responses to the threat of environmental pollution. However, due to inconsistencies between the direct and indirect effects, it is not clear whether the threat of pollution favors increased liberalism or conservatism. Future research on people's political responses to threat may benefit by not only paying attention to the type of threat but by paying attention to people's diverging emotional and cognitive responses to threat. 


\section{REFERENCES}

Aarts, A. A., \& Lin, S. C. (2015). Estimating the reproducibility of psychological science. Science, 349(6251), 943-950. https://ink.library.smu.edu.sg/lkcsb_research/5257

Adler, N. E., Epel, E. S., Castellazzo, G., \& Ickovics, J. R. (2000). Relationship of subjective and objective social status with psychological and physiological functioning: Preliminary data in healthy, white women. Health Psychology, 19(6), 586-592. https://doi.org/10.1037//0278-6133.19.6.586

Batson, C. D., Ahmad, N., \& Stocks, E. L. (2011). Four forms of prosocial motivation: Egoism, altruism, collectivism, and principlism. In D. Dunning (Ed.), Frontiers of social psychology. Social motivation (p. 103-126). Psychology Press.

Batson, C. D., Kennedy, C. L., Nord, L. A., Stocks, E. L., Fleming, D. Y. A., Marzette, C. M., Lishner, D. A., Hayes, R. E., Kolchinsky, L. M., \& Zerger, T. (2007). Anger at unfairness: Is it moral outrage? European Journal of Social Psychology, 37(6), 1272-1285. https://doi.org/10.1002/ejsp.434

Becker, J. C., Tausch, N., \& Wagner, U. (2011). Emotional consequences of collective action participation: Differentiating self-directed and outgroup-directed emotions. Personality and Social Psychology Bulletin, 37(12), 1587-1598. https://doi.org/10.1177/0146167211414145

Becker, J. C., \& Wright, S. C. (2011). Yet another dark side of chivalry: Benevolent sexism undermines and hostile sexism motivates collective action for social change. Journal of Personality and Social Psychology, 101(1), 62-77. https://doi.org/10.1037/a0022615

Bonanno, G. A., \& Jost, J. T. (2007). Conservative shift among high-exposure survivors of the September 11th terrorist attacks. Basic and Applied Social Psychology, 28(4), 311-323. https://doi.org/10.1207/s15324834basp2804_4

Brandt, M. J., Turner-Zwinkels, F. M., Karapirinler, B., van Leeuwen, F., Bender, M., van Osch, Y., \& Adams, B. G. (2019). Threat and politics across countries. PsyArXiv. https://doi.org/10.31234/osf.io/e9uk7

Buchanan, E. M., \& Scofield, J. E. (2018). Methods to detect low quality data and its implication for psychological research. Behavior Research Methods, 50(6), 25862596. https://doi.org/10.3758/s13428-018-1035-6

Buhrmester, M., Kwang, T., \& Gosling, S. D. (2011). Amazon's Mechanical Turk: A new source of inexpensive, yet high-quality, data? Perspectives on Psychological Science, 6(1), 3-5. https://doi.org/10.1177/1745691610393980 
Cacioppo, J. T., Petty, R. E., \& Feng Kao, C. F. (1984). The efficient assessment of need for cognition. Journal of Personality Assessment, 48(3), 306-307.

https://doi.org/10.1207/s15327752jpa4803_13

Campbell, T. H., \& Kay, A. C. (2014). Solution aversion: On the relation between ideology and motivated disbelief. Journal of Personality and Social Psychology, 107(5), 809-824. https://doi.org/10.1037/a0037963

Choma, B. L., Hafer, C. L., Dywan, J., Segalowitz, S. J., \& Busseri, M. A. (2012). Political liberalism and political conservatism: Functionally independent?

Personality and Individual Differences, 53(4), 431-436. https://doi.org/10.1016/j.paid.2012.04.012

Christian, B. (2019). Mothers Rise Up march: Rosamund Kissi-Debrah whose daughter died of asthma attack linked to air pollution joins hundreds at London climate rally. Evening Standard. https://www.standard.co.uk/news/london/hundredsmarch-in-central-london-to-demand-action-on-climate-change-a4140316.html

Civiqs. (2020). Coronavirus: Outbreak concern.

https://civiqs.com/results/coronavirus_concern

Cova, F., \& Díaz, R. (2020). Individual differences and reactions to the coronavirus outbreak. Open Science Framework. https://osf.io/497s2/

Crowson, M. H., Debacker, T. K., \& Thoma, S. J. (2006). The role of authoritarianism, perceived threat, and need for closure or structure in predicting post-9/11 attitudes and beliefs. The Journal of Social Psychology, 146(6), 733-750. https://doi.org/10.3200/SOCP.146.6.733-750

Day, M. V., \& Fiske, S. T. (2017). Movin' on up? How perceptions of social mobility affect our willingness to defend the system. Social Psychological and Personality Science, 8(3), 267-274. https://doi.org/10.1177/1948550616678454

Eadeh, F. R. (2017). Healthcare vs. hawkishness: The divergent effects of affect on context-driven shifts in attitudes. Arts \& Sciences Electronic Theses and Dissertations. https://openscholarship.wustl.edu/art_sci_etds/1098

Eadeh, F. R., \& Chang, K. K. (2019). Can threat increase support for liberalism? New insights into the relationship between threat and political preferences. Social Psychological and Personality Science, OnlineFirst. https://doi.org/10.1177/1948550618815919 
Eidelman, S., \& Crandall, C. S. (2009). A psychological advantage for the status quo. In J. T. Jost, A. C. Kay, \& H. Thorisdottir (Ed.), Social and Psychological Bases of Ideology and System Justification (pp. 85-106). Oxford. http://doi.org/10.1093/acprof:oso/9780195320916.003.004

Friesen, J. P., Laurin, K., Shepherd, S., Gaucher, D., \& Kay, A. C. (2019). System justification: Experimental evidence, its contextual nature, and implications for social change. British Journal of Social Psychology, 58(2), 315-339. https://doi.org/10.1111/bjso.12278

Frijda, N. H., \& Mesquita, B. (1998). The analysis of emotions. In M. E. Mascolo \& S. Griffin (Eds.), What Develops in Emotional Development? (pp. 237-295). Plenum Press. https://doi.org/10.1007/978-1-4899-1939-7_11

Gibson, J. J. (1979). The theory of affordances. In The Ecological Approach to Visual Perception (pp. 127-137). Boston, MA: Houghton Mifflin. https://amzn.com/1848725787

Graham, J. (2009). Missing data analysis: Making it work in the real world. Annual Review of Psychology, 60(1), 549-576. https://doi.org/10.1146/annurev.psych.58.110405.085530

Graham, J., Nosek, B. A., Haidt, J., Iyer, R., Koleva, S., \& Ditto, P. H. (2011). Mapping the moral domain. Journal of Personality and Social Psychology, 101(2), 366385. https://doi.org/10.1037/a0021847

Gray, K., \& Wegner, D. M. (2011). Dimensions of moral emotions. Emotion Review, 3(3), 258-260. https://doi.org/10.1177/1754073911402388

Hardin, C. D., \& Higgins, E. T. (1996). Shared reality: How social verification makes the subjective objective. In R. M. Sorrentino \& E. T. Higgins (Eds.), Handbook of motivation and cognition (pp. 28-84). Guilford Press. https://psycnet.apa.org/record/1996-98385-002

Hasson, Y., Tamir, M., Brahms, K. S., Cohrs, J. C., \& Halperin, E. (2018). Are liberals and conservatives equally motivated to feel empathy toward others? Personality and Social Psychology Bulletin, 44(10), 1449-1459. https://doi.org/10.1177/0146167218769867

Hayes, A. F. (2017). Introduction to Mediation, Moderation, and Conditional Process Analysis (2 $2^{\text {nd }}$ ed.). Guildford Press. https://amzn.com/1609182308 
Hayes, A. F., \& Cai, L. (2007). Using heteroskedasticity-consistent standard error estimators in OLS regression: An introduction and software implementation. Behavior Research Methods, 39(4), 709-722. https://doi.org/10.3758/BF03192961

Heir, T., Piatigorsky, A., \& Weisæth, L. (2009). Longitudinal changes in recalled perceived life threat after a natural disaster. British Journal of Psychiatry, 194(6), 510-514. doi:10.1192/bjp.bp.108.056580

Hennes, E. P., Nam, H. H., Stern, C., \& Jost, J. T. (2012). Not all ideologies are created equal: Epistemic, existential, and relational needs predict system-justifying attitudes. Social Cognition, 30(6), 669-688.

https://doi.org/10.1521/soco.2012.30.6.669

Hirsh, J. B., DeYoung, C. G., Xu, X., \& Peterson, J. B. (2010). Compassionate liberals and polite conservatives: Associations of agreeableness with political ideology and moral values. Personality and Social Psychology Bulletin, 36(5), 655664. https://doi.org/10.1177/0146167210366854

Hutcherson, C. A., \& Gross, J. J. (2011). The moral emotions: A social-functionalist account of anger, disgust, and contempt. Journal of Personality and Social Psychology, 100(4), 719-437. http://doi.org/10.1037/a0022408

Iyer, A., \& Leach, C. W. (2009). Helping disadvantaged out-groups challenge unjust inequality. In S. Stürmer \& M. Snyder, The psychology of prosocial behavior: Group processes, intergroup relations, and helping (1 ${ }^{\text {st }}$ ed., pp. 337-353). WileyBlackwell. https://amzn.com/1405178809

Iyer, A., \& Ryan, M. K. (2009). Challenging gender inequality in the workplace: Men's and women's pathways to collective action. Journal of Social Issues, 65, 291 314. https://doi.org/10.1111/j.1540-4560.2009.01625.x

Jackson, J. C., von Egmond, M., Choi, V., Ember, C., Halberstadt., Balanovic, J., . . . Gelfand, M. (2019). Ecological and cultural factors underlying the global distribution of prejudice. PLOS ONE, 14(9), Article e0221953. https://doi.org/10.1371/journal.pone.0221953

JASP Team. (2019). JASP [Computer software]. https://jasp-stats.org/

Johnson, I. R., \& Fujita, K. (2012). Change we can believe in: Using perceptions of changeability to promote system-change motives over system-justification motives in information search. Psychological Science, 23(2), 133140. https://doi.org/10.1177/0956797611423670 
Jost, J. (2015). Resistance to change: A social psychological perspective. Social Research, 82(3), 607-636. https://muse.jhu.edu/article/603152

Jost, J. T. (2017). Ideological asymmetries and the essence of political psychology. Political Psychology, 38(2), 167-208. https://doi.org/10.1111/pops.12407

Jost, J. T. (2019). A quarter century of system justification theory: Questions, answers, criticisms, and societal applications. British Journal of Social Psychology, 58(2), 263-314. https://doi.org/10.1111/bjso.12297

Jost, J. T., \& Banaji, M. R. (1994). The role of stereotyping in system-justification and the production of false consciousness. British Journal of Social Psychology, 33(1), 1-27. https://doi.org/10.1111/j.2044-8309.1994.tb01008.x

Jost, J. T., Becker, J., Osborne, D., \& Badaan, V. (2017). Missing in (collective) action: Ideology, system justification, and the motivational antecedents of two types of protest behavior. Current Directions in Psychological Science, 26(2), 99-108. https://doi.org/10.1177/0963721417690633

Jost, J. T., Chaikalis-Petritsis, V., Abrams, D., Sidanius, J., van der Toorn, J., \& Bratt, C. (2012). Why men (and women) do and don't rebel: Effects of system justification on willingness to protest. Personality and Social Psychology Bulletin, 38(2), 197208. https://doi.org/10.1177/0146167211422544

Jost, J. T., Federico, C. M., \& Napier, J. L. (2009). Political ideology: Its structure, functions, and elective affinities. Annual Review of Psychology, 60(1), 307-337. https://doi.org/10.1146/annurev.psych.60.110707.163600

Jost, J. T., Gaucher, D., \& Stern, C. (2015). "The world isn't fair": A system justification perspective on social stratification and inequality. In M. Mikulincer, P. R. Shaver, J. F. Dovidio, \& J. A. Simpson (Eds.), APA handbooks in psychology. APA handbook of personality and social psychology, Vol. 2. Group processes (p. 317340). American Psychological Association. https://doi.org/10.1037/14342-012

Jost, J. T., Glaser, J., Kruglanski, A. W., \& Sulloway, F. J. (2003). Political conservatism as motivated social cognition. Psychological Bulletin, 129(3), 339-375. https://doi.org/10.1037/0033-2909.129.3.339

Jost, J. T., \& Hunyady, O. (2003). The psychology of system justification and the palliative function of ideology. European Review of Social Psychology, 13(1), 111-153. https://doi.org/10.1080/10463280240000046 
Jost, J. T., \& Hunyady, O. (2005). Antecedents and consequences of system-justifying ideologies. Current Directions in Psychological Science, 14(5), 260-265. https://doi.org/10.1111/j.0963-7214.2005.00377.x

Jost, J. T., Ledgerwood, A., \& Hardin, C. D. (2008). Shared reality, system justification, and the relational basis of ideological beliefs. Social and Personality Psychology Compass, 2(1), 171-186. https://doi.org/10.1111/j.1751-9004.2007.00056.x

Jost, J. T., Stern, C., Rule, N. O., \& Sterling, J. (2017). The politics of fear: Is there an ideological asymmetry in existential motivation? Social Cognition, 35(4), 324353. https://doi.org/10.1521/soco.2017.35.4.324

Kahn, D., \& Björklund, F. (2020). The intent and extent of collective threats: A datadriven conceptualization of collective threats and their relation to political preferences. Unpublished manuscript.

Kay, A. C., \& Friesen, J. (2011). On social stability and social change: Understanding when system justification does and does not occur. Current Directions in Psychological Science, 20(6), 360-364. https://doi.org/10.1177/0963721411422059

Kay, A. C., Gaucher, D., Napier, J. L., Callan, M. J., \& Laurin, K. (2008). God and the government: Testing a compensatory control mechanism for the support of external systems. Journal of Personality and Social Psychology, 95(1), 18-35. https://doi.org/10.1037/0022-3514.95.1.18

Kay, A. C., Gaucher, D., Peach, J. M., \& Laurin, K. (2009). Inequality, discrimination, and the power of the status quo: Direct evidence for a motivation to see the way things are as the way they should be. Journal of Personality and Social Psychology, 97(3), 421-434. https://doi.org/10.1037/a0015997

Kay, A. C., \& Jost, J. T. (2003). Complementary justice: Effects of "poor but happy" and "poor but honest" stereotype exemplars on system justification and implicit activation of the justice motive. Journal of Personality and Social Psychology, 85(5), 823-837. https://doi.org/10.1037/0022-3514.85.5.823

Kay, A. C., Jost, J. T., \& Young, S. (2005). Victim derogation and victim enhancement as alternate routes to system justification. Psychological Science, 16(3), 240-246. https://doi.org/10.1111/j.0956-7976.2005.00810.x

Keltner, D., \& Robinson, R. J. (1997). Defending the status quo: Power and bias in social conflict. Personality and Social Psychology Bulletin, 23(10), 1066-1077. https://doi.org/10.1177/01461672972310007 
Kruglanski, A. W., Webster, D. M., \& Klem, A. (1993). Motivated resistance and openness to persuasion in the presence or absence of prior information. Journal of Personality and Social Psychology, 65(5), 861-876. https://doi.org/10.1037/00223514.65.5.861

Laham, S. M., \& Corless, C. (2016). Threat, morality and politics: A differentiated threat account of moral and political values. In J. P. Forgas, L. Jussim, \& P. A. M. van Lange (Eds.), The social psychology of morality (pp. 56-70). New York, NY: Routledge. http://amzn.com/B01BC2QPR6

Lakens, D. (2017). How a power analysis implicitly reveals the smallest effect size you care about. The 20\% Statistician. http://daniellakens.blogspot.com/2017/05/howpower-analysis-implicitly-reveals.html

Lambert, A. J., Eadeh, F. R., \& Hanson, E. J. (2019). Anger and its consequences for judgment and behavior: Recent developments in social and political psychology. Advances in Experimental Social Psychology, 59, 103-173. https://doi.org/10.1016/bs.aesp.2018.12.001

Lipkus, I. M. (1991). The construction and preliminary validation of a global belief in a just world scale and the exploratory analysis of the multidimensional belief in a just world scale. Personality and Individual Differences, 12(11), 1171-1178. https://doi.org/10.1016/0191-8869(91)90081-L

Litman, L., Robinson, J., \& Abberbock, T. (2017). TurkPrime.com: A versatile crowdsourcing data acquisition platform for the behavioral sciences. Behavior Research Methods, 49(2), 433-442. https://doi.org/10.3758/s13428-016-0727-z

MacKinnon, D. P., Fairchild, A.J., \& Fritz, M.S. (2007). Mediation analysis. Annual Review of Psychology, 58, 593-614.

Marshall, C. (2018). Illegal levels of air pollution linked to child's death. $B B C$. https://www.bbc.com/news/science-environment-44612642

Marshall, C. (2019). Ella Kissi-Debrah 'pollution' death: Backing for new inquest. $B B C$. https://www.bbc.com/news/health-46823309

Maxwell, S. E., Kelley, K., \& Rausch, J. R. (2008). Sample size planning for statistical power and accuracy in parameter estimation. Annual Review of Psychology, 59, 537-563. https://doi.org/10.1146/annurev.psych.59.103006.093735 
McCall, L., Burk, D., Laperriere, M., \& Richeson, J. A. (2017). Exposure to rising inequality shapes Americans' opportunity beliefs and policy support. Proceedings of the National Academy of Sciences, 11(36), 9593-9598.

https://doi.org/10.1073/pnas.1706253114

Mendez, M. F. (2017). A neurology of the conservative-liberal dimension of political ideology. The Journal of Neuropsychiatry and Clinical Neurosciences, 29(2), 8694. https://doi.org/10.1176/appi.neuropsych.16030051

Milfont, T. L., \& Duckitt, J. (2010). The environmental attitudes inventory: A valid and reliable measure to assess the structure of environmental attitudes. Journal of Environmental Psychology, 30(1), 80-94. https://doi.org/10.1016/j.jenvp.2009.09.001

Miller, D. A., Cronin, T., Garcia, A. L., \& Branscombe, N. R. (2009). The relative impact of anger and efficacy on collective action is affected by feelings of fear. Group Processes \& Intergroup Relations, 12(4), 445-462. https://doi.org/10.1177/1368430209105046

Motyl, M., Demos, A. P., Carsel, T. S., Hanson, B. E., Melton, Z. J., Mueller, A. B., Prims, J. P., Sun, J., Washburn, A. N., Wong, K. M., Yantis, C., \& Skitka, L. J. (2017). The state of social and personality science: Rotten to the core, not so bad, getting better, or getting worse? Journal of Personality and Social Psychology, 113(1), 34-58. https://doi.org/10.1037/pspa0000084

Nail, P. R., \& McGregor, I. (2009). Conservative shift among liberals and conservatives following 9/11/01. Social Justice Research, 22, 231-240. https://doi.org/10.1007/s11211-009-0098-z

Nail, P. R., McGregor, I., Drinkwater, A. E., Steele, G. M., \& Thompson, A. W. (2009). Threat causes liberals to think like conservatives. Journal of Experimental Social Psychology, 45(4), 901-907. http://dx.doi.org/10.1016/j.jesp.2009.04.013

Napier, J. L., \& Jost, J. T. (2008). Why are conservatives happier than liberals? Psychological Science, 19(6), 565-572. https://doi.org/10.1111/j.14679280.2008.02124.x

Neuberg, S. L., Cialdini, R. B., Brown, S. L., Luce, C., Sagarin, B. J., \& Lewis, B. P. (1997). Does empathy lead to anything more than superficial helping? Comment on Batson et al. (1997). Journal of Personality and Social Psychology, 73(3), 510-516. https://doi.org/10.1037/0022-3514.73.3.510 
Newport, F. (2014). Republicans expand edge as better party against terrorism. Gallup News. https://news.gallup.com/poll/175727/republicans-expand-edge-better-partyagainst-terrorism.aspx

Niezink, L. W., Siero, F. W., Dijkstra, P., Buunk, A. P., \& Barelds, D. P. H. (2012). Empathic concern: Distinguishing between tenderness and sympathy. Motivation and Emotion, 36(4), 544-549. https://doi.org/10.1007/s11031-011-9276-z

O'Grady, T., \& Vandegrift, D. (2019). Moral foundations and decisions to donate bonus to charity: Data from paid online participants in the United States. Data in Brief, 25, 104331. https://doi.org/10.1016/j.dib.2019.104331

Oppenheim, M. (2019). Ella Kissi-Debrah: Mother wins fight for new inquest into daughter's death which she blames on air pollution. The Independent. https://www.independent.co.uk/news/uk/home-news/ella-kissi-debrah-inquestdeath-air-pollution-high-court-rosamund-a8896116.html

Osborne, D., Jost, J. T., Becker, J. C., \& Badaan, V. (2019). Protesting to challenge or defend the system? A system justification perspective on collective action. European Journal of Social Psychology, 49(2), 244-269. https://doi.org/10.1002/ejsp.2522

Osborne, D., \& Sibley, C. G. (2013). Through rose-colored glasses: System-justifying beliefs dampen the effects of relative deprivation on well-being and political mobilization. Personality and Social Psychology Bulletin, 39(8), 991-1004. https://doi.org/10.1177/0146167213487997

Pena, E. A., \& Slate, E. H. (2019). Gvlma: Global validation of linear models assumptions [R package]. https://CRAN.R-project.org/package=gvlma

Petrocik, J. (1996). Issue ownership in presidential elections, with a 1980 case study. American Journal of Political Science, 40(3), 825-850. https://doi.org/10.2307/2111797

Pieper, D., Hirano, H., \& Harton, H. C. (2020). The effect of environmental threats and terrorism and violent-crime threats on political orientation and attitudes. Open Science Framework. https://osf.io/gubcj

Revelle, W. (2019). Psych: Procedures for psychological, psychometric, and personality research [R package]. Northwestern University, Evanston, Illinois. https://CRAN.R-project.org/package=psych. 
Robertson, R. E., Tran, F. W., Mejia, J., \& Mourani, C. (2016). IPtoCountry: Convert IP addresses to country names or full location with geoplotting [R package]. https://www.r-pkg.org/pkg/IPtoCountry

Roser, M., Ritchie, H., \& Ortiz-Ospina, E. (2020). Coronavirus disease (COVID-19) statistics and research. Our World in Data. https://ourworldindata.org/coronavirus

Runciman, W. G. (1966). Relative deprivation and social justice: A study of attitudes to social inequality in twentieth-century England. University of California Press. https://amzn.com/0710039239

Saad, L. (2007). Democratic party winning on issues. Gallup News. https://news.gallup.com/poll/103102/democratic-party-winning-issues.aspx

Schein, C., \& Gray, K. (2015). The unifying moral dyad: Liberals and conservatives share the same harm-based moral template. Personality and Social Psychology Bulletin, 41(8), 1147-1163. https://doi.org/10.1177/0146167215591501

Schimmack, U. (2020). A meta-psychological perspective on the decade of replication failures in social psychology. Replicability Index.

https://replicationindex.com/2020/01/05/the-decade-of-replication-failures-insocial-psychology/

Seeberg, H. B. (2017). How stable is political parties' issue ownership? A cross-time, cross-national analysis. Political Studies, 65(2), 475-492.

https://doi.org/10.1177/0032321716650224

Smith, H. J., Cronin, T., \& Kessler, T. (2008). Anger, fear, or sadness: Faculty members' emotional reactions to collective pay disadvantage. Political Psychology, 29(2), 221-246. https://doi.org/10.1111/j.1467-9221.2008.00624.x

Spanovic, M., Lickel, B., Denson, T. F., \& Petrovic, N. (2010). Fear and anger as predictors of motivation for intergroup aggression: Evidence from Serbia and Republika Srpska. Group Processes \& Intergroup Relations, 13(6), 725-739. https://doi.org/10.1177/1368430210374483

Storbeck, J., \& Clore, G. L. (2007). On the interdependence of cognition and emotion. Cognition \& Emotion, 21(6), 1212-1237. https://doi.org/10.1080/02699930701438020

Tausch, N., Becker, J. C., Spears, R., Christ, O., Saab, R., Singh, P., \& Siddiqui, R. N. (2011). Explaining radical group behavior: Developing emotion and efficacy routes to normative and nonnormative collective action. Journal of Personality and Social Psychology, 101(1), 129-148. https://doi.org/10.1037/a0022728 
Thórisdóttir, H., \& Jost, J. T. (2011). Motivated closed-mindedness mediates the effect of threat on political conservatism. Political Psychology, 32(5), 785-811.

https://doi.org/10.1111/j.1467-9221.2011.00840.x

Trochim, W. M. K. (2020a). Statistical power. Research Methods Knowledge Base. https://socialresearchmethods.net/kb/statistical-power/

Trochim, W. M. K. (2020b). What is probabilistic equivalence? Research Methods Knowledge Base. https://socialresearchmethods.net/kb/probabilistic-equivalence/

Tzuyin Lai, V., Peter, H., \& Casasanto, D. (2012). Affective primacy vs. cognitive primacy: Dissolving the debate. Frontiers in Psychology, 3, 243.

https://doi.org/10.3389/fpsyg.2012.00243

Vainio, A., Mäkiniemi, J.-P., \& Paloniemi, R. (2014). System justification and the perception of food risks. Group Processes \& Intergroup Relations, 17(4), 509523. https://doi.org/10.1177/1368430213503502

van Buuren, S., \& Groothuis-Oudshoorn, K. (2011). MICE: Multivariate imputation by chained equations in R [R package]. Journal of Statistical Software, 45(3), 1-67. https://www.jstatsoft.org/v45/i03/.

van der Toorn, J., Tyler, T. R., \& Jost, J. T. (2011). More than fair: Outcome dependence, system justification, and the perceived legitimacy of authority figures. Journal of Experimental Social Psychology, 47(1), 127-138.

https://doi.org/10.1016/j.jesp.2010.09.003

van Doorn, J., Zeelenberg, M., \& Breugelmans, S. M. (2014). Anger and prosocial behavior. Emotion Review, 6(3), 261- 268.

https://doi.org/10.1177/1754073914523794

van Zomeren, M., Postmes, T., \& Spears, R. (2008). Toward an integrative social identity model of collective action: A quantitative research synthesis of three sociopsychological perspectives. Psychological Bulletin, 134(4), 504-535. https://doi.org/10.1037/0033-2909.134.4.504

Vargas-Salfate, S., Paez, D., Khan, S. S., Liu, J. H., \& Gil de Zúñiga, H. (2018). System justification enhances well-being: A longitudinal analysis of the palliative function of system justification in 18 countries. British Journal of Social Psychology, 57(3), 567-590. https://doi.org/10.1111/bjso.12254 
Wakslak, C. J., Jost, J. T., Tyler, T. R., \& Chen, E. S. (2007). Moral outrage mediates the dampening effect of system justification on support for redistributive social policies. Psychological Science 18(3), 267-74. https://doi.org/10.1111/j.14679280.2007.01887.x

Waytz, A., Iyer, R., Young, L., \& Graham, J. (2016). Ideological differences in the expanse of empathy. In P. Valdesolo \& J. Graham (Eds.), Claremont symposium on applied social psychology series. Social psychology of political polarization (p. 61-77). Routledge/Taylor \& Francis Group. http://amzn.com/1138810649

Xie, C., Bagozzi, R. P., \& Grønhaug, K. (2015). The role of moral emotions and individual differences in consumer responses to corporate green and non-green actions. Journal of the Academy of Marketing Science, 43(3), 333-356. https://doi.org/10.1007/s11747-014-0394-5

Yentes, R. D., \& Wilhelm, F. (2018). Careless: Procedures for computing indices of careless responding [R package]. https://cran.rproject.org/web/packages/careless/index.html

Zabjek, A. (2019). Thunberg faces counter-rally by workers in Canada's oil heartland. Reuters. https://www.reuters.com/article/climate-change-thunberg/correctedthunberg-faces-counter-rally-by-workers-in-canadas-oil-heartlandidUSL2N2730XF 


\section{APPENDIX A}

\section{INFORMED CONSENT}

\section{Informed Consent}

Invitation to Participate: You are invited to participate in a research project conducted through the University of Northern Iowa. The University requires that you give your agreement to participate in this project. The following information is provided to help you make an informed decision about whether to participate.

Nature and Purpose: The purpose of this study is to study people's attitudes on world events, natural systems, and society.

Explanation of Procedures: In this study, you will be asked to read a short one-page article, write about your reaction to the article, answer questions about your thoughts and feelings related to the article, answer question related to social attitudes, and answer questions about your background (age, gender, and ethnicity). This study is expected to last 15 minutes. You may discontinue involvement in the study at any time.

Discomfort and Risks: There is minimal anticipated risk involved with participating in this study. There is chance that the article may contain information some people find discomforting.

Benefits and Compensation: This study may help us understand how people feel about attitudes in certain situations, which could be responsible for changes in social processes. You will be compensated $\$ 1.00$ for participating for an approved HIT (Human Intelligence Task). You will receive a secret code at the end of the survey to submit for your payment.

Confidentiality: No guarantees can be made regarding the interception of data transmitted electronically; however extreme precaution will be taken to secure your data. Once the researcher verifies your residence in the United States, all identifying information (i.e., IP addresses, latitude, and longitude) will be deleted from the data. We will not report your individual sensitive information to any person or agency. We may post general location information such as the number of participants in each state of the country as well as demographic information (e.g., race and gender). The summarized findings with no identifying information will be published online and may be published in an academic journal or presented at a scholarly conference.

Right to Refuse or Withdraw: Your participation is voluntary. You are free to withdraw from participation at any time or to choose not to participate at all, and by doing so, you will not be penalized or lose benefits to which you are otherwise entitled. 
Questions: If you have questions about the study or desire information in the future regarding your participation or the study generally, you can contact Dylan Pieper at pieperd@uni.edu or the project investigator's faculty advisor Nicholas Schwab, Ph.D. at nicholas.schwab@uni.edu. You can also contact the office of the IRB Administrator, University of Northern Iowa, at anita.gordon@uni.edu or 319-273-6148, for answers to questions about the rights of research participants and the participant review process. 


\title{
APPENDIX B
}

\section{POLLUTION CONDITIONS}

\section{Two-year-old May Sustain Health Problems Due to Polluted Water Supply}

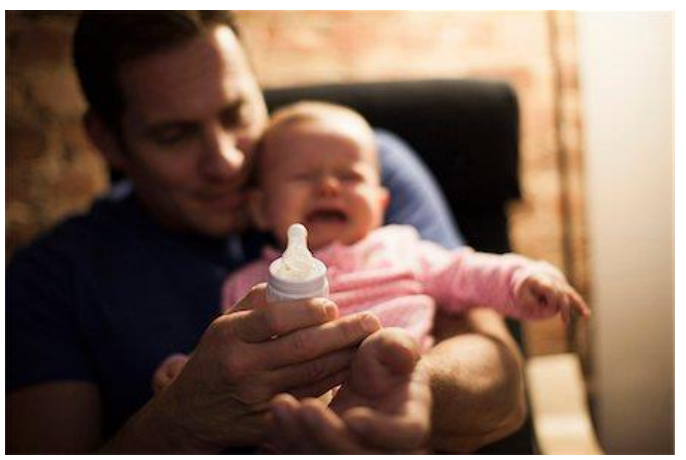

\author{
Springfield, Mississippi - Adam Reed knew \\ that something was wrong when his bubbly, \\ energetic 2-year-old daughter, Josephine, \\ suddenly became anxious and irritable all the \\ time. Reed eventually took his daughter to the \\ doctor for a blood test. His worries were soon \\ confirmed when her blood tests revealed that \\ she was suffering from severe heavy metal \\ poisoning caused by drinking polluted \\ Springfield water.
}

Springfield's water pollution has been a growing issue in the past decade and has resulted from toxic sewage spills and industrial waste into the town's nearby river. The regulation of toxic pollution has remained lax in the United States. In fact, according to the EPA, 41 states have reported higher than acceptable levels of lead in drinking water in the last three fiscal years. "We just don't know what's going to happen to her," Reed said in an interview while consoling Josephine. "My daughter's just a kid. She doesn't know what's going on, and we're all scared for what comes next."

Heavy metal poisoning has severe consequences for children younger than six, who can suffer from organ damage, slowed development, and behavioral problems later in life.

Despite these risks, the privatization of water systems are disserving local communities. Privatized systems are not only more expensive, but also cut corners, with these negligent practices resulting in the deterioration of existing infrastructures for the sake of shortterm profit.

Casey Dinges, the senior managing director of the American Society of Civil Engineers, has stated that the US needs to "seriously invest" in cleaner public water services. Those investments may include stringent regulations of water cleaning plants and additional grants to fund the EPA.

The long-term damage to children who are exposed to contaminated water is incredibly severe. Distraught with his daughter's condition and the lack of a serious resolution to Springfield's pollution problem, Reed has stated, "I want what's best for my daughter, but I don't think these private companies care

From Eadeh and Chang (2019, Study 2) 


\section{2-Year Old Dies of Asthma Attack Caused by Polluting in Evansville, Indiana}

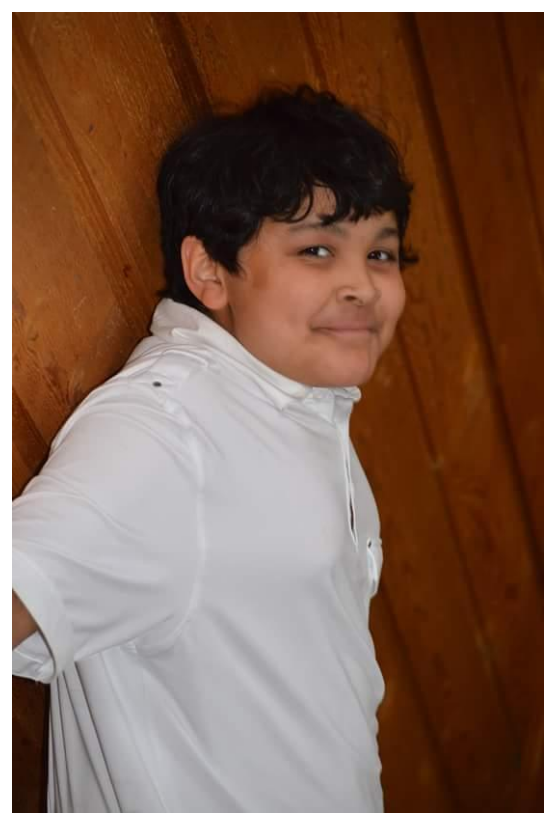

Evansville, Indiana - Evansville contains some of America's largest coal-fired power plants. These plants pump out millions of pounds of toxic air pollution, levels that are comparable to Hong Kong. According to a Center for Public Integrity investigation, areas like Evansville contain an extreme concentration of super polluting coal plants.

This pollution has hit some families particularly hard. Local 12-year old Kavon Cooper suffered from intense asthma, which his mother described as "a constant battle." He needed medicine to breathe if he stayed in Evansville too long. His asthma attacks were so severe that he would sometimes have to be hospitalized. Because of the severity of his asthma, Kavon stayed home with the windows closed as much as possible, often playing video games with the hopes of testing them for a living someday.

On April 18, 2015, Kavon collapsed and died at home, lying in the hallway by the bathroom right outside his bedroom. The cause of death was an acute asthma attack. At the time, Kavon's family couldn't understand what had happened. However, it's no coincidence that toxic particle and sulfur dioxide levels jumped to extreme levels the morning Kavon died, according to the air monitor near the Cooper family home. Moreover, after learning about this spike in pollution, Kavon's mother realized that his asthma was much better whenever he left Evansville. She also explained that that "there's a lot of illness, a lot of sickness in this area."

One extreme polluter near Kavon's area, Gibson, is the fourth-largest coal plant in the United States, and released 2.9 million pounds of air pollutants in 2014. Much of their pollution contains sulfuric acid, a lung irritant which the EPA says contributes to the formation of fine, asthma-related particles. Worse yet, Evansville polluters have used settlements to install cheaper, less-effective environmental controls rather than address this dangerous pollution.

These extreme polluters and corner-cutting measures have put local communities in danger. Kavon's brother, Kameron, tragically stated in Kavon's obituary, "I just want my brother. We just want him back. 


\section{APPENDIX C \\ COMPARISON CONDITIONS}

Comparison Condition A

\section{Recent Research Reveals Mysteries of Food Allergies}

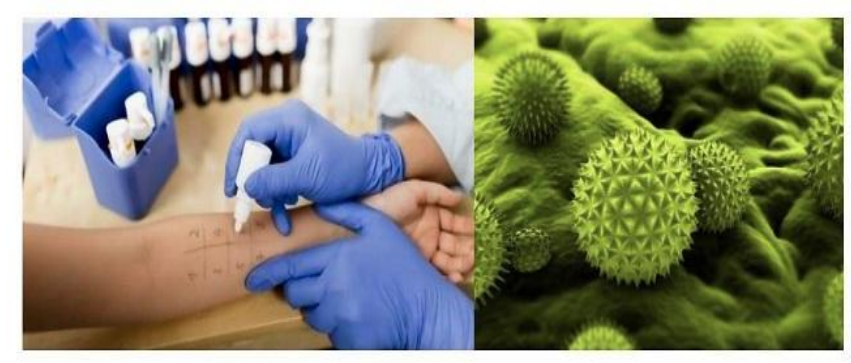

Food allergies or food intolerances affect nearly everyone at some point. People often have an unpleasant reaction to something they ate and wonder if they have a food allergy. One out of three people either say that they have a food allergy or that

they modify the family diet because a family member is suspected of having a food allergy. But only about $5 \%$ of children have clinically proven allergic reactions to foods. In teens and adults, food allergies occur in about $4 \%$ of the total population.

This difference between the clinically proven prevalence of food allergy and the public perception of the problem is in part due to reactions called "food intolerances" rather than food allergies. A food allergy, or hypersensitivity, is an abnormal response to a food that is triggered by the immune system. The immune system is not responsible for the symptoms of a food intolerance, even though these symptoms can resemble those of a food allergy. For example, being allergic to milk is different from not being able to digest it properly due to lactose intolerance. It is extremely important for people who have true food allergies to identify them and prevent allergic reactions to food because these reactions can cause devastating illness and, in some cases, be fatal.

Food allergies involve two features of the human immune response. One is the production of immunoglobulin $\mathrm{E}$ ( $\operatorname{IgE}$ ), a type of protein called an antibody that circulates through the blood. The other is the mast cell, a specific cell that occurs in all body tissues but is especially common in areas of the body that are typical sites of allergic reactions, including the nose and throat, lungs, skin, and gastrointestinal tract.

The ability of a given individual to form IgE against something as benign as food is an inherited predisposition. Generally, such people come from families in which allergies are common - not necessarily food allergies but perhaps hay fever, asthma, or hives. Someone with two allergic parents is more likely to develop food allergies than someone with one allergic parent. 


\section{Comparison Condition B}

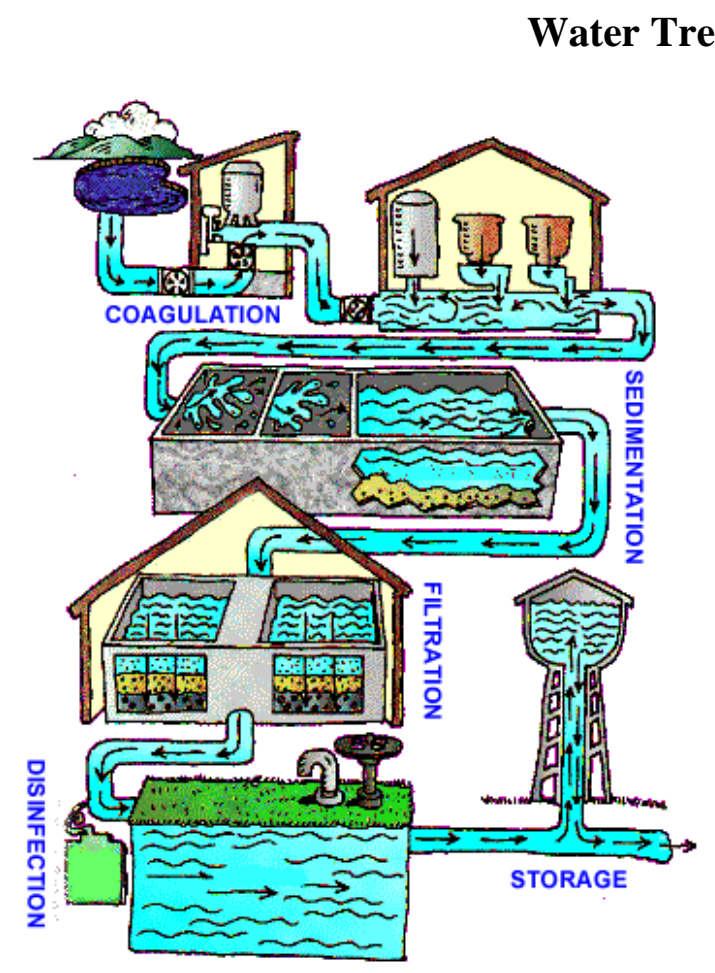

Drinking water supplies in the United States are among the safest in the world. Public drinking water systems use various methods of water treatment to provide safe drinking water for their communities. Today, the most common steps in water treatment used by community water systems (mainly surface water treatment) include:

\section{Coagulation and Flocculation}

Coagulation and flocculation are often the first steps in water treatment. Chemicals with a positive charge are added to the water. The positive charge of these chemicals neutralizes the negative charge of dirt and other dissolved particles in the water. When this occurs, the particles bind with the chemicals and form larger particles, called floc.

\section{Sedimentation}

During sedimentation, floc settles to the bottom of the water supply, due to its weight. This settling process is called sedimentation.

\section{Filtration}

Once the floc has settled to the bottom of the water supply, the clear water on top will pass through filters of varying compositions (sand, gravel, and charcoal) and pore sizes, in order to remove dissolved particles, such as dust, parasites, bacteria, viruses, and chemicals.

\section{Disinfection}

After the water has been filtered, a disinfectant (for example, chlorine, chloramine) may be added in order to kill any remaining parasites, bacteria, and viruses, and to protect the water from germs when it is piped to homes and businesses. 


\section{APPENDIX D}

\section{POWER ANALYSIS}

Replicability of psychological effects is diagnostic of a reliable science. Estimates of replicability in the social and behavioral science vary from $20 \%$ to $70 \%$ (Aarts \& Lin, 2015; Klein et al., 2018; Schimmack, 2020). Some research suggests that the social and personality psychology is improving as a science as trends move toward decreasing questionable research practices (e.g., $p$-hacking) and increasing best practices (e.g., conducting power analyses) (Motyl et al., 2017, cf. Schimmack, 2020).

One way to avoid low replicability and improve psychological science is by conducting statistical power analyses. Statistical power is the probability to correctly reject the null hypothesis when it is false, or rather, to detect a probable effect if the effect does in fact exist in a population (Trochim, 2020a). For example, if a researcher sets their desired power to $95 \%$, they can calculate the number of participants they need to detect an effect of a given strength (e.g., $r=.30$ ) with your desired alpha (or chance of concluding that there is an effect in the data when there is no effect in the population; typically $a<.05$ ). High statistical power can be achieved by sample size planning for significance tests $(p>\alpha)$ for the "smallest effect sizes your care about" (Lakens, 2017) or sample size planning for accuracy in parameter estimation (AIPE; Maxwell et al., 2008).

A statistical power analysis was conducted for the present study to achieve $95 \%$ statistical power for a difference of means $f$ test ( $\alpha=.05$; see Appendix A). The study being replicated and extended (Eadeh \& Chang, 2019, Study 2) used a statistical power of $80 \%$ for sample size calculations and found an effect size $\eta^{2}=.06$ (equivalent to $r=.24$ ) 
for the effect of environmental threat on support for environmental regulatory policies. Using this effect size, a power analysis for the current study suggested a sample size of 412 participants. This sample size estimate was increased by $20 \%$ to account for planned exclusions, which meant collecting data from at least 495 participants. This power analysis procedure was intended to increase the replicability and scientific credibility of the present findings, especially in the context of social psychology's replicability crisis. One limitation of this power analysis is that it did not account other variables in the model or for mediation or moderation. Power for mediation was not tested because the effect sizes for indirect effects were unknown. Hence, the following power analysis was a best-guess estimation based the known effect size of the direct effect.

\# R code for power analysis

\# Convert the eta-squared to Cohen's $\mathrm{f}$

fes<-sqrt $(.06 /(1-.06))$

fes

$\operatorname{library}(\mathrm{pwr})$

pwr.anova.test $(\mathrm{k}=2, \mathrm{f}=\mathrm{fes}$, sig.level=0.05, power $=.95)$

\# A one-way ANOVA power analysis suggests 103 participants per condition

\# There is a maximum of four between-subject conditions that will be compared, so multiply by four to get the target sample size:

\# Target sample size: 412

\# Next, pad this target for the possibility of $20 \%$ missing or low-quality data, rounding up:

ceiling $((103 * 4)+((103 * 4) * .20))$

\# Target sample size (with padding): 495 


\section{APPENDIX E \\ INCLUSION AND EXCLUSION CRITERIA}

\section{Pre-exclusions:}

- US only

- $95 \%$ hit approval rate

- 5000-500,000 approved hits

- Block duplicate IPs

- Block duplicate geocodes

- Block suspicious geocodes

\section{$\underline{\text { Post-exclusions: }}$}

\section{First step}

I removed data that meets one or both of the following criteria:

1. Missing all data (1 case removed) [Pre-registered]

2. IP geocoding outside the US (Robertson et al. 2016) (11 cases removed) [Pre-registered]

3. Duplicate IPs - if it appears that the data came from the same person, the second line of data will be excluded from analyses (1 case removed) [Pre-registered]

\section{Second step}

Following Buchanan and Scofield (2018), I removed data that met one or both of the following criteria:

1. A clicking check (flags participants whose number of mouse clicks count is less than the number of answered items on a specified Qualtrics page) (0 cases removed) [Preregistered; forgot timer/click-counter]

2. A timing check (flags participants reading two standard deviations faster than average character reading speeds on a specified Qualtrics page) (34 cases removed) [Preregistered]

\section{Third step}

I removed data that met one or more of the following criteria:

1. Age and year born not matching (participants will not be excluded if they omit one or the other) (16 cases removed) [Pre-registered]

2. Honesty check (if participants answer $2=A$ little or $1=$ None at all) $(2$ cases removed) [Pre-registered]

3. Careless answering via long-string analysis (when a participant is considered an outlier for the number of times the same response option is used in a row on a conventional boxplot) (Yentes \& Wilhelm, 2018) (3 cases removed) [Pre-registered, with deviation]

$\circ \quad$ Because of low variability, outliers were long-string lengths that did not equal 2. Thus, I only removed long-string lengths that were equal to 8, because with two reverse coded items, the most items they should have completed a row was 6 .

4. Unrelated commentary in their reflection on the article (1 case) [Pre-registered] 


\section{APPENDIX F}

\section{SYSTEM JUSTIFICATION SCALE}

5-point response scale: from $1=$ strongly disagree to 5 = strongly agree Items are reverse scored where there is an $*$

Instructions: To what extent do you agree or disagree with the following statements?

1) In general, you find society to be fair.

2) In general, the American political system operates as it should.

3) American society needs to be radically restructured.*

4) The United States is the best country in the world to live in.

5) Most policies serve the greater good.

6) Everyone has a fair shot at wealth and happiness.

7) Our society is getting worse every year.*

8) Society is set up so that people usually get what they deserve.

From Kay and Jost (2003) 


\section{APPENDIX G}

\section{ENVIRONMENTAL POLICY PREFERENCES}

7-point response scale: from $1=$ Strongly disagree to $7=$ Strongly agree

Items are reverse scored where there is an *

Instructions: Please rate how much you agree or disagree with the following statements.

1. The federal government should aggressively carry out environmental protection regulations.

2. The federal government has a responsibility to ensure companies are reducing their pollution levels.

3. Federal funding of the Environmental Protection Agency should be our top priority, even if it means a reduction in funding for other areas.

4. Private companies should be required, by federal law, to use cleaner energy solutions.

5. I would support fining coal companies millions of dollars if their actions contributed to harming local communities

6. I would support the aggressive federal regulation of coal companies.

7. Private companies that cause extreme water pollution should be punished.

8. Private companies that contribute to water pollution should be aggressively regulated by the federal government.

9. The federal government does not have a right to oversee environmental matters. *

10. No additional tax dollars should go to the Environmental Protection Agency. *

11. Clean energy solutions are too costly for tax-payers. *

12. Private companies should legally abide by their own environmental standards. *

13. The federal government should have a minimal role in regulating the coal industry. *

14. Coal companies are not obligated to reduce pollution. *

15. Private companies should not be aggressively regulated for the sake of preventing water pollution. *

16. Private companies should not be punished for causing water pollution. * 


\section{APPENDIX H}

\section{DEMOGRAPHICS}

What is your age?

What is your ethnicity?

1. American Indian or Alaskan Native

2. Asian

3. Black or African-American

4. Native Hawaiian or other Pacific islander

5. White

6. Some other ethnicity (please specify)

What is your gender?

1. Female

2. Male

3. Some other gender (please specify)

What is the highest level of school you have completed or the highest degree you have received?

1. Less than high school degree

2. High school degree or equivalent (e.g., GED)

3. Some college but no degree

4. Associate degree

5. Bachelor degree

6. Graduate or professional degree

How honest were your responses on this survey?

(From $1=$ not at all to $5=$ very much so)

What year were you born?

Do you have any comments for the researcher? 


\section{APPENDIX I}

\section{SCATTERPLOT MATRIX}

\section{Scatterplots for Variables by Condition}

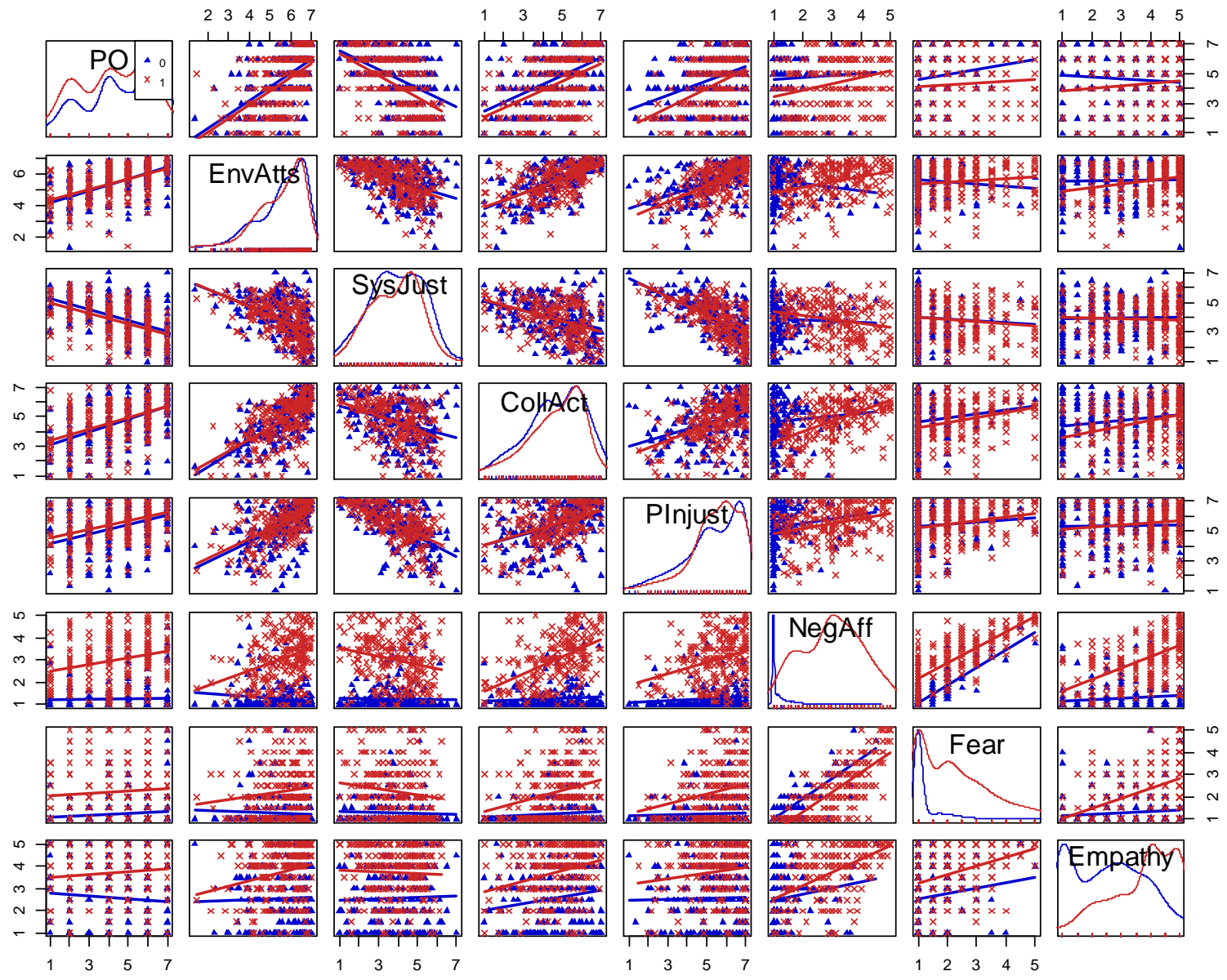

Note. Variables were measured on 5- or 7-point Likert-type scales. Red "X" symbols represent the data points for the threat condition, and blue triangles represent the data points for the control conditions. Red lines are lines of best fit for the threat conditions, and blue lines are lines of best fit for the comparison conditions. The center diagonal line illustrates the univariate distribution for each variable across both conditions. Truncated labels from top-left to bottom-right: $\mathrm{PO}=$ Political Orientation. EnvAtts $=$ Environmental Regulation Attitudes. SysJust $=$ System Justification, CollAct $=$ Collective Action Intentions, PInjust $=$ Perceived Injustice, and NegAff $=$ Negative Affect. For the full color version, please visit https://osf.io/2md4e/. 


\section{APPENDIX}

\section{CORRELATION MATRICES}

Table 3. Means, Standard Deviations, and Correlations with Confidence Intervals for Variables in the Environmental Threat Conditions $(n=218)$

\begin{tabular}{|c|c|c|c|c|c|c|c|c|c|c|}
\hline Variable & $M$ & $S D$ & 1 & 2 & 3 & 4 & 5 & 6 & 7 & 8 \\
\hline 1. Political Orientation & 4.32 & 1.81 & & & & & & & & \\
\hline 2. Negative Affect & 3.03 & 1.07 & $\begin{array}{r}.26 * * \\
{[.13, .38]}\end{array}$ & & & & & & & \\
\hline 3. Fear & 2.23 & 1.20 & $\begin{array}{c}.08 \\
{[-.06, .21]}\end{array}$ & $\begin{array}{r}.78 * * \\
{[.72, .83]}\end{array}$ & & & & & & \\
\hline 4. Empathy & 3.75 & 1.12 & $\begin{array}{c}.10 \\
{[-.03, .23]}\end{array}$ & $\begin{array}{r}.55 * * \\
{[.45, .64]}\end{array}$ & $\begin{array}{r}.41 * * \\
{[.30, .52]}\end{array}$ & & & & & \\
\hline 5. System Justification & 3.83 & 1.25 & $\begin{array}{r}-.51 * * \\
{[-.60,-.41]}\end{array}$ & $\begin{array}{r}-.23 * * \\
{[-. .35,-.10]}\end{array}$ & $\begin{array}{c}-.14 * \\
{[-.27, .00]}\end{array}$ & $\begin{array}{c}-.04 \\
{[-.17, .09]}\end{array}$ & & & & \\
\hline 6. Perceived Injustice & 5.50 & 1.24 & $\begin{array}{r}.44 * * \\
{[.33, .54]}\end{array}$ & $\begin{array}{r}.29 * * \\
{[.17, .41]}\end{array}$ & $\begin{array}{r}.24 * * \\
{[.11, .36]}\end{array}$ & $\begin{array}{c}.13 * \\
{[.00, .26]}\end{array}$ & $\begin{array}{c}-.60 * * \\
{[-.68,-.51]}\end{array}$ & & & \\
\hline $\begin{array}{l}\text { 7. Environmental } \\
\text { Policy Preferences }\end{array}$ & 5.53 & 1.08 & $\begin{array}{r}.55 * * \\
{[.45, .64]}\end{array}$ & $\begin{array}{r}.33 * * \\
{[.21, .45]}\end{array}$ & $\begin{array}{c}.13 \\
{[.00, .26]}\end{array}$ & $\begin{array}{r}.24 * * \\
{[.11, .36]}\end{array}$ & $\begin{array}{c}-.50 * * \\
{[-.60,-.40]}\end{array}$ & $\begin{array}{r}.58 * * \\
{[.49, .67]}\end{array}$ & & \\
\hline $\begin{array}{l}\text { 8. Collective Action } \\
\text { Intentions }\end{array}$ & 4.68 & 1.45 & $\begin{array}{r}.49 * * \\
{[.38, .58]}\end{array}$ & $\begin{array}{r}.52 * * \\
{[.41, .61]}\end{array}$ & $\begin{array}{r}.29 * * \\
{[.16, .40]}\end{array}$ & $\begin{array}{r}.31 * * \\
{[.19, .43]}\end{array}$ & $\begin{array}{c}-.41 * * \\
{[-.51,-.29]}\end{array}$ & $\begin{array}{r}.45^{* *} \\
{[.33, .55]}\end{array}$ & $\begin{array}{r}.58 * * \\
{[.49, .67]}\end{array}$ & \\
\hline $\begin{array}{l}\text { 9. Collective Donation } \\
\text { Behavior }\end{array}$ & .33 & .47 & $\begin{array}{c}.15^{*} \\
{[.02, .28]}\end{array}$ & $\begin{array}{r}.26 * * \\
{[.13, .38]}\end{array}$ & $\begin{array}{c}.17^{*} \\
{[.04, .30]}\end{array}$ & $\begin{array}{r}.19 * * \\
{[.06, .31]}\end{array}$ & $\begin{array}{l}-.08 \\
{[.05,-.21]}\end{array}$ & $\begin{array}{c}.13 \\
{[.00, .26]}\end{array}$ & $\begin{array}{r}.31 * * \\
{[.19, .23]}\end{array}$ & $\begin{array}{r}.22 * * \\
{[.09, .34]}\end{array}$ \\
\hline
\end{tabular}

Note. $M$ and $S D$ are used to represent mean and standard deviation. Values in square brackets indicate the $95 \%$ confidence interval for each Pearson correlation (or point-biserial correlation for collective donation behavior). Political orientation ranges from $1=$ very conservative to $7=$ very liberal .

$*$ indicates $p<.05$. ** indicates $p<.01$. Bold indicates $p<.05$. 
Table 4. Means, Standard Deviations, and Correlations with Confidence Intervals for Variables in the Comparison Conditions $(n=211)$

\begin{tabular}{|c|c|c|c|c|c|c|c|c|c|c|}
\hline Variable & $M$ & $S D$ & 1 & 2 & 3 & 4 & 5 & 6 & 7 & 8 \\
\hline 1. Political Orientation & 4.70 & 1.77 & & & & & & & & \\
\hline 2. Negative Affect & 1.28 & 0.57 & $\begin{array}{c}.04 \\
{[-.10, .18]}\end{array}$ & & & & & & & \\
\hline 3. Fear & 1.25 & 0.61 & $\begin{array}{c}.12 \\
{[-.02, .25]}\end{array}$ & $\begin{array}{r}.85 * * \\
{[.81, .88]}\end{array}$ & & & & & & \\
\hline 4. Empathy & 2.59 & 1.26 & $\begin{array}{c}-.09 \\
{[-.22, .05]}\end{array}$ & $\begin{array}{c}.12 \\
{[-.01, .25]}\end{array}$ & $\begin{array}{c}.12 \\
{[-.02, .25]}\end{array}$ & & & & & \\
\hline 5. System Justification & 3.93 & 1.37 & $\begin{array}{r}-.48 * * \\
{[-.58,-.37]}\end{array}$ & $\begin{array}{c}-.03 \\
{[-.17, .10]}\end{array}$ & $\begin{array}{c}-.05 \\
{[-.18, .09]}\end{array}$ & $\begin{array}{c}.03 \\
{[-.10, .17]}\end{array}$ & & & & \\
\hline 6. Perceived Injustice & 5.33 & 1.43 & $\begin{array}{r}.40 * * \\
{[.28, .50]}\end{array}$ & $\begin{array}{c}.11 \\
{[-.02, .24]}\end{array}$ & $\begin{array}{c}.06 \\
{[-.07, .20]}\end{array}$ & $\begin{array}{c}.03 \\
{[-.10, .17]}\end{array}$ & $\begin{array}{c}-.64 * * \\
{[-.72,-.56]}\end{array}$ & & & \\
\hline $\begin{array}{l}\text { 7. Environmental } \\
\text { Policy Preferences }\end{array}$ & 6.00 & 1.11 & $\begin{array}{r}.58 * * \\
{[.49, .67]}\end{array}$ & $\begin{array}{c}-.12 \\
{[-.25, .02]}\end{array}$ & $\begin{array}{c}-.07 \\
{[-.21, .06]}\end{array}$ & $\begin{array}{c}.03 \\
{[-.10, .17]}\end{array}$ & $\begin{array}{c}-.45 * * \\
{[-.55,-.33]}\end{array}$ & $\begin{array}{r}.52 * * \\
{[.41, .61]}\end{array}$ & & \\
\hline $\begin{array}{l}\text { 8. Collective Action } \\
\text { Intentions }\end{array}$ & 4.69 & 1.49 & $\begin{array}{r}.51 * * \\
{[.40, .60]}\end{array}$ & $\begin{array}{c}.08 \\
{[-.06, .21]}\end{array}$ & $\begin{array}{c}.12 \\
{[-.02, .25]}\end{array}$ & $\begin{array}{c}.17^{*} \\
{[.04, .30]}\end{array}$ & $\begin{array}{c}-.33 * * \\
{[-.45,-.21]}\end{array}$ & $\begin{array}{r}.37 * * \\
{[.25, .48]}\end{array}$ & $\begin{array}{r}.64 * * \\
{[.56, .72]}\end{array}$ & \\
\hline $\begin{array}{l}\text { 9. Collective Donation } \\
\text { Behavior }\end{array}$ & .33 & .47 & $\begin{array}{c}.14^{*} \\
{[.00, .27]}\end{array}$ & $\begin{array}{c}.13 \\
{[-.02, .26]}\end{array}$ & $\begin{array}{c}.11 \\
{[.00, .24]}\end{array}$ & $\begin{array}{c}.10 \\
{[-.03, .23]}\end{array}$ & $\begin{array}{l}-.09 \\
{[-.23, .04]}\end{array}$ & $\begin{array}{c}.11 \\
{[-.03, .24]}\end{array}$ & $\begin{array}{r}.20 * * \\
{[.07, .33]}\end{array}$ & $\begin{array}{r}.28 * * \\
{[.15, .40]}\end{array}$ \\
\hline
\end{tabular}

Note. $M$ and $S D$ are used to represent mean and standard deviation. Values in square brackets indicate the $95 \%$ confidence interval for each Pearson correlation (or point-biserial correlation for collective donation behavior). Political orientation ranges from $1=$ very conservative to $7=v e r y$ liberal .

$*$ indicates $p<.05$. ** indicates $p<.01$. Bold indicates $p<.05$. 